Relative effects of wetland buffers and landscape composition on water quality and anuran diversity in agricultural wetlands

by

Margaret E. Sawatzky

A thesis submitted to the Faculty of Graduate and Postdoctoral Affairs in partial fulfillment of the requirements for the degree of

Master of Science

in

Biology

\author{
Carleton University \\ Ottawa, Ontario \\ (C) 2016 \\ Margaret E. Sawatzky
}




\section{Overview}

Ponds in agricultural areas can be important havens for wetland-dependent wildlife, especially in regions with high rates of wetland loss. However, diverse wildlife can only persist in these agricultural wetlands if the water is of sufficient quality and if wetlands are surrounded by enough terrestrial habitat for semi-aquatic taxa such as anurans (frogs and toads). Most recommended protection measures for agricultural wetlands fall into one of two categories: (i) conserving a certain percentage of natural vegetation (undisturbed land) in the landscape surrounding each wetland, or (ii) retaining or implementing vegetated buffers between wetlands and adjacent crop fields (Castelle et al. 1992; Findlay and Houlahan 1997). Landscape-scale conservation of undisturbed land is known to increase anuran species richness in most types of wetlands (e.g. Houlahan and Findlay 2003; Herrmann et al. 2005), but its role in protecting the water quality of small, lentic water bodies is less well-established. Vegetated buffers along streams have been shown to intercept contaminants from runoff (Castelle et al. 1994), but multiple aspects of their role in aquatic habitat improvement and terrestrial habitat provisioning around non-riparian agricultural wetlands remain unclear.

The following work is divided into two chapters. The first chapter, Wetland Buffers Are No Substitute for Landscape-Scale Conservation, examines the roles of landscape-scale conservation and wetland buffers in protecting water quality of agricultural wetlands. It addresses the following questions:

(1) Does increasing undisturbed land cover in the landscape reduce nutrient and pesticide levels in agricultural wetlands?

(2) Does complying with buffer guidelines reduce nutrient and pesticide levels in agricultural wetlands? If so, how large should wetland buffers be? 
(3) What is the relative importance of landscape-scale undisturbed land conservation and compliance with buffer guidelines for reducing nutrient and pesticide levels in agricultural wetlands?

The second chapter, Do Wetland Buffers Work for Frogs and Toads? examines the role of wetland buffers in promoting anuran species richness and abundance. It focuses less on landscape composition than the first chapter does, because anurans are already known to respond to landscape composition, usually at scales of 500 to $3000 \mathrm{~m}$ (Hecnar and M'Closkey 1998; Houlahan and Findlay 2003; Price et al. 2005). The second chapter addresses the following questions:

(1) Can wetland buffers increase anuran species richness and abundance? If so, (a) how should they be vegetated, and (b) how large should they be?

(2) How strong are wetland buffer effects on anuran species richness and abundance in agricultural wetlands, relative to the effects of landscape composition (woodland cover, road density, and water cover)?

Our ${ }^{1}$ research findings show that landscape-scale land management is key to protecting water quality and anuran diversity in agricultural wetlands, and that for buffers to be effective, they must be larger than current guidelines dictate. To improve water quality, crop cover should be minimized within a $200 \mathrm{~m}$ radius of agricultural wetlands: this could mean instituting $200 \mathrm{~m}$ wide wetland buffers, or requiring a certain proportion of land within a $200 \mathrm{~m}$ landscape around wetlands to be conserved in an "undisturbed" state. To protect anurans, buffers at least $30 \mathrm{~m}$ wide, vegetated with grassland and scattered trees, should be maintained around ponds, and

\footnotetext{
${ }^{1}$ I (Margaret Sawatzky) conducted all field work and analyses described in this document, and wrote all thesis drafts. The pronoun, "we," and the possessive pronoun, "our," are used throughout this document in preparation for when I submit the chapters as papers for publication jointly with Dr. Lenore Fahrig. Dr. Fahrig provided guidance with research planning, and contributed to the editing process.
} 
woodland cover should be maximized (and road density minimized) within a $1500 \mathrm{~m}$ landscape around wetlands.

In addition to the information provided in the main text of the thesis, further details about study methods and the relationships between study variables are located in the appendices. Raw data are located in the online supplementary materials.

\section{REFERENCES}

Castelle AJ, Conolly C, Emers M, et al. 1992. Wetland buffers: Use and effectiveness. Olympia, Washington.

Findlay CS and Houlahan J. 1997. Anthropogenic correlates of species richness in southeastern Ontario wetlands. Conservation Biology 11: 1000-9.

Hecnar SJ and M'Closkey RT. 1998. Species richness patterns of amphibians in southwestern Ontario ponds. Journal of Biogeography 25: 763-72.

Herrmann H, Babbitt K, Baber M, and Congalton R. 2005. Effects of landscape characteristics on amphibian distribution in a forest-dominated landscape. Biological Conservation 123: $139-49$.

Houlahan JE and Findlay CS. 2003. The effects of adjacent land use on wetland amphibian species richness and community composition. Canadian Journal of Fisheries and Aquatic Sciences 60: 1078-94.

Price SJ, Marks DR, Howe RW, et al. 2005. The importance of spatial scale for conservation and assessment of anuran populations in coastal wetlands of the western Great Lakes, USA. Landscape Ecology 20: 441-54. 


\section{Acknowledgements}

I would like to thank my supervisor, Lenore Fahrig, for her support throughout this project: helping me to select an interesting and applied ecological research topic, making suggestions about site selection and data analysis, and — most of all—helping me to edit both papers associated with my thesis, while still allowing this research to remain my own. Her clarity of thought and incisive questions have been invaluable during the research process. I also greatly valued the opportunity to sit in on her Landscape Ecology class in 2015.

I also thank my committee members, Steven Cooke and Scott Findlay, for their constructive criticisms and helpful suggestions about my research plans during our committee meetings. I am grateful to Cecily Flemming, of the Ontario Ministry of Environment and Climate Change, for her help in locating and interpreting Ontario wetland buffer guidelines.

I would also like to express my gratitude to the many people who helped me with technical aspects of my research project. I greatly appreciate Rebecca Dalton's advice on water quality sampling techniques, and Stacey Robinson's willingness to loan me water sampling equipment; these researchers also arranged for my water samples to be analyzed for pesticides at Environment Canada. I thank the 37 private landowners (who wish to remain anonymous) who allowed me to conduct research on their properties. I also thank Dan Bert for his help with ordering field equipment and with all things computer-related; Dan Patterson for accepting me as a late student into his very useful course, Introduction to GIS; and the other members of the Geomatics and Ecology Research Laboratory for helpful suggestions about statistics and using ArcGIS software. Most particularly, I thank all of my summer field assistants, especially Christopher Love, Katherine Petrie, and Erik Pervin: they were incredibly dedicated and helpful with all aspects of data collection. 
I gratefully acknowledge the assistance of provincial and federal government. This research was funded by an Ontario Graduate Scholarship, as well as Lenore Fahrig's NSERC research grant.

Finally, I would like to thank my family and friends who supported me throughout this research. In particular, Amy Plint helped to edit my original project proposal when I was applying for government funding. Kristina Shostak and Hamdan Al-Buhaisi helped me to regain perspective in times of stress. Last but not least, I thank my parents. They are always supportive of, and interested in, all of my endeavours, and this thesis was no exception. This research would not have been possible without them. Thank you.

Margaret E. Sawatzky 


\section{Table of Contents}

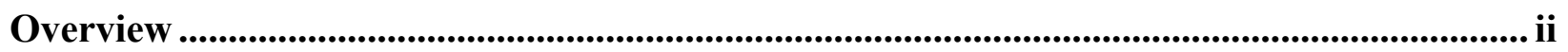

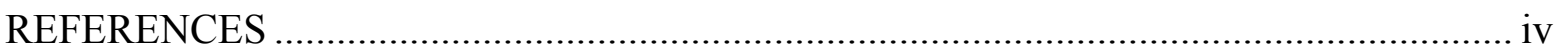

Acknowledgements ....................................................................................................................... $\mathrm{v}$

Wetland Buffers Are No Substitute for Landscape-Scale Conservation .................................... 1

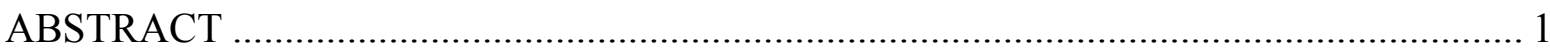

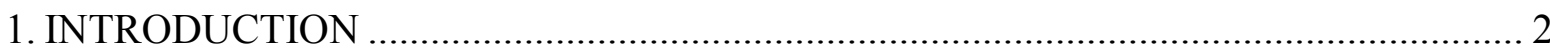

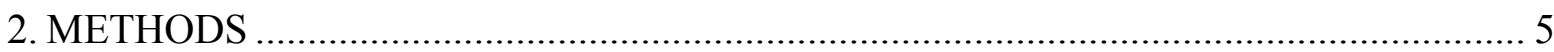

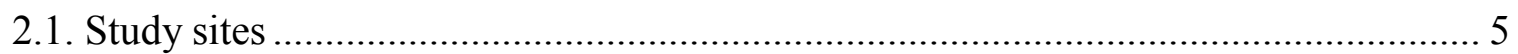

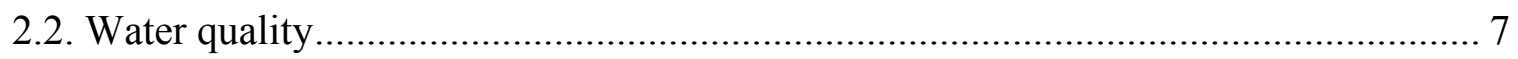

2.3. Undisturbed land, landscape scale, and buffer guideline compliance ........................ 9

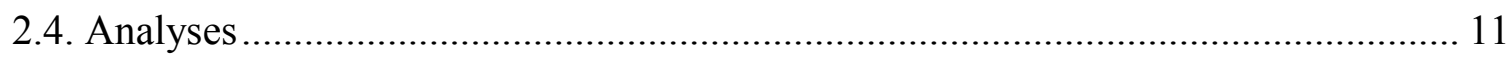

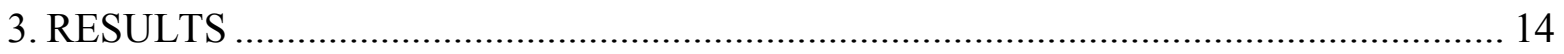

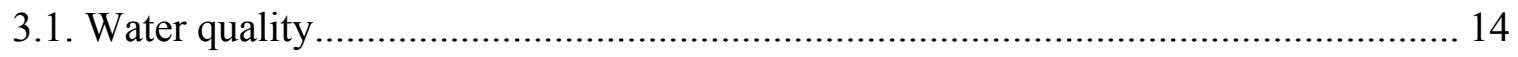

3.2. Undisturbed land, landscape scale, and predictor variables .................................... 14

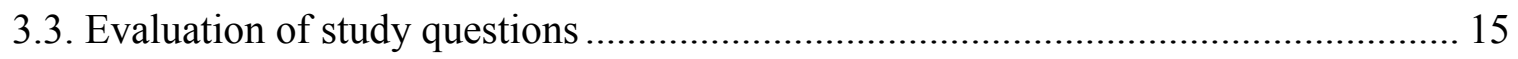

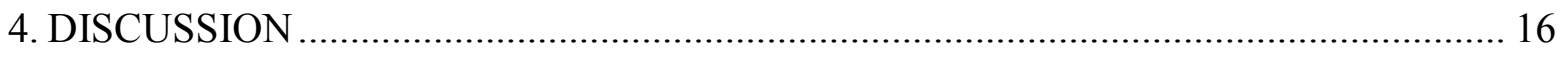

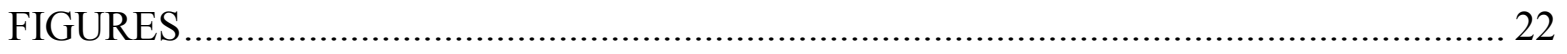

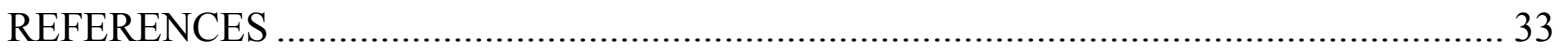

Appendix 1: City of Ottawa protocols for nitrate analysis .................................................. 38

Appendix 2: Environment Canada protocols for atrazine and neonicotinoid analyses ......... 42

Appendix 3: Correlations between predictor variables and potentially confounding variables..

Appendix 4: Model fits for water quality variables regressed on various measures of buffer

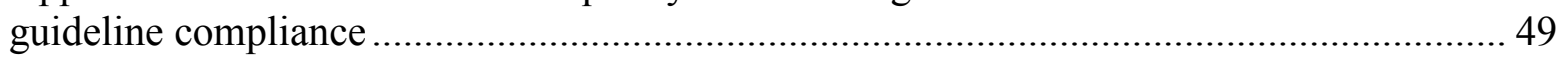

Do Wetland Buffers Work for Frogs and Toads? ........................................................................... 50

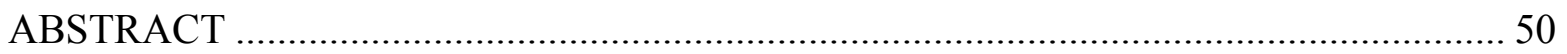

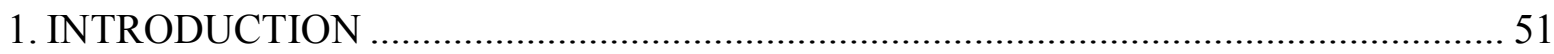

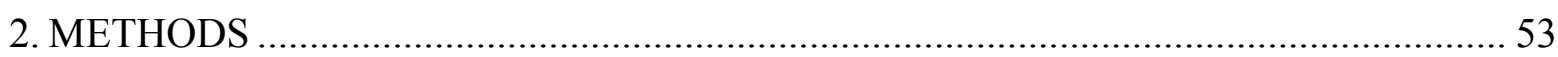

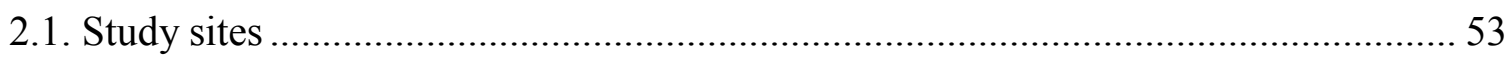

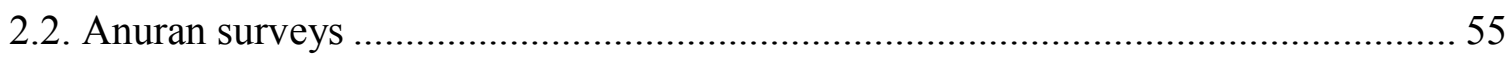

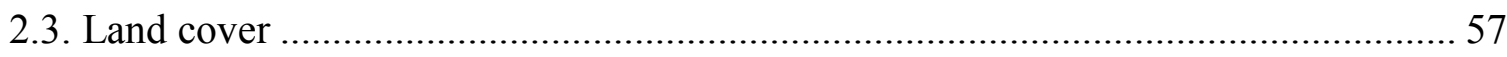

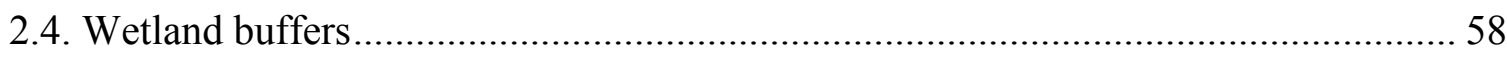

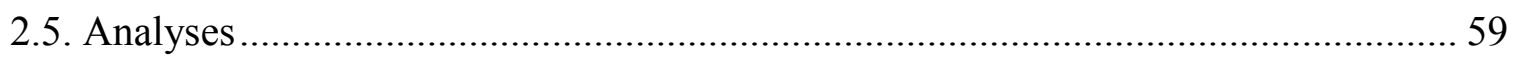




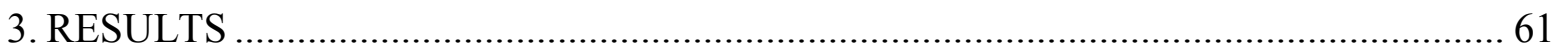

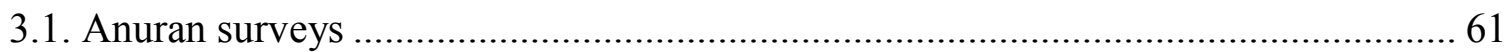

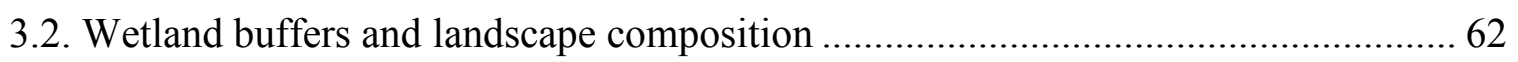

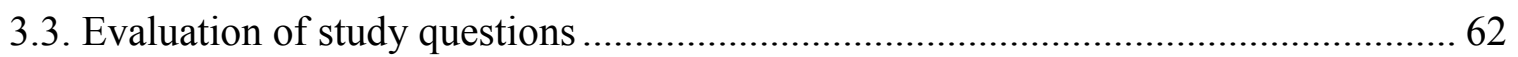

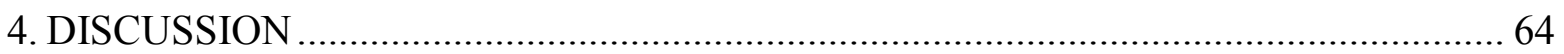

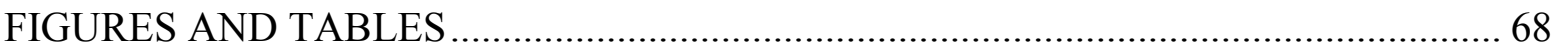

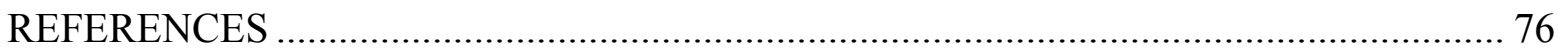

Appendix 1: Correlations between predictor variables and potentially confounding

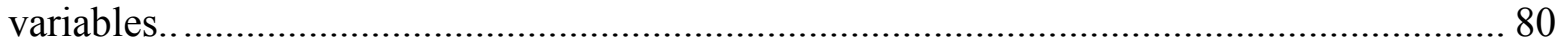

Appendix 2: Relationships between anuran response variables and buffer predictor variables.. 


\title{
Wetland Buffers Are No Substitute for Landscape-Scale Conservation
}

\begin{abstract}
Wetlands in agricultural areas are at risk of contamination by fertilizers and pesticides. One way to reduce wetland contamination is to limit intensive agriculture such as annual row crops, instead preserving "undisturbed" land cover types such as woodland. Another option is to implement undisturbed buffer zones around the perimeter of wetlands. We examined the effects of (i) landscape-scale conservation of undisturbed land and (ii) compliance with wetland buffer guidelines on nutrient and pesticide levels in 37 small agricultural wetlands in eastern Ontario, Canada. Most buffer guidelines in Ontario require 5 to $30 \mathrm{~m}$ wide buffers adjacent to water bodies. We found that nitrate, atrazine, and neonicotinoid levels in agricultural wetlands decreased with undisturbed land cover in surrounding $200 \mathrm{~m}$ landscapes, but were unaffected by wetland buffers, regardless of how compliance with buffer guidelines was measured. To effectively protect water quality in agricultural wetlands, we recommend either increasing the width of wetland buffers to $200 \mathrm{~m}$, or abandoning the buffer paradigm in favour of landscapescale conservation.
\end{abstract}

Key words: buffer zone, buffer strip, vegetated filter strip, wetland, pond, agriculture, nitrate, atrazine, neonicotinoid, acetamiprid, clothianidin, imidacloprid, thiamethoxam, land use, landscape composition, local vs. landscape effects, landscape scale, scale of effect 


\section{INTRODUCTION}

Agricultural expansion and intensification can increase nutrient loads and pesticide contamination in nearby wetlands, with negative consequences for ecosystem health (Carpenter et al. 1998; Murray et al. 2011; Schäfer et al. 2011). Nutrients such as nitrogen and phosphorus occur naturally in aquatic systems, but artificially high amounts can alter community composition via eutrophication (Carpenter et al. 1998), and can have direct lethal or sublethal effects on wetland species. For example, field-relevant concentrations of nitrate can be toxic to freshwater invertebrates and amphibians (Hecnar 1995; Camargo et al. 2005). Agricultural pesticides such as atrazine and neonicotinoids can also kill or otherwise harm aquatic organisms, and reduce biodiversity (Graymore et al. 2001; Liess and Von Der Ohe 2005; Murray et al. 2011; Schäfer et al. 2011; Beketov et al. 2013; Morrissey et al. 2015).

The most direct solution to this problem is to limit the spread of intensive agriculture, and conserve natural land cover in landscapes surrounding wetlands of interest. Crosbie and ChowFraser (1999) found that nutrient levels in marshes increased with the percentage of agricultural land use within the watershed, and decreased with the amount of woodland cover. Similarly, Houlahan and Findlay (2004) showed that nitrogen and phosphorus concentrations in wetlands declined as woodland cover in the surrounding landscape increased. Few studies have examined the effects of landscape composition at large spatial scales on pesticide concentrations in wetlands, but small-scale studies suggest that pesticide levels in water bodies also increase with the amount of nearby agricultural land use (Rasmussen et al. 2011; McMurry et al. 2016).

However, conserving undisturbed land at a landscape scale around wetlands in agricultural regions can be challenging. To begin with, the appropriate landscape scale is 
unclear: different scientists have found land uses within $100 \mathrm{~m}$ up to the entire watershed to significantly affect water quality in lentic wetlands (Crosbie and Chow-Fraser 1999; Houlahan and Findlay 2004; Declerck et al. 2006). Furthermore, if the appropriate landscape scale exceeds the size of one person's property, landscape-scale conservation would require coordinating the efforts of multiple landowners.

Another way to reduce agricultural wetland contamination is to implement buffers, or strips of relatively undisturbed, permanently vegetated land, next to wetlands (Muscutt et al. 1993; Castelle et al. 1994; Coukell et al. 2004). Buffers have been recommended around water bodies by local, regional, and national governments in many parts of the world. In Ontario, Canada, buffers 5-120 $\mathrm{m}$ in width are recommended for aquatic habitat protection (Coukell et al. 2004; Ontario Farm Environmental Coalition 2004; Niagara Planning and Development Services Department 2015); in the USA, width recommendations range from 4.6-106.7 m (McElfish et al. 2008). Buffers along rivers and streams have been shown to intercept runoff, reduce bank erosion, reduce nutrient loads, and reduce pesticide contamination (Castelle et al. 1994; Vought et al. 1995; Wenger 1999). For example, Madison et al. (1992) found that grass buffers could trap up to $95 \%$ of nitrate and $93 \%$ of atrazine from agricultural runoff.

However, it is unclear what size of buffer would effectively protect water quality in lentic agricultural wetlands, or how such buffers should be vegetated. Most field studies of buffer effectiveness have focused on riparian buffers along streams and rivers rather than on buffers around lentic wetlands in regions with flat topography, as in many agricultural regions. These studies have variously concluded that buffers $5-90 \mathrm{~m}$ in width are necessary to protect water quality (Castelle et al. 1994; Vought et al. 1995; Wenger 1999; Rasmussen et al. 2011). Some studies have suggested that grass buffers are more effective than woodland buffers, but others 
have come to the opposite conclusion, or have found all types of non-crop vegetation to be equally effective (Schmitt et al. 1999; Wenger 1999).

Furthermore, compliance with buffer guidelines is difficult to measure. Official buffer guidelines usually focus on buffer width, measured as the minimum distance from a water body to cropland or other developed land (Ontario Farm Environmental Coalition 2004; Niagara Planning and Development Services Department 2015), but real buffers vary in width. Some American states calculate the average width of a buffer, rather than minimum width, to determine buffer guideline compliance. However, the most relevant way to measure the degree of compliance has not been empirically determined, and is not discussed in Ontario buffer guideline documents (Coukell et al. 2004; Ontario Farm Environmental Coalition 2004; McElfish et al. 2008; Planning and Development Services Department 2015).

The effectiveness of wetland buffers relative to landscape-scale conservation of natural land cover around wetlands is also unclear. Most multi-scale studies of land use effects on water quality focus exclusively on spatial scales larger than recommended wetland buffer widths, partly because the resolution of available land cover maps is too low to examine scales smaller than $100 \mathrm{~m}$ (e.g. Knutson et al. 1999; Sliva and Williams 2001).

We use a focal patch study design to examine the effects of landscape-scale conservation of undisturbed land, and compliance with wetland buffer guidelines, on nutrient and pesticide levels in lentic agricultural wetlands (ponds). Specifically, we address three main questions:

(1) Does increasing undisturbed land cover in the landscape reduce nutrient and pesticide levels in agricultural wetlands?

(2) Does complying with buffer guidelines reduce nutrient and pesticide levels in agricultural wetlands? If so, how large should wetland buffers be? 
(3) What is the relative importance of landscape-scale undisturbed land conservation and compliance with buffer guidelines for reducing nutrient and pesticide levels in agricultural wetlands?

\section{METHODS}

\subsection{Study sites}

Study region

All research was conducted in agriculture-dominated regions of eastern Ontario, in the Mixedwood Plains Ecozone (Figure 1). The topography of the study region is very flat, and the soils are primarily brunisols and gleysols on a base of sedimentary rock. Approximately $50 \%$ of this region is used for agriculture, $20 \%$ is woodland, $10 \%$ is wetland, $10 \%$ is a combination of woodland and wetland, and $4 \%$ is built up; the remainder consists of a variety of land cover types such as quarries and abandoned farmland. Nitrogen is applied to crop fields at rates of approximately $15-314 \mathrm{~kg} / \mathrm{ha}$ in this region, and total pesticides are applied at rates of approximately $1.03 \mathrm{~kg} / \mathrm{ha}$; less fertilizer and very few pesticides are applied to hay or pasture (Huffman et al. 2008; McGee et al. 2010).

Site selection

We selected study wetlands to maximize variation in the two main predictor variableslandscape-scale undisturbed land cover and buffer guideline compliance-while minimizing the correlation between them. During site selection, undisturbed land was measured as woodland 
because this was the only highly precise land cover information we had, but we later updated these measurements with field-based estimates of undisturbed land around each of the study wetlands. We also aimed to avoid spatial autocorrelation, control for wetland size and type, and minimize variation in potentially confounding landscape variables such as built-up land cover, road density, and water cover. Of the almost 100,000 wetlands in our study region, we selected a set of 61 wetlands that met the criteria.

After asking private landowners for permission to access the 61 potential study wetlands, we secured 37 final study sites (Figure 1). Approximately one quarter of these wetlands was in each of the four possible combinations of high and low landscape-scale undisturbed land cover and high and low buffer guideline compliance (Figure 2). Study wetlands were spread as evenly as possible across the study region, and all study wetlands were at least $2 \mathrm{~km}$ apart to avoid spatial autocorrelation. All study wetlands were ponds - primarily open water, with some emergent vegetation around the edge-less than 0.5 ha in size. Three of these ponds were natural; the remainder were originally dug or blasted, but had not been used for agriculture (e.g. for irrigation or watering livestock) or quarrying for at least 5 or 20 years, respectively. All ponds were within $40-800 \mathrm{~m}$ of roads. Most (31/37) ponds had at least $25 \%$ agricultural cover, less than $5 \%$ built-up cover, less than $2 \mathrm{~km}$ roads $/ \mathrm{km}^{2}$, and less than $15 \%$ water cover, within a 1 $\mathrm{km}$ radius. The exceptions had up to $10 \%$ built-up cover, up to $2.5 \mathrm{~km}$ roads $/ \mathrm{km}^{2}$, or up to $40 \%$ water cover within a $1 \mathrm{~km}$ radius, but were chosen in such a way that correlations between predictor variables and the potentially confounding landscape variables remained as low as possible. None of the ponds was adjacent to pasture. 


\section{Data sources and software}

Most of the wetland, landscape, and buffer information used during site selection was collected from government maps and aerial photographs. Potential study wetlands were located using the Wetland Unit dataset (OMNR 2011), the Ontario Hydro Network Waterbody dataset (OMNR 2010), and aerial photographs from the Digital Raster Acquisition Project Eastern Ontario (OMNR 2009) and Google Maps (Google 2015). Buffer compliance was estimated from the same aerial photographs. Woodland cover within a $1 \mathrm{~km}$ radius of ponds was based on the Agricultural Resource Inventory (OMAFRA 2010) and the Southern Ontario Land Resource Information System (OMNR 2002). Other information about surrounding landscapes was gathered from these sources, as well as from the Ontario Hydro Network Small Scale Watercourse dataset (OMNR 2012) and the National Road Network Ontario dataset (OMNR 2014). Information about wetland history and current usage was determined by speaking with landowners and through personal observation in the field.

All calculations of wetland size, landscape-scale variables, and buffer size were conducted in ArcMap 10.3 or ArcMap 10.3.1 (ESRI 2014, 2015).

\subsection{Water quality}

We measured concentrations of nitrate, the herbicide atrazine, and four neonitcotinoid insecticides (acetamiripid, clothianidin, imidacloprid, and thiomethoxam) in all study ponds during the 2015 growing season. Nitrate is the worst common pollutant in agricultural fertilizers (FAO 1996), and atrazine and neonicotinoids are common agricultural pesticides of concern (Graymore et al. 2001; Main et al. 2014; Schaafsma et al. 2015). 
We collected two water samples from each pond in June 2015, and one sample in July 2015. We expected agricultural chemical contamination of water bodies to be highest in June (Lapp et al. 1998; Byer et al. 2011; Main et al. 2014), but we took a third water sample in July for nitrate because we were concerned about detection rates. In each sampling period, we began by sampling ponds that were farther south and gradually worked our way north, because we expected that fertilizer and pesticide application would occur slightly earlier in more southerly areas. We took all water samples at least 36 hours after rain events of more than $2 \mathrm{~mm}$, to avoid potentially confounding effects of major rains. We collected water samples away from dense vegetation, approximately $2 \mathrm{~m}$ from shore, and from the middle $80 \%$ of the water column. All water samples were refrigerated at $4-5^{\circ} \mathrm{C}$ until laboratory analysis.

One June water sample and the July water sample from each pond were analyzed for nitrate within 5 days of sampling using ion chromatography. This work was conducted by Laboratory Services at the City of Ottawa, and the full protocols are in Appendix 1. The lower detection limit for this process was $0.04 \mathrm{ppm}$.

The second June water sample from each pond was analyzed for atrazine and neonicotinoid pesticides (acetamiripid, clothianidin, imidacloprid, and thiomethoxam) in September and October 2015 using solid phase extraction followed by high performance liquid chromatography and mass spectrometry. This work was conducted by Environment Canada, and the full protocols are in Appendix 2. The lower detection limits of this process were $0.00040 \mathrm{ppb}$ for atrazine, $0.00010 \mathrm{ppb}$ for acetamiprid, $0.00025 \mathrm{ppb}$ for clothianidin, $0.00025 \mathrm{ppb}$ for imidacloprid, and $0.00020 \mathrm{ppb}$ for thiamethoxam.

We finalized our water quality response variables as follows. Nitrate concentrations were converted to binary values ( 0 if never detected, 1 if detected in June or July) due to low detection 
rates (see Section 3.1). Atrazine concentrations were used without further modification. We summed acetamiprid, clothianidin, imidacloprid, and thiamethoxam concentrations to create a single variable, neonicotinoid concentration, because detection rates for several individual neonicotinoids were low (see Section 3.1). Furthermore, all four neonicotinoids are insecticides and are believed to have similar toxicity to aquatic organisms (Morrissey et al. 2015). If a pesticide was not detected in a pond, its concentration was estimated to be $0 \mathrm{ppb}$.

\subsection{Undisturbed land, landscape scale, and buffer guideline compliance}

The two main predictor variables were (i) undisturbed land cover in the landscape within an appropriate distance of each pond (Questions 1 and 3) and (ii) compliance with buffer guidelines (Questions 2 and 3).

During site selection (Section 2.1), we used woodland cover within a $1 \mathrm{~km}$ radius of ponds to approximate undisturbed land cover, and treed area adjacent to ponds to approximate buffer compliance, because information about woodland was readily available and was more precise than information about other cover types.

Although this was a necessary approximation during site selection, we took the following issues into account when analyzing our data: (i) woodland is not the only type of undisturbed land in agricultural landscapes; (ii) the spatial scale at which landscape composition affects pond water chemistry was unknown; and (iii) the most appropriate way to measure buffer guideline compliance was unknown. We therefore created detailed maps of multiple cover types (woodland, scrub, hay, pasture, orchards lawn, row crops, and non-vegetated lands such as roads and quarries) within $700 \mathrm{~m}$ of each pond in the field (Figure 3), a $700 \mathrm{~m}$ radius being the 
maximum practical scale for on-the-ground mapping. We then evaluated undisturbed land, landscape scale, and buffer guideline compliance as follows.

\section{Undisturbed land}

We defined undisturbed land in the same way both at the landscape scale and in wetland buffers. Buffer guidelines usually focus on the proximity of crops to water bodies, so most vegetated lands other than crop fields — including woodland, scrub, hay, pasture, and lawn — are implicitly considered to be "undisturbed" in these regulations (Cecily Flemming, OMECC, pers. comm.). It also seems intuitive that nutrient and pesticide concentrations would decrease with the proportion of non-crop land at a landscape scale. We used this information as a starting point, and then empirically confirmed which land cover types were "disturbed" and "undisturbed" using multi-scale analyses (Section 2.4).

\section{Landscape scale}

We measured undisturbed land cover at 200, 300, 400, 500, 600, and $700 \mathrm{~m}$ radii around ponds, and determined the most appropriate landscape scale using multi-scale analyses (Section 2.4). We used $200 \mathrm{~m}$ as the smallest landscape radius to ensure that our landscapes were larger than the maximum regulated buffer width for aquatic habitat protection $(120 \mathrm{~m})$, and $700 \mathrm{~m}$ as the largest due to logistical constraints.

\section{Buffer guideline compliance}

We measured compliance with buffer guidelines in three ways: wetland buffer width, area-based compliance, and perimeter-based compliance (Figure 4). Buffer width was the 
minimum width of adjacent undisturbed land, as per Ontario guidelines (Cecily Flemming, OMECC, pers. comm.). Area-based compliance was the percentage of the area circumscribed by a recommended buffer width that contained undisturbed land contiguous with the pond edge. Perimeter-based compliance was measured as the percentage of a pond's perimeter that had buffer vegetation at least as wide as a recommended buffer width. For the area-based and perimeter-based compliance measurements, we considered buffer widths recommended by Ontario governments: 5, 9, 13, 16, 30, 50, and $120 \mathrm{~m}$ (Coukell et al. 2004; Ontario Farm Environmental Coalition 2004; Niagara Planning and Development Services Department 2015).

\subsection{Analyses}

Our main study questions dealt with the effects of landscape-scale undisturbed land cover and wetland buffers on pond water quality. However, before we could address these questions, we conducted preliminary analyses to determine the most appropriate definition of undisturbed land and the appropriate landscape scale (i.e. the scale at which landscape composition most strongly affected water chemistry). We then evaluated our main study questions by examining the relationships between water quality and (i) landscape-scale undisturbed land cover (Questions 1 and 3), and (ii) compliance with buffer guidelines (Questions 2 and 3).

All statistical tests were performed in R, Version 3.2.4 (R Core Team 2016). We conducted most analyses using standard R functions, but calculated AICc values and conducted multi-model inference using the package, MuMIn (Barton 2016).

We omitted one of the 37 study ponds from analyses of nitrate because we were only able to visit the pond in June, rather than June and July. 


\section{Definition of undisturbed land and landscape scale}

We determined the appropriate definition of undisturbed land using non-parametric regression and correlation analyses. We examined the relationship between water quality variables and proportional cover of (i) row crops, (ii) row crops or hay, (iii) non-vegetated land, (iv) woodland, (v) scrub, and (vi) permanent anthropogenic vegetation such as hay, pasture, lawn, and orchard, within $5,10,20,30,50,70,100,150,200,300,400,500,600$, or $700 \mathrm{~m}$ from the edge of each pond. Hay was included in two land cover categories (ii and vi) because it is sometimes grown in rotation with row crops such as corn or soy, but sometimes represents permanent, low-intensity anthropogenic vegetation; our dataset did not allow us to distinguish between these. For nitrate, we conducted logistic regressions of nitrate detection on the proportional cover of each land cover type at each spatial scale. For atrazine and neonicotinoid concentrations, we conducted Spearman's rank-based correlation analyses. We defined "disturbed" land cover types as those associated with the strongest increases in nitrate detection probability or pesticide concentrations, and "undisturbed" land as all other cover types.

We determined the most appropriate landscape scale using the statistical analyses above for spatial scales between 200 and $700 \mathrm{~m}$ (see Section 2.3). The appropriate landscape scale was indicated by the analysis producing the strongest relationship between water quality variables and proportional disturbed land cover.

\section{Evaluation of study questions}

Based on the results of our analyses above, in addressing our main objectives we defined undisturbed land as lands other than crops or hay (henceforth non-crop/hay), and $200 \mathrm{~m}$ as the landscape radius (see Section 3.1). 
To evaluate the effects of landscape-scale undisturbed land cover on water quality (Question 1) we conducted a bivariate logistic regression of nitrate detection, and bivariate linear regressions of log-transformed atrazine and neonicotinoid concentrations, on undisturbed land cover within $200 \mathrm{~m}$.

We examined the effects of buffer guideline compliance on water quality in ponds (Question 2) using bivariate logistic regressions of nitrate detection, and bivariate linear regressions of log-transformed atrazine and neonicotinoid concentrations, on each of the fifteen buffer predictor variables (buffer width; area-based compliance with 5, 9, 13, 16, 30, 50, and 120 m guidelines; and perimeter-based compliance with 5, 9, 13, 16, 30, 50, and $120 \mathrm{~m}$ guidelines).

We compared the effects of landscape-scale undisturbed land cover and buffer guideline compliance on pond water quality variables (Question 3) using multi-model inference. The full model for each water quality variable (nitrate detection, log-transformed atrazine concentration, or log-transformed neonicotinoid concentration) was as follows: Water quality variable $=b_{0}+$ $b_{1}($ landscape variable $)+b_{2}($ buffer variable $)+b_{3}($ landscape variable $*$ buffer variable $)$. Because we measured buffer compliance in 15 different ways (buffer width; area-based compliance with $5,9,13,16,30,50$, and $120 \mathrm{~m}$ guidelines; and perimeter-based compliance with 5, 9, 13, 16, 30, 50, and 120 m guidelines), we examined 15 sets of models. In each set, the landscape variable was undisturbed land cover, measured between the edge of the wetland buffer and the $200 \mathrm{~m}$ landscape scale (i.e. the "buffer-independent landscape"; Figure 5). Similar to the analyses for Questions 1 and 2, we used logistic regression models for nitrate detection, and linear regression models for log-transformed atrazine and neonicotinoid concentrations. Because the two predictor variables (landscape-scale conservation and buffer guideline compliance) were measured in different units, and we wanted to compare their effects using estimated partial regression 
coefficients, we standardized all predictor variables to a mean of 0 and standard deviation of 1 for these analyses.

\section{RESULTS}

\subsection{Water quality}

Nitrate was detected in 16 of 36 ponds, with a maximum concentration of $14.28 \mathrm{ppm}$. Atrazine was detected in all 37 ponds, with concentrations ranging 0.0051 to $1.6 \mathrm{ppb}$. Acetamiripid, clothianidin, imidacloprid, and thiomethoxam were detected in 2, 25, 10, and 18 ponds, respectively; at least one neonicotinoid was found in 28 ponds. The maximum individual neonicotinoid concentration was $1.3 \mathrm{ppb}$ (for thiamethoxam), and the maximum total neonicotinoid concentration was $1.3231 \mathrm{ppb}$.

\subsection{Undisturbed land, landscape scale, and predictor variables}

Combined row crop and hay cover (hereafter crop/hay) was the only land cover category associated with significant increases in all three water quality response variables (nitrate detection, atrazine concentration, and neonicotinoid concentration; Figures 6-8). When landscape scales of 200-700 m were considered, the strongest relationships between water quality variables and a land cover type always occurred with crop/hay at $200 \mathrm{~m}$. Other statistically significant relationships included positive correlations between row crop cover and pesticide concentrations (Figure 7-8), and negative correlations between woodland cover and 
neonicotinoid concentrations (Figure 8). Therefore we defined undisturbed land cover as all land cover other than crops or hay.

Undisturbed land cover within $200 \mathrm{~m}$ of study ponds ranged from 1 to $87 \%$ (mean $=$ $51 \%)$. Buffer widths were 1 to $131 \mathrm{~m}($ mean $=23 \mathrm{~m})$. Area and perimeter based compliance measurements for each buffer guideline were highly correlated with each other (Spearman's $\rho=$ 0.895 to 0.987 , depending on the guideline; Appendix 3), and ranged from 30 to $100 \%$ compliance for $5 \mathrm{~m}$ guidelines, and 0 to $100 \%$ compliance for $120 \mathrm{~m}$ guidelines.

\subsection{Evaluation of study questions}

\section{Landscape effects on water quality (Question 1)}

Nitrate detection probabilities, atrazine concentrations, and neonicotinoid concentrations in study ponds decreased significantly with proportion of undisturbed land cover within $200 \mathrm{~m}$ (nitrate $-\mathrm{p}=0.043$; atrazine $-\mathrm{p}=0.038$; neonicotinoids $-\mathrm{p}=0.001$; Figure 9). The relationship between neonicotinoid concentration and undisturbed land cover remained significant even when all nine $0 \mathrm{ppb}$ neonicotinoid concentrations were excluded from the analysis $(\mathrm{p}=0.020)$.

\section{Buffer effects on water quality (Question 2)}

There was little evidence for an effect of buffer guideline compliance on nitrate detection, atrazine concentrations, or neonicotinoid concentrations, regardless of how compliance was measured. Exceptions were that neonicotinoid concentrations significantly decreased with (i) area-based compliance with $120 \mathrm{~m}$ buffer guidelines $(\mathrm{p}=0.012)$, and (ii) perimeter-based compliance with $120 \mathrm{~m}$ buffer guidelines $(\mathrm{p}=0.002)$. No other relationships between water 
quality variables and buffer guideline compliance were statistically significant, although regression coefficients were consistently negative (data not shown).

Relative effects of landscape-scale undisturbed land and wetland buffers on water quality (Question 3)

Landscape-scale undisturbed land cover was more important than buffer guideline compliance in reducing nutrient and pesticide levels in study ponds. Models including only landscape-scale undisturbed land cover as a predictor variable were almost always more informative than null models, while models including only a buffer predictor variable were almost always less informative than null models (Figure 10). In additive models, landscape-scale undisturbed land cover nearly always explained more variation in water quality response variables than did buffer predictor variables (Figure 11).

\section{DISCUSSION}

Nitrate, atrazine, and neonicotinoid levels in our study ponds ranged from absent to present in harmful concentrations. Canadian Environmental Quality Guidelines recommend that to protect freshwater organisms in the long term, nitrate concentrations should be less than 13 ppm, atrazine concentrations should be less than $1.8 \mathrm{ppb}$, and imidacloprid (neonicotinoid) concentrations be less than $0.23 \mathrm{ppb}$ (CCME 2014). These limits were exceeded in four of our 37 study ponds - we observed a nitrate concentration of $14.28 \mathrm{ppm}$ in one pond, and neonicotinoid concentrations of $0.29,0.40$, and $1.6 \mathrm{ppb}$ in three other ponds. We also detected $12.4 \mathrm{ppm}$ nitrate and $1.6 \mathrm{ppb}$ atrazine in two ponds, which approach the "harmful" thresholds. Thus, water quality in some ponds was probably sufficiently protected, while water quality in other ponds was not. 
Our results indicate that landscape-scale "undisturbed" land cover can protect water quality more effectively than compliance with buffer guidelines. Nitrate detection rates, atrazine concentrations, and neonicotinoid concentrations were significantly lower in ponds that had higher amounts of undisturbed land within $200 \mathrm{~m}$ of the pond edge, particularly when undisturbed land cover increased beyond 40\% (Figure 9). Furthermore, even when undisturbed land was measured only in the landscape external to the wetland buffer (Section 2.4; Figure 5), (i) regression models containing only a landscape-scale predictor variable explained nitrate and pesticide levels better than regression models containing only a buffer predictor variable (Figure 10), and (ii) landscape-scale predictor variables nearly always explained more variation in nitrate and pesticide levels than buffer predictor variables in additive regression models (Figure 11). In other words, undisturbed land does not need to be contiguous with wetlands in order to improve water quality, and landscape-scale undisturbed land cover affects water quality more strongly than compliance with buffer guidelines.

Our landscape-scale results are qualitatively similar to other studies of Ontario wetlands. Crosbie and Chow-Fraser (1999) found that nutrient concentrations in coastal Ontario wetlands decreased with woodland cover (a measure of undisturbed land) and increased with agricultural cover in the landscape. Similarly, Houlahan and Findlay (2004) found that nitrogen and phosphorus concentrations in Ontario wetlands decreased with woodland cover (undisturbed land) in the landscape.

Our findings also suggest that water quality in small farmland ponds may respond to land cover at smaller spatial scales than water quality in rivers or large wetlands in less agriculturedominated environments. Our empirically-determined landscape scale $(200 \mathrm{~m})$ is smaller than those reported for rivers and streams, which often respond to landscape composition at the scale 
of a catchment or watershed (Sliva and Williams 2001; King et al. 2005). It is also smaller than those previously reported for large Ontario wetlands: Crosbie and Chow-Fraser (1999) measured woodland and agricultural land cover at the scale of the watershed, and Houlahan and Findlay (2004) empirically determined that woodland cover within $2000-2500 \mathrm{~m}$ of focal wetlands most strongly explained variation in water quality. However, Declerck et al. (2006), examining water quality in small farmland ponds in Belgium, found suspended solids to most strongly decrease with woodland cover and increase with crop cover within $100 \mathrm{~m}$ of the pond, despite examining spatial scales as large as $3200 \mathrm{~m}$. Although we measured different water quality response variables, we found a similarly small landscape scale.

Another possibility is that we did not find a larger landscape scale to be appropriate because we did not examine spatial scales beyond $700 \mathrm{~m}$. However, this is unlikely because in our study the effects of land cover on nitrate and neonicotinoids steadily weakened, and the effects of land cover on atrazine levelled off, beyond a 200 m landscape scale (Figures 6-8). Also, we conducted post hoc non-parametric analyses (logistic regression and Spearman's rankbased correlations) examining the relationships between our water quality variables and proportional woodland cover - a proxy for undisturbed land cover — at scales of 1000 and 1500 m. Relationships between water quality and undisturbed land cover at $200 \mathrm{~m}$ were still stronger than the relationships in these post-hoc analyses.

Our empirically-determined definition of undisturbed land is broadly consistent with Ontario buffer guidelines. Although some guidelines recommend specific vegetation types such as trees or shrubs, most simply focus on the proximity of crops to water bodies, implying that row crops represent "disturbed" land and all other cover types are "undisturbed" (Coukell et al. 2004; Ontario Farm Environmental Coalition 2004). Consistent with this, of the multiple land 
uses we measured, we found only row crop or crop/hay cover to significantly increase nitrate and pesticide levels in ponds. Interestingly, neonicotinoid concentrations were much more strongly related to crop/hay cover than row crop cover alone. Since neonicotinoids are typically applied to row crops, and not to hay, this finding reinforces the fact hay is often rotated with row crops in our study area. Overall, these results suggest that disallowing row crops from buffers is probably adequate to protect water quality in agricultural eastern Ontario, as long as this exclusion is permanent (i.e. hay should not be allowed in buffers if it is being rotated with row crops).

Although we found no effects of other anthropogenic cover types (orchard, pasture, lawn, and non-vegetated land) on water quality, and considered them to be "undisturbed" in our study region, we caution against unilaterally considering these cover types to be "undisturbed" in other contexts. In our study landscapes, orchard, pasture, lawn, and non-vegetated land were not very prevalent (median cover amounts $=0,0,3$, and $0.6 \%$, respectively). However, fertilizers and pesticides are sometimes applied to orchards and lawns, livestock may contribute to nutrient loads, and impervious surfaces can facilitate surface runoff, so in regions where these cover types are more prevalent, they may have adverse impacts (Arnold and Gibbons 1996; Merwin et al. 1996; Hubbard et al. 2004; Zhou et al. 2008).

While we found Ontario buffer guidelines to define undisturbed land well for our study region (though see caveat above), compliance with current buffer guidelines had little effect on water quality. The only statistically significant relationships occurred between neonicotinoid concentration and compliance with the $120 \mathrm{~m}$ buffer guideline - a guideline that is very close to our empirically-determined landscape scale of $200 \mathrm{~m}$. These findings suggest that if buffers are to protect water quality in lentic agricultural wetlands, they should be at least $200 \mathrm{~m}$ wide. 
Our result that buffers of less than $200 \mathrm{~m}$ do not affect water quality contrasts with previous studies (Castelle et al. 1994; Vought et al. 1995; Wenger 1999). For example, Rasmussen et al. (2011) found that the levels of toxic pesticides in streams decreased as minimum buffer width increased, and recommended a $6.6 \mathrm{~m}$ as a minimum buffer width along streams. Other authors have generally concluded that buffer between 5 and $50 \mathrm{~m}$ wide can intercept the majority of contaminants from agricultural runoff by physically blocking the movement of sediments to which contaminants are bound, or by providing soil into which water containing dissolved contaminants can infiltrate (Castelle et al. 1994; Vought et al. 1995; Wenger 1999; Environmental Law Institute 2003).

There are two main, non-exclusive explanations for why we did not observe wetland buffer effects on water quality. First, wetland buffers may not be effective in regions with flat topography. Our study sites were all in relatively flat areas, and may therefore have been fed less by surface runoff than by groundwater or subsurface runoff. A meta-analysis of nitrogen removal in buffer zones found that buffer size had no effect on nitrogen transport by subsurface runoff (Mayer et al. 2007). Presumably buffers would have even less of an effect on contaminant transport in groundwater. This situation is probably quite common, as many agricultural regions are flat (e.g. North America's Prairie Pothole Region, the Fens in the United Kingdom, and the Huang-Huai-Hai Plain in China). If buffers are not effective in regions with flat topography, then conservation planners in these regions might need to change their focus from implementing buffers around wetlands (e.g. Huel 2000) to limiting agricultural expansion and limiting the use of fertilizers and pesticides on agricultural lands.

Second, wetland buffers may be less effective at intercepting highly soluble compounds than at intercepting compounds that typically bind to sediment. The focal compounds in our 
study — nitrate, atrazine, and neonicotinoids — are all highly soluble. While several studies have shown buffers to successfully intercept soluble compounds such as nitrate, it is generally acknowledged that buffers are more effective at intercepting particulate pollutants than those in solution (Helmers et al. 2008). For example, in a field study with artificial runoff events, Schmitt et al. (1999) found that buffers were more consistently effective against contaminants that are often bound to sediment, such as phosphorus, than against more soluble compounds such as atrazine.

Regardless of the reason, though, our results indicate that wetland buffers less than $200 \mathrm{~m}$ wide are not an effective way to improve overall water quality in small water bodies in flat agricultural areas during the growing season. Buffers may still be of some use against the acute contaminant pulses associated with major rain events, but we cannot draw such conclusions from the present research.

In conclusion, we recommend that landscape-scale conservation be pursued over compliance with current buffer guidelines to protect water quality in agricultural wetlands, particularly in regions with flat topography. Non-crop cover types, particularly woodland, should be maintained within a $200 \mathrm{~m}$ radius of lentic agricultural wetlands. This may mean mandating $200 \mathrm{~m}$ wetland buffers such that $100 \%$ of the land within a $200 \mathrm{~m}$ landscape would be conserved, or instituting landscape-scale protection measures by asking landowners to conserve a certain proportion of undisturbed land within $200 \mathrm{~m}$ of wetlands on their properties. We also recommend that hay not be designated as an "undisturbed" land use in areas where it is grown in rotation with row crops. 


\section{FIGURES}

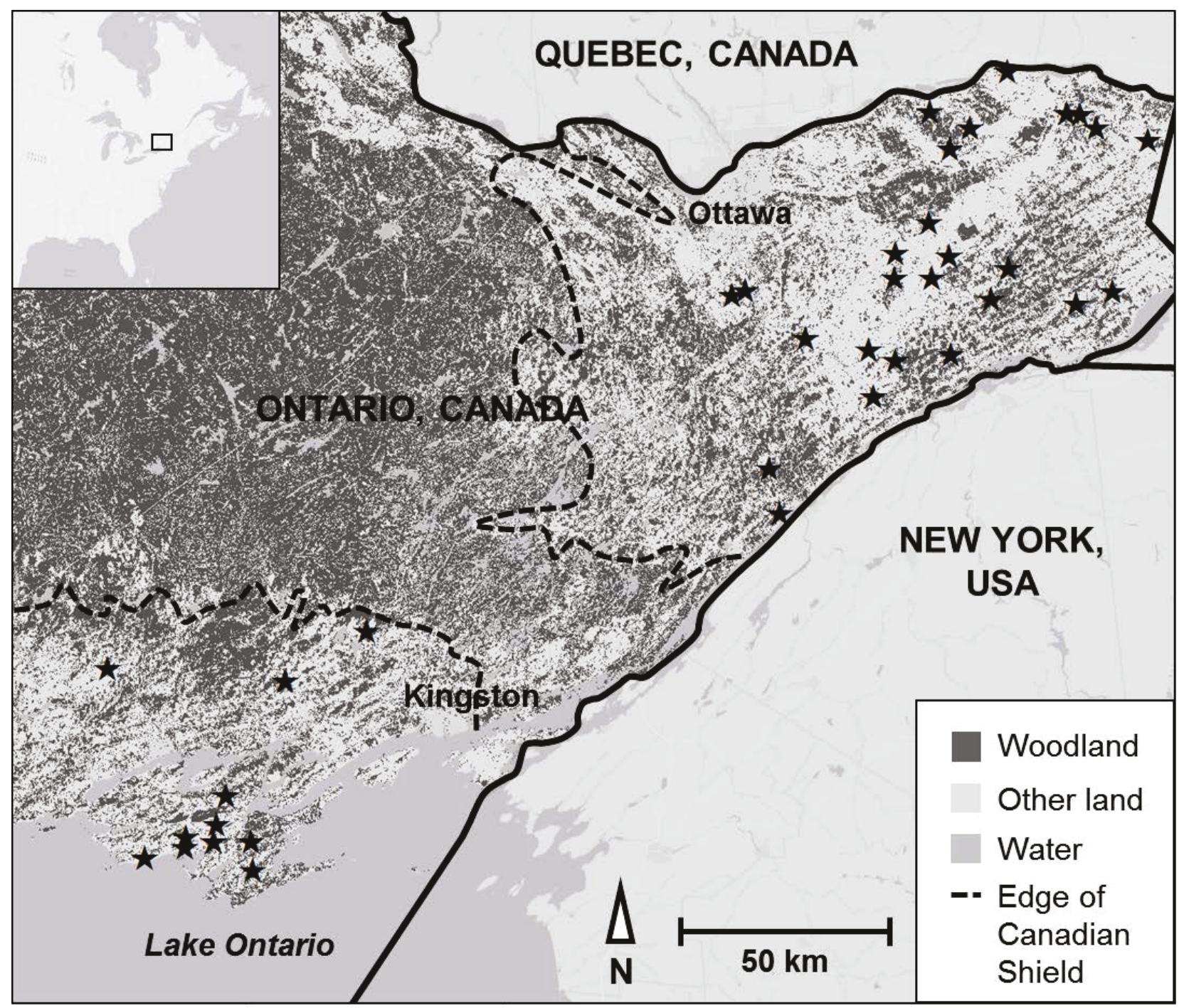

Figure 1. Locations of all 37 study ponds (black stars) in agricultural landscapes of eastern Ontario, Canada. 


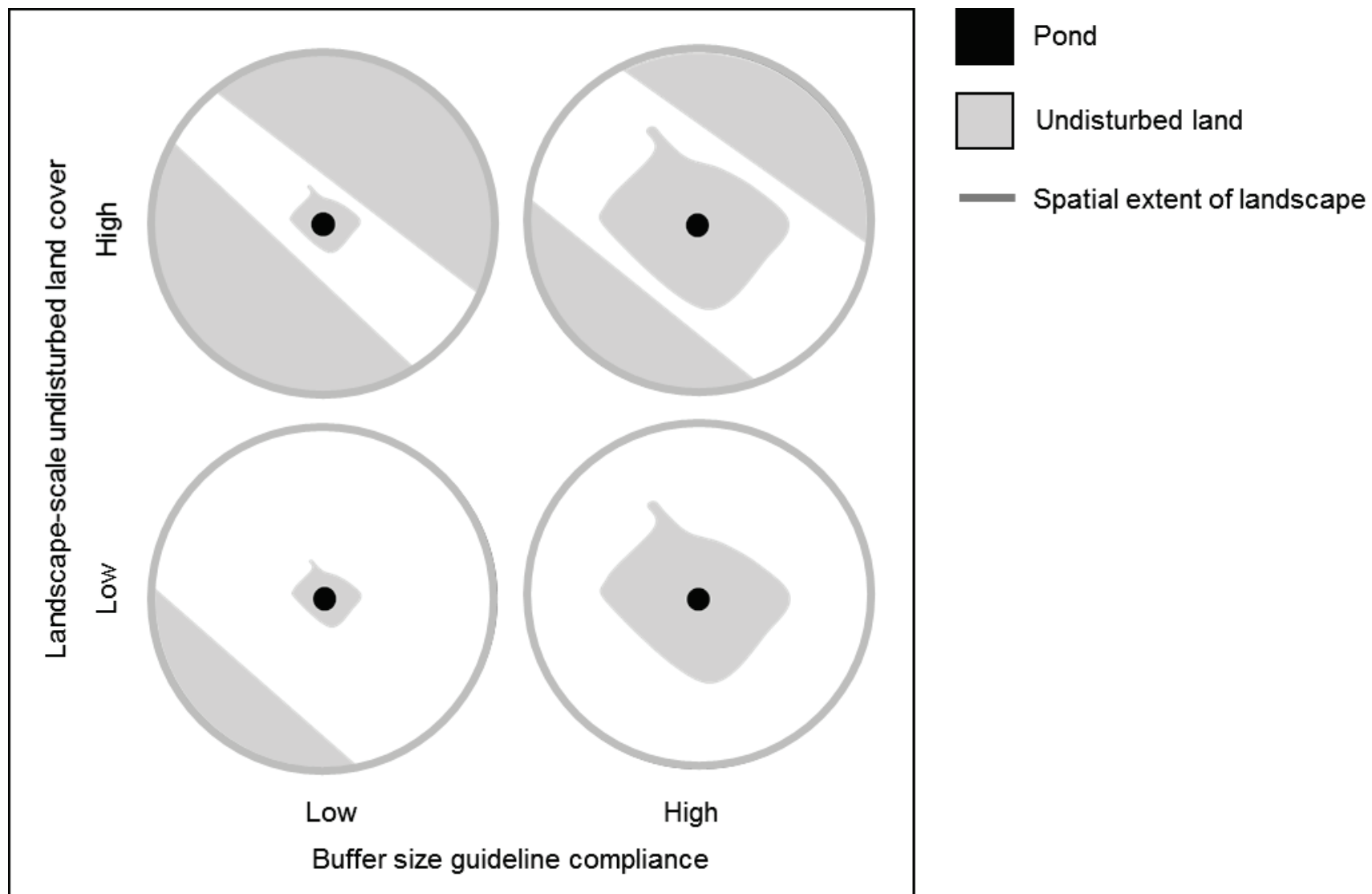

Figure 2. Illustration of the four categories of farmland ponds. We selected similar numbers of study ponds from each of the following four categories: (i) high undisturbed land cover and low buffer guideline compliance, (ii) high undisturbed land cover and high buffer guideline compliance, (iii) low undisturbed land cover and low buffer guideline compliance, and (iv) low undisturbed land cover and high buffer guideline compliance. 


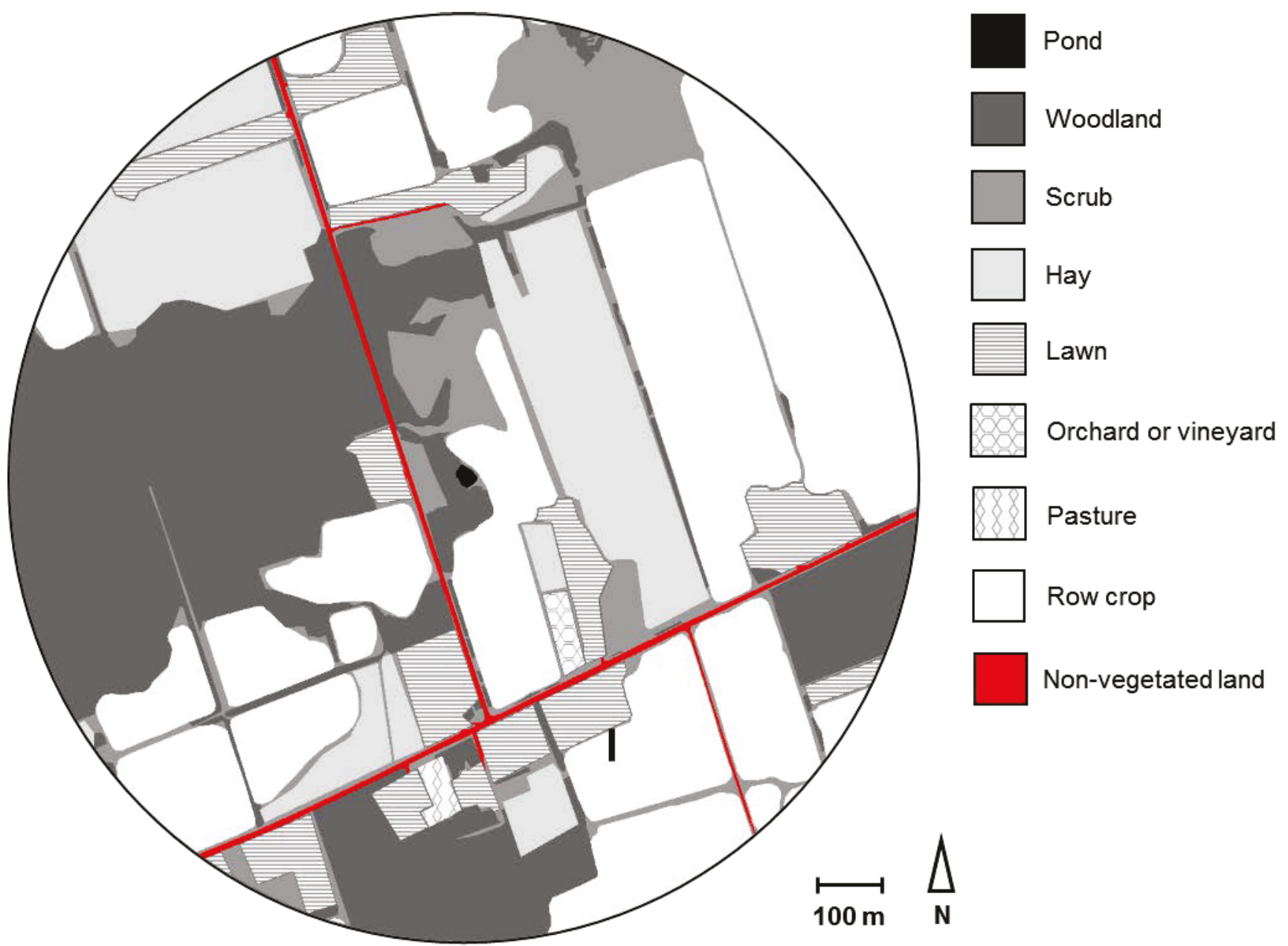

Figure 3. Map of all land cover types examined within $700 \mathrm{~m}$ from the edge of one study pond. Maps were created for all 37 study ponds in the field during the year of sampling (2015). 

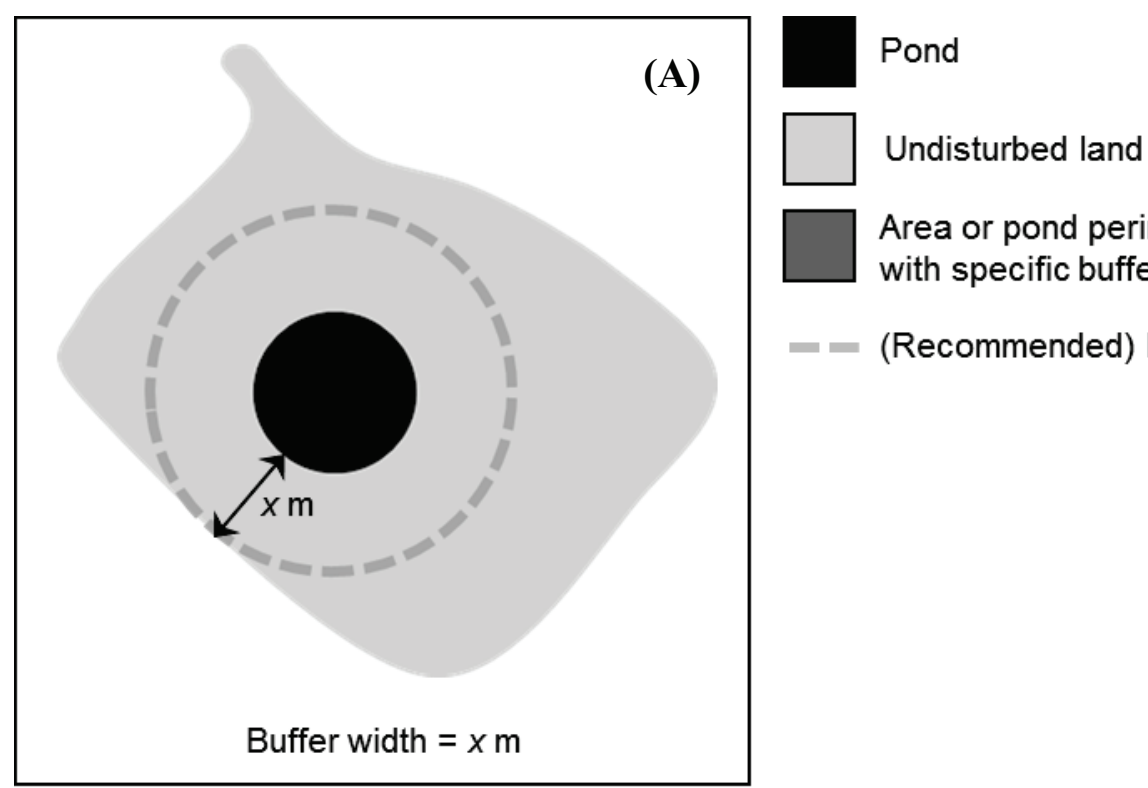

Area or pond perimeter complying with specific buffer width guidelines

$=$ (Recommended) buffer width
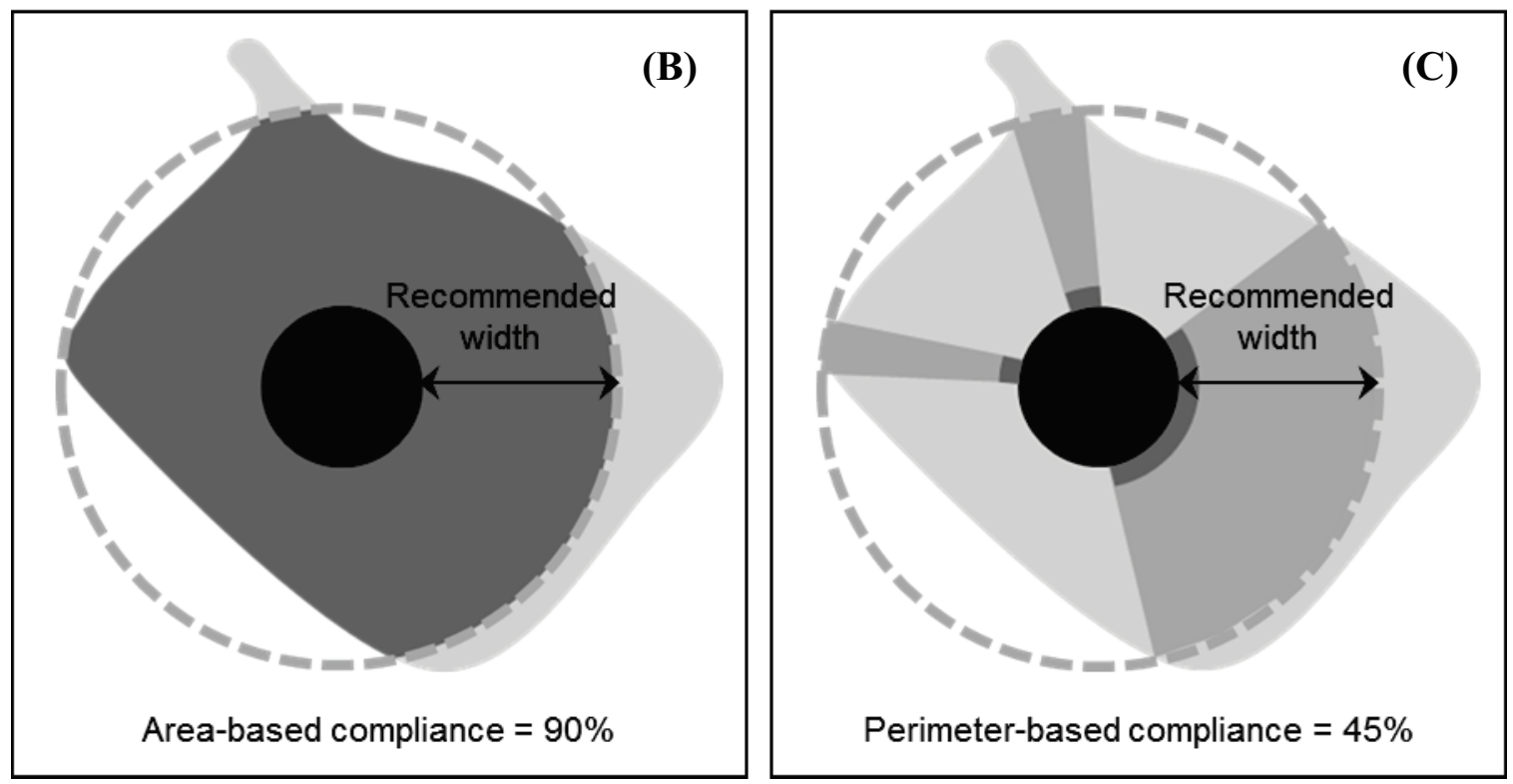

Figure 4. Diagrams showing the three ways that compliance with buffer guidelines was measured. (A) Buffer width was measured as the minimum width of undisturbed land around the pond, or, the distance from a pond's edge to crop fields or hay. (B) Area-based compliance was measured as the percentage of the area within a recommended buffer width that contained undisturbed land contiguous with the pond edge. (C) Perimeter-based compliance was measured as the percentage of a pond's perimeter that had a buffer at least as wide as a recommended buffer width. 

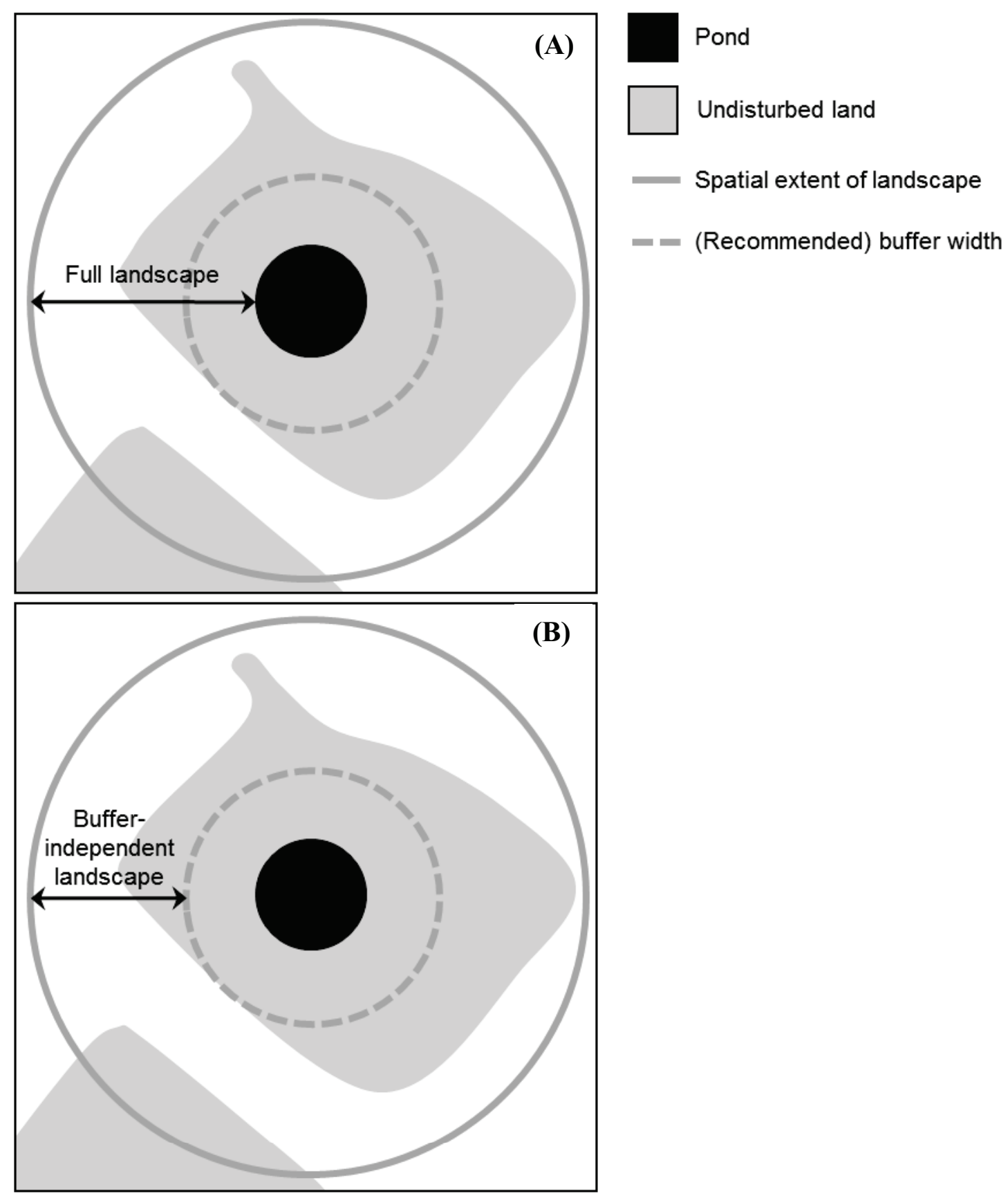

Figure 5. Area considered as "landscape" when measuring landscape-scale undisturbed land cover. (A) In analyses focusing on landscape effects on water quality (Question 1), undisturbed land cover was measured throughout the full landscape within $200 \mathrm{~m}$ of the pond edge. (B) In analyses comparing landscape vs. wetland buffer effects on water quality (Question 3), landscape-scale undisturbed land cover was measured within the portion of the landscape that did not overlap the wetland buffer (the buffer-independent landscape). 


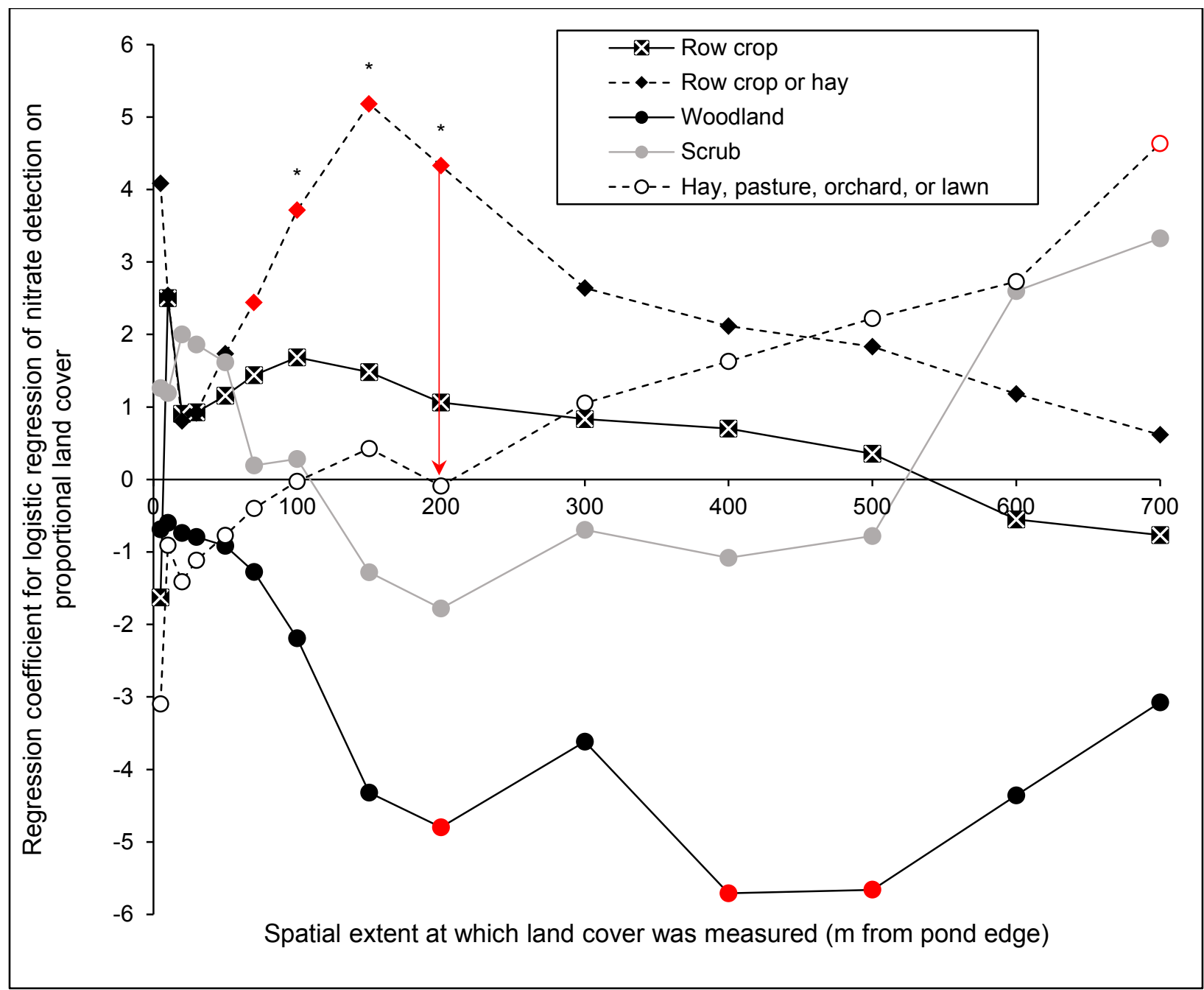

Figure 6. Regression coefficients for the logistic regression of nitrate detection in 36 study ponds on the proportion of various land cover types in the surrounding area. Proportional land cover was measured between the pond edge and spatial extents of 5-700 m. Regressions with $\mathrm{p}<$ 0.1 are indicated by red data points; regressions with $p<0.05$ are additionally marked with an asterisk. A combination of row crop and hay was the best definition of disturbed land for this study, making non-crop/hay the best definition of undisturbed land. Since we considered $200 \mathrm{~m}$ to be the smallest possible landscape scale, a $200 \mathrm{~m}$ landscape radius was the best scale for nitrate detection (red arrow). 


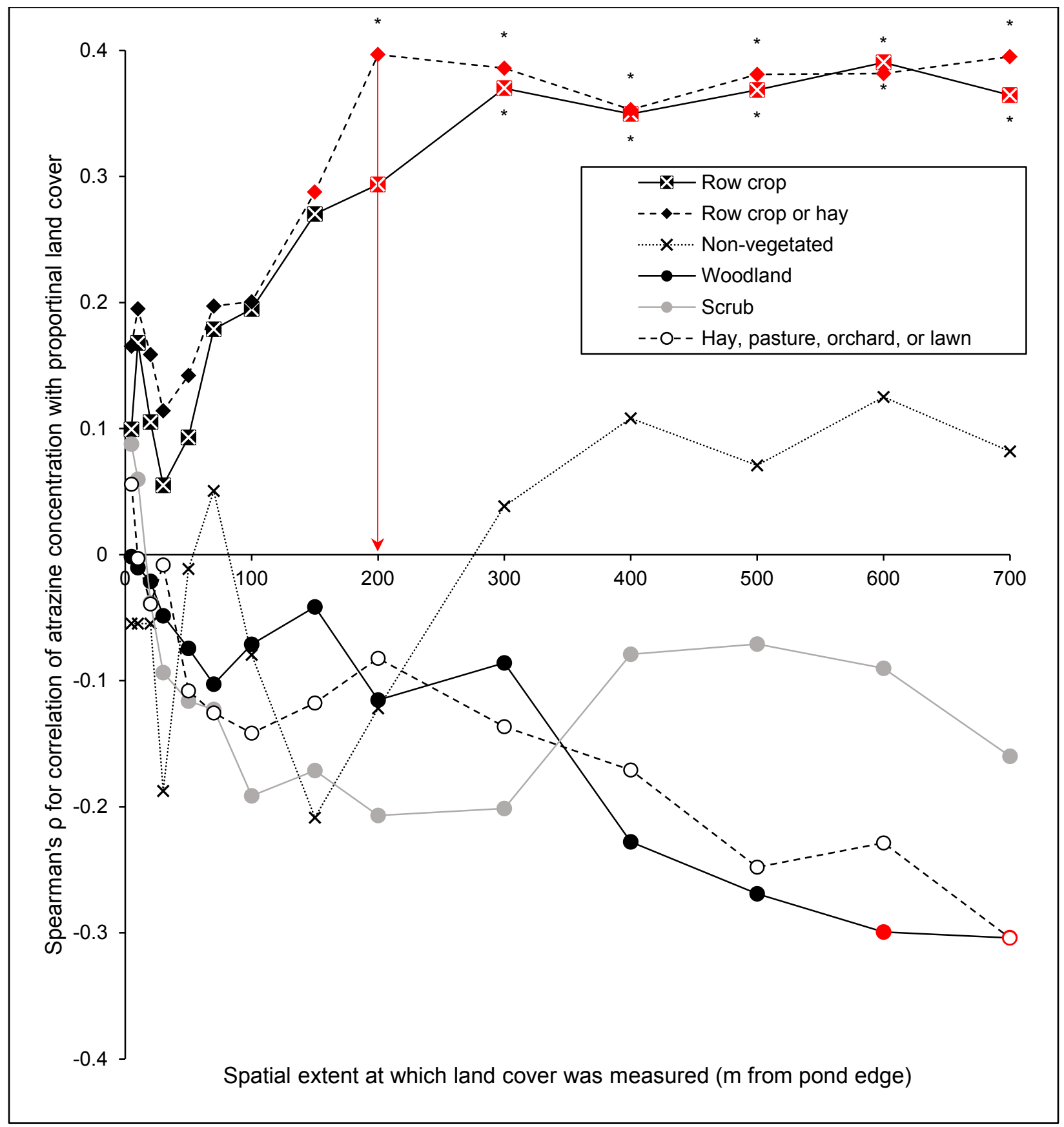

Figure 7. Spearman's $\rho$ values for the rank-based correlations of atrazine concentration in 37 study ponds with the proportional cover of various land cover types in the surrounding area. Proportional land cover was measured between the pond edge and spatial extents of 5-700 $\mathrm{m}$. Correlations with $\mathrm{p}<0.1$ are indicated by red data points; correlations with $\mathrm{p}<0.05$ are additionally marked with an asterisk. A combination of row crop and hay was found to be the best definition of disturbed land for this study - making non-crop/hay the best definition of undisturbed land - so a $200 \mathrm{~m}$ landscape radius was the best scale for atrazine concentrations (red arrow). 


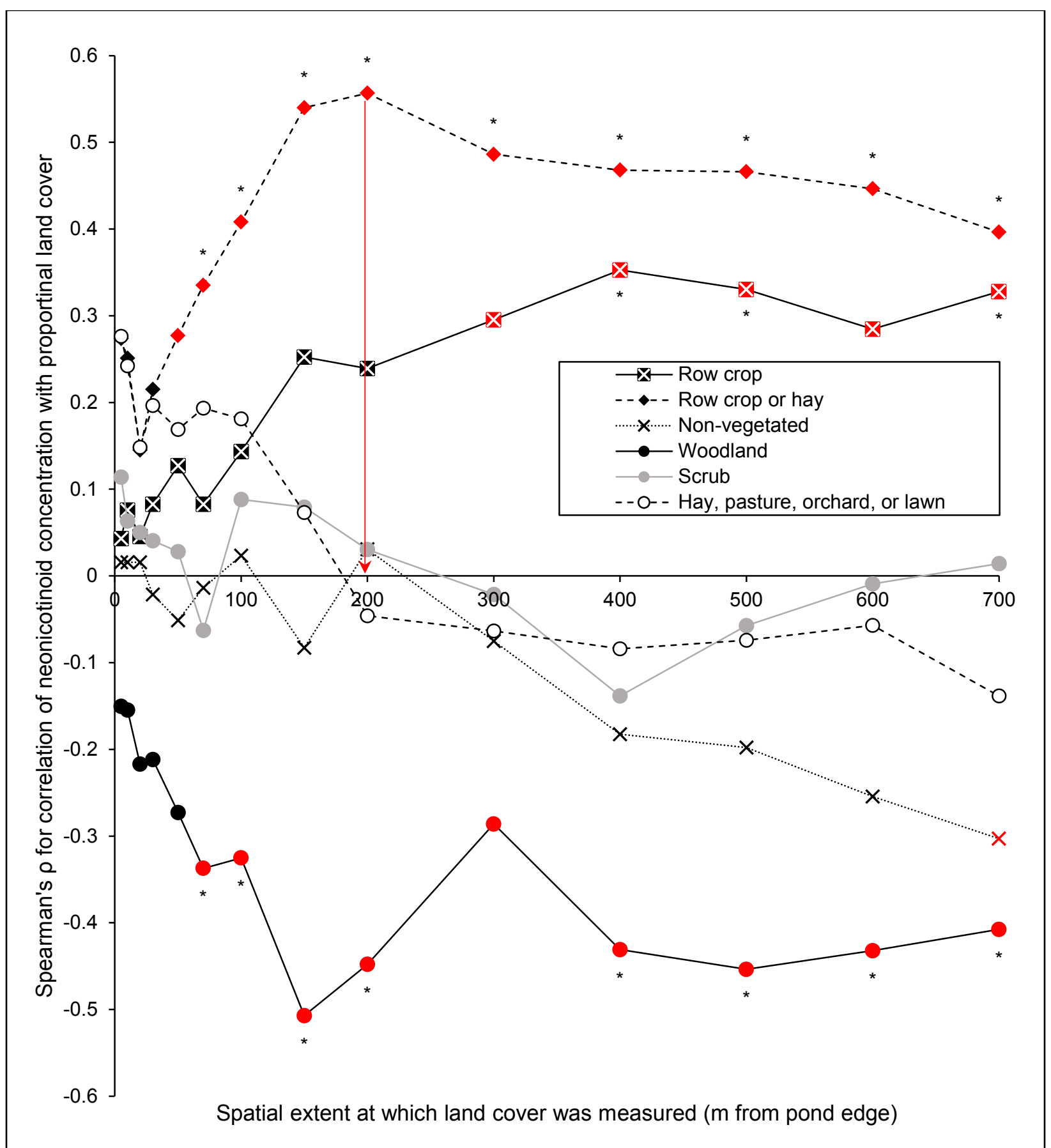

Figure 8. Spearman's $\rho$ values for the rank-based correlations of neonicotinoid concentration in 37 study ponds with the proportional cover of various land cover types in the surrounding area. Proportional land cover was measured between the pond edge and spatial extents of 5-700 $\mathrm{m}$. Correlations with $p<0.1$ are indicated by red data points; correlations with $p<0.05$ are additionally marked with an asterisk. A combination of row crop and hay was found to be the best definition of disturbed land for this study - making non-crop/hay the best definition of undisturbed land - so a $200 \mathrm{~m}$ landscape radius was the best scale for neonicotinoid concentrations (red arrow). 

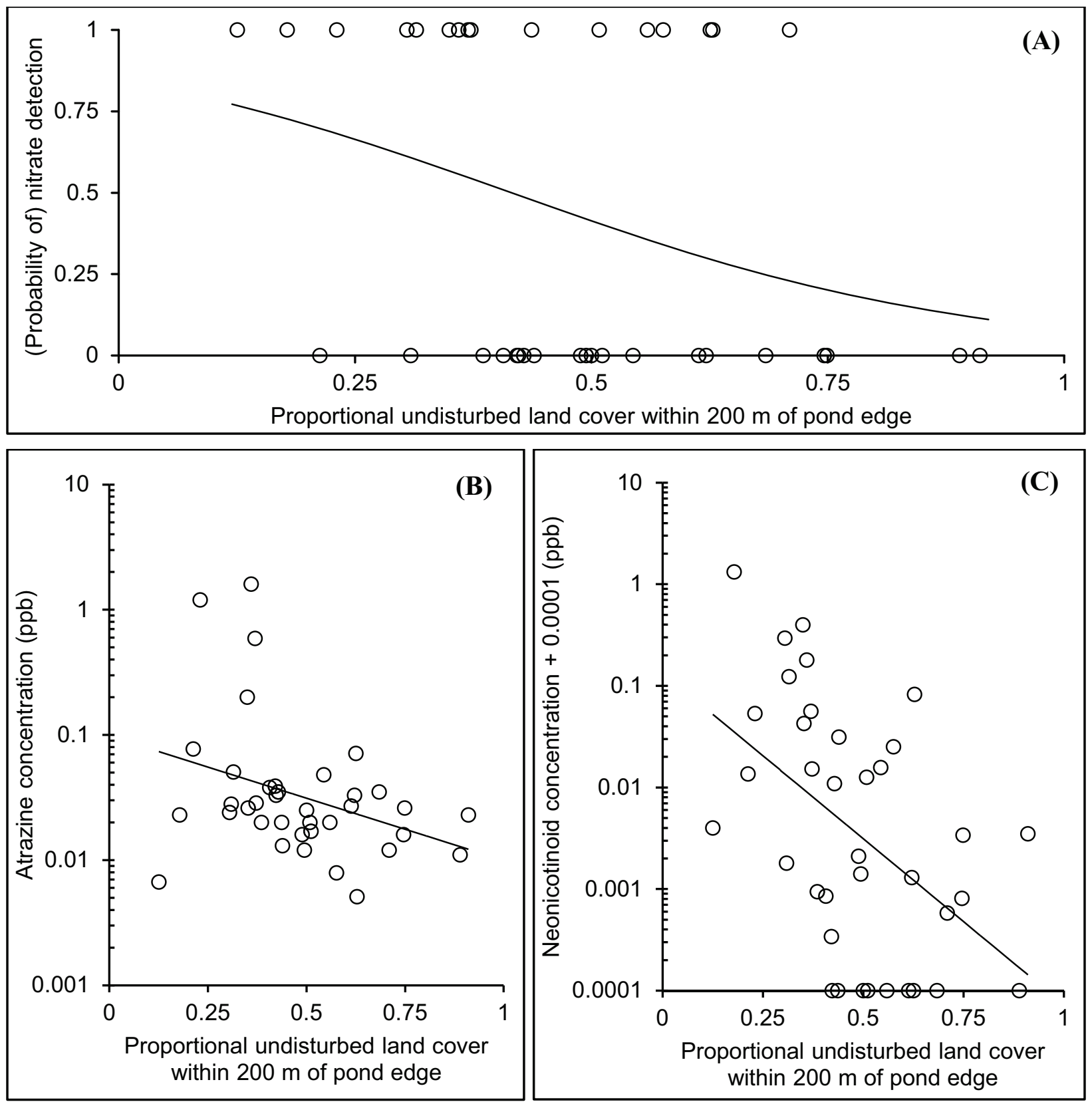

Figure 9. The effect of undisturbed land (non-crop/hay) cover at a $200 \mathrm{~m}$ landscape scale on (A) nitrate detection, (B) atrazine concentration, and (C) neonicotinoid concentration in in study ponds ( $\mathrm{n}=36$ for nitrate detection; $\mathrm{n}=37$ for atrazine and neonicotinoid concentrations). Regression lines are shown in black. All relationships were statistically significant $(\mathrm{p}<0.05)$. 


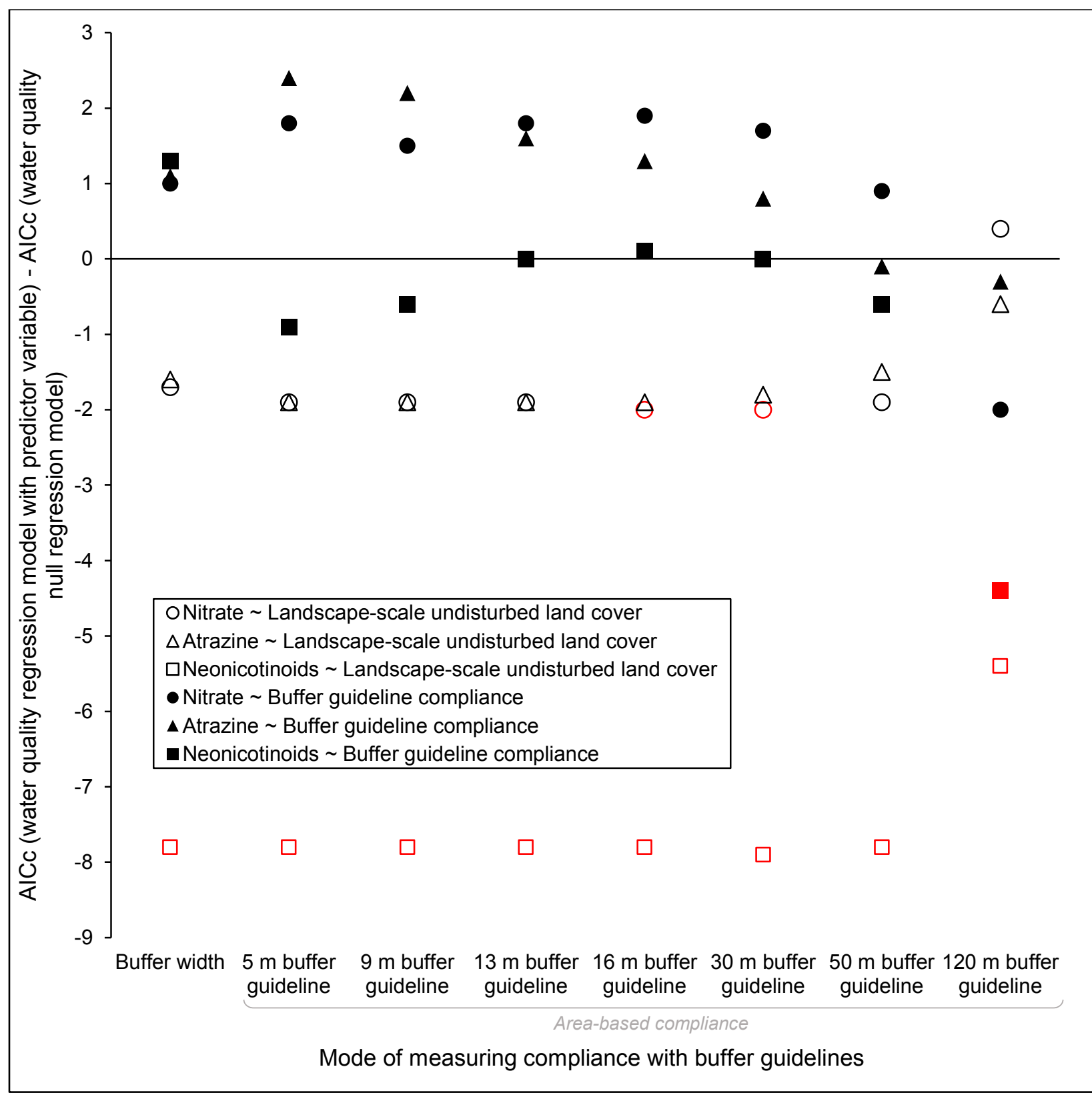

Figure 10. Differences between AICc values of regression models containing a given predictor variable and AICc values for null models, when response variables were water quality variables in study ponds. Open symbols are regressions of water quality variables on landscape-scale undisturbed land cover; closed symbols are regressions on buffer guideline compliance. Buffer guideline compliance was measured as buffer width or as area-based compliance with one of seven buffer guidelines (see Figure 4); perimeter-based compliance (not shown) was also highly correlated with values for both predictor variables and resulted in similar model fit (Appendices $3-4)$. Landscape-scale undisturbed land cover was measured as the proportional cover of undisturbed land between the edge of the buffer and the full extent of the landscape $(200 \mathrm{~m})$. Regression models with AICc values at least 2 points lower (better fit) than the null model are indicated in red. 


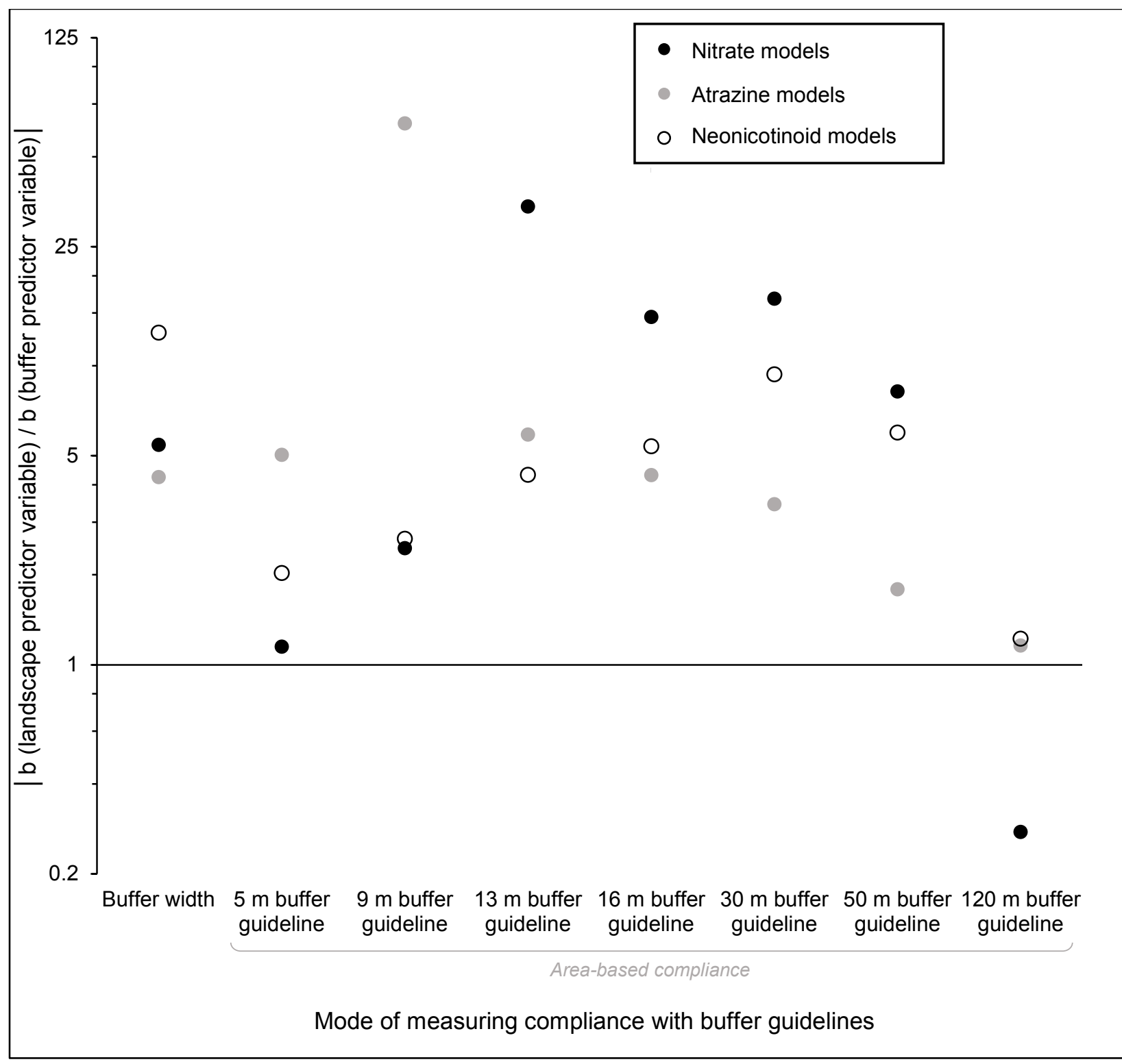

Figure 11. Absolute value of the ratio between partial standardized regression coefficients for landscape-scale undisturbed land cover and buffer guideline compliance, when water quality variables in study ponds were regressed on both predictor variables in additive models. Buffer guideline compliance was measured as buffer width or as area-based compliance with one of seven buffer guidelines (see Figure 4); perimeter-based compliance (not shown) was also highly correlated with values for both predictor variables (Appendix 3) and resulted in similar partial regression coefficients as area-based compliance. In each additive model, landscape-scale undisturbed land cover was measured as the proportional cover of undisturbed land between the edge of the buffer and the full extent of the landscape $(200 \mathrm{~m})$. 


\section{REFERENCES}

Arnold CL Jr. and Gibbons CJ. 1996. Impervious surface coverage: The emergence of a key environmental indicator. Journal of the American Planning Association 62: 243-58.

Barton K. 2016. MuMIn: Multi-Model Inference. Written for R package version 1.15.6.

Beketov MA, Kefford BJ, Schäfer RB, and Liess M. 2013. Pesticides reduce regional biodiversity of stream invertebrates. Proceedings of the National Academy of Sciences 110: $11039-43$.

Byer JD, Struger J, Sverko E, et al. 2011. Spatial and seasonal variations in atrazine and metolachlor surface water concentrations in Ontario (Canada) using ELISA. Chemosphere 82: 1155-60.

Camargo JA, Alonso A, and Salamanca A. 2005. Nitrate toxicity to aquatic animals: A review with new data for freshwater invertebrates. Chemosphere 58: 1255-67.

Carpenter SR, Caraco NF, Correll DL, et al. 1998. Nonpoint pollution of surface waters with phosphorus and nitrogen. Ecological Applications 8: 559-68.

Castelle AJ, Johnson A, and Conolly C. 1994. Wetland and stream buffer size requirements-A review. Journal of Environmental Quality 23: 878-82.

CCME. 2014. Canadian Water Quality Guidelines for the Protection of Aquatic Life. In:Canadian Environmental Quality Guidelines. eqg-rcqe.ccme.ca/en/index.html. Viewed Jul 2016.

Coukell G, Williamson E, Shulist R, et al. 2004. Best Management Practices: Buffer Strips (Alison Lane, Ed). Toronto, Canada: OMAFRA.

Crosbie B and Chow-Fraser P. 1999. Percentage land use in the watershed determines the water and sediment quality of 22 marshes in the Great Lakes basin. Canadian Journal of Fisheries and Aquatic Sciences 56: 1781-91.

Declerck S, De Bie T, Ercken D, et al. 2006. Ecological characteristics of small farmland ponds: associations with land use practices at multiple spatial scales. Biological Conservation 131: $523-32$.

Environment Canada. 2015a. Laboratory test services report BMK-NEO-15-06 for determination of the concentration of neonicotinoids in water samples from agricultural sites by ESI+LC-MS/MS. 
Environment Canada. 2015b. Laboratory test services report BMK-HERB-15-05 for analysis of atrazine in water samples from agricultural sites by ESI+ LC-MS/MS.

Environmental Law Institute. 2003. Conservation thresholds for land use planners. Washington, DC: Environmental Law Institute.

ESRI. 2014. ArcMap 10.3. Environmental Systems Research Institute: Redlands, CA.

ESRI. 2015. ArcMap 10.3.1. Environmental Systems Research Institute: Redlands, CA.

FAO. 1996. Fertilizers as water pollutants. In:Control of Water Pollution from Agriculture. Rome, Italy: FAO.

Google. 2015. Google Maps. www.google.ca/maps. Viewed Apr 2015.

Graymore M, Stagnitti F, and Allinson G. 2001. Impacts of atrazine in aquatic ecosystems. Environment International 26: 483-95.

Haas A. 2015. LSU The determination of ions ( $\mathrm{F}, \mathrm{Cl}, \mathrm{NO}_{2}, \mathrm{NO}_{3}$ and $\left.\mathrm{SO}_{4}\right)$ in water by ion chromatography. Ottawa, Canada: City of Ottawa Environmental Services Department.

Hecnar SJ. 1995. Acute and chronic toxicity of ammonium nitrate fertilizer to amphibians from southern Ontario. Environmental Toxicology and Chemistry 14: 2131-7.

Helmers MJ, Isenhart TM, Dosskey MG, et al. 2008. Buffers and vegetative filter strips. In:Final Report: Gulf Hypoxia and Local Water Quality Concerns Workshop. St Joseph, MI: American Society of Agricultural and Biological Engineers.

Houlahan JE and Findlay CS. 2004. Estimating the "critical" distance at which adjacent land-use degrades wetland water and sediment quality. Landscape Ecology 19: 677-90.

Hubbard RK, Newton GL, and Hill GM. 2004. Water quality and the grazing animal. Journal of Animal Science 82 (E-Supplement): E255-E263.

Huel D. 2000. Managing Saskatchewan wetlands: A landowner's guide. Regina, Canada: Saskatchewan Wetland Conservation Corporation.

Huffman T, Yang JY, Drury CF, et al. 2008. Estimation of Canadian manure and fertilizer nitrogen application rates at the crop and soil-landscape polygon level. Canadian Journal of Soil Science 88: 619-627.

King RS, Baker ME, Whigham DF, et al. 2005. Spatial considerations for linking watershed land cover to ecological indicators in streams. Ecological Applications 15: 137-53. 
Knutson MG, Sauer JR, Olsen DA, et al. 1999. Effects of landscape composition and wetland fragmentation on frog and toad abundance and species richness in Iowa and Wisconsin, USA. Conservation Biology 13: 1437-46.

Lapp P, Madramootoo CA, Enright P, et al. 1998. Water quality of an intensive agricultural watershed in Quebec. Journal of the American Water Resources Association 34: 427437.

Liess $\mathrm{M}$ and Der Ohe PC Von. 2005. Analyzing effects of pesticides on invertebrate communities in streams. Environmental Toxicology and Chemistry 24: 954-65.

Madison C, Blevins R, and Frye W. 1992. Effects of tillage and grass filter strips on surface runoff of water, nitrate, sediment, and atrazine. Soil Science News and Views 13: Paper 66.

Main AR, Headley JV, Peru KM, et al. 2014. Widespread use and frequent detection of neonicotinoid insecticides in wetlands of Canada's Prairie Pothole Region. PLoS ONE 9: e92821.

Mayer PM, Reynolds SK, McCutchen MD, and Canfield TJ. 2007. Meta-analysis of nitrogen removal in riparian buffers. Journal of Environmental Quality 36: 1172-80.

McElfish JM, Kihslinger RL, and Nichols SS. 2008. Planner's Guide to Wetland Buffers for Local Governments. Washington, DC: Environmental Law Institute.

McGee B, Berges H, and Beaton D. 2010. Economics Information-Survey of Pesticide Use in Ontario, 2008 Estimates of Pesticides Used on Field Crops, Fruit and Vegetable Crops, and Other Agricultural Crops. www.omafra.gov.on.ca/english/crops/facts/pesticideuse.htm. Viewed August 2016.

McMurry ST, Belden JB, Smith LM, et al. 2016. Land use effects on pesticides in sediments of prairie pothole wetlands in North and South Dakota. Science of the Total Environment 565: $682-9$.

Merwin IA, Ray JA, Steenhuis TS, and Boll J. 1996. Groundcover management systems influence fungicide and nitrate-N concentrations in leachate and runoff from a New York apple orchard. Journal of the American Society for Horticultural Science 121: 249-57.

Morrissey CA, Mineau P, Devries JH, et al. 2015. Neonicotinoid contamination of global surface waters and associated risk to aquatic invertebrates: A review. Environment International 74: 291-303.

Murray J, Andersen D, Kent R, et al. 2011. Presence and levels of priority pesticides in selected Canadian aquatic ecosystems. Gatineau, Canada: Environment Canada. 
Muscutt A, Harris G, Bailey S, and Davies D. 1993. Buffer zones to improve water quality: a review of their potential use in UK agriculture. Agriculture, Ecosystems \& Environment 45: 59-77.

Niagara Planning and Development Services Department. 2015. Natural environment. In:Niagara Regional Official Plan. Niagara, Canada: Regional Municipality of Niagara.

OMAFRA. 2010. Agricultural Resource Inventory (ARI). geo1.scholarsportal.info.proxy.library.carleton.ca. Viewed Nov 2014.

OMNR. 2002. Southern Ontario Land Resource Information System (SOLRIS). geo1.scholarsportal.info.proxy.library.carleton.ca. Viewed Oct 2014.

OMNR. 2009. Digital Raster Acquisition Project Eastern Ontario (DRAPE). geo1.scholarsportal.info.proxy.library.carleton.ca. Viewed Mar 2015.

OMNR. 2010. Ontario Hydro Network (OHN) - Waterbody. geo1.scholarsportal.info.proxy.library.carleton.ca. Viewed Oct 2014.

OMNR. 2011. Wetland Unit. /geo1.scholarsportal.info.proxy.library.carleton.ca. Viewed Oct 2014.

OMNR. 2012. Ontario Hydro Network (OHN) - Small Scale Watercourse. geo1.scholarsportal.info.proxy.library.carleton.ca. Viewed Oct 2014.

OMNR. 2014. National Road Network Ontario (ON). www.geobase.ca. Viewed Oct 2014.

Ontario Farm Environmental Coalition. 2004. Canada-Ontario Environmental Farm Plan Workbook (Smith, H J and Myslik, Jim and Stone, Bob and MacMillan, Cindy Bradley and Armitage, David and Fitzgibbon, John and Graham, Andrew, Ed). Toronto, Canada: Ontario Federation of Agriculture.

R Core Team. 2016. R: A Language and Environment for Statistical Computing. Vienna, Austria.

Rasmussen JJ, Baattrup-Pedersen A, Wiberg-Larsen P, et al. 2011. Buffer strip width and agricultural pesticide contamination in Danish lowland streams: Implications for stream and riparian management. Ecological Engineering 37: 1990-7.

Schaafsma A, Limay-Rios V, Baute T, et al. 2015. Neonicotinoid insecticide residues in surface water and soil associated with commercial maize (corn) fields in southwestern Ontario. PloS ONE 10: e0118139-e 0118159 
Schäfer RB, Brink PJ van den, and Liess M. 2011. Impacts of pesticides on freshwater ecosystems. In: Sánchez-Bayo, Francisco and van den Brink, Paul J. and Mann, Reinier M. (Ed). Ecological Impacts of Toxic Chemicals. Bussum, NL: Bentham.

Schmitt T, Dosskey M, and Hoagland K. 1999. Filter strip performance and processes for different vegetation, widths, and contaminants. Journal of Environmental Quality 28: 1479-89.

Sliva L and Williams DD. 2001. Buffer zone versus whole catchment approaches to studying land use impact on river water quality. Water Research 35: 3462-72.

Vought LB-M, Pinay G, Fuglsang A, and Ruffinoni C. 1995. Structure and function of buffer strips from a water quality perspective in agricultural landscapes. Landscape and Urban Planning 31: 323-31.

Wenger S. 1999. A review of the scientific literature on riparian buffer width, extent and vegetation. Athens, GA: Office of Public Service and Outreach, Institute of Ecology, University of Georgia.

Zhou W, Troy A, and Grove M. 2008. Modeling residential lawn fertilization practices: Integrating high resolution remote sensing with socioeconomic data. Environmental Management 41: 742-52. 


\section{Appendix 1: City of Ottawa protocols for nitrate analysis}

Water samples were analyzed for nitrate $\left(\mathrm{NO}_{3}^{-}\right)$using ion chromatography with chemical suppression of eluent conductivity. In this analytical process, each water sample is injected into a stream of liquid solvent (eluent) and run through an ion exchange column. Anions in the water sample (in this case, $\mathrm{NO}_{3}^{-}$) are separated on an ion exchange resin based on their affinity for a low-capacity, strongly basic anion exchanger. These anions are then passed through a chemical suppressor, with both suppresses eluent conductivity, and converts anions to highly conductive acidic forms (e.g. $\mathrm{NO}_{3}{ }^{-}$would become nitric acid, $\mathrm{HNO}_{3}$ ). The acidic forms of these anions are measured using a conductivity meter, and conductivity is examined on a chromatogram: peaks in conductivity indicate the presence of an anion, the retention time indicates the identity of the anion, and the magnitude of the peak relative to a baseline indicates the amount of anion present.

The City of Ottawa conducted ion chromatography using a Dionex ICS-1000 Ion Chromatography System (ICS-1000) interfaced with the Dionex ${ }^{\mathrm{TM}}$ Chromeleon $^{\mathrm{TM}}$ analytical software. Analyses followed the protocols in the City of Ottawa Environmental Services Department Document LSU-W000148, Version 1.0: The Determination of Ions (F, $\mathrm{Cl}_{1} \mathrm{NO}_{2}$, $\mathrm{NO}_{3}$, and $\mathrm{SO}_{4}$ ) in Water by Ion Chromatography (Haas 2015). Specific protocols were as follows.

\section{Sampling and storage}

Samples of at least $50 \mathrm{~mL}$ were collected in plastic bottles, and stored at $2-6^{\circ} \mathrm{C}$ until analysis. Analyses were performed within 5 days of sample collection. 


\section{Operating conditions}

The ICS-1000 pump flow rate was set to $2.00 \mathrm{~mL} / \mathrm{minute}$, and the suppressor was set at $27 \mathrm{~mA}$. The eluent used was a solution of $19.0769 \mathrm{mg} / \mathrm{L}$ sodium carbonate and $14.28335 \mathrm{mg} / \mathrm{L}$ sodium bicarbonate in deionized water, and it was de-gassed prior to use by letting it stand for at least 12 hours.

\section{Analytical process}

Samples were injected into the ICS-1000 using an AS-DV Autosampler, as follows. Five $\mathrm{mL}$ aquilots from samples were loaded into $5 \mathrm{~mL}$ Dionex polyvials, along with $25 \mu \mathrm{L}$ of a bromide tracer. Vials were capped and placed in the autosampler carousel. From the carousel, 25 $\mu \mathrm{L}$ of each sample was mechanically extracted and injected into the ICS-1000 for anion analysis. Nitrate peaks were identified in ICS-1000 output chromatograms based on retention time, and nitrate concentration was determined based on peak magnitude. The bromide tracer was used as a reference peak to ensure that $\mathrm{NO}_{3}{ }^{-}$peaks had been properly selected.

\section{Calibration and quality control}

A calibration curve was created for every set of samples. Four mixed calibration standards with $0.10,2.5,5.0,7.5$, and $10.0 \mathrm{mg} / \mathrm{L} \mathrm{NO}_{3}{ }^{-}$(Table A1-1) were included at the beginning of each sample set. The calibration curve was built by joining conductivity values point to point, and forcing the line through zero.

To determine calibration accuracy, two additional mixed quality control standards with 1.75 and $8.75 \mathrm{mg} / \mathrm{L} \mathrm{NO}_{3}{ }^{-}$(Table A1-2) were included at the beginning of each sample run. 
Analysts evaluated how closely the $\mathrm{NO}_{3}{ }^{-}$conductivity peaks of the quality control standards fell to those predicted by the calibration curve.

To further monitor precision and accuracy, an individual standard solution for nitrate $(2.50 \mathrm{mg} / \mathrm{L})$, and a deionized water blank were included at the beginning of each sample run. Furthermore, one of every 15 water samples was analyzed in duplicate, and one of every 30 water samples was analyzed in duplicate with the duplicated being spiked with additional calibration standard (undiluted mixed calibration standard (Table A1-1) added to the water sample in a 1:4 ratio). Lastly, to check for measurement drift, every twentieth sample was an extra aquilot of calibration standard C (Table A1-1).

\section{Sample dilutions}

When nitrate concentrations exceeded the calibration range, samples were diluted with deionized water to ensure that anion peaks were on-scale.

\section{Detection limits}

The lower detection limit for $\mathrm{NO}_{3}{ }^{-}$was $0.04 \mathrm{mg} / \mathrm{L}$. This value was the undiluted reported detection limit, or, the minimum concentration of an analyte which could still yield an accurate concentration measurement. This value is approximately five times larger than the method detection limit, which is defined as the concentration of an analyte where there is a $99 \%$ chance that it will be detected in a sample. 
Table A1-1. Anion concentrations (mg/L) in different dilutions of a mixed calibration standard. Modified from Haas (2015).

\begin{tabular}{cccccc}
\hline & \multicolumn{5}{c}{ Calibration standard (dilution factor) } \\
Anion & A $(1 / 100)$ & B (1/4) & C (1/2) & D (3/4) & E (Undiluted) \\
\hline Fluoride $\left(\mathrm{F}^{-}\right)$ & 0.05 & 1.25 & 2.5 & 3.75 & 5.0 \\
Chloride $\left(\mathrm{Cl}^{-}\right)$ & 0.2 & 5.0 & 10.0 & 15.0 & 20.0 \\
Nitrite $\left(\mathrm{NO}_{2}^{-}\right)$ & 0.04 & 1.0 & 2.0 & 3.0 & 4.0 \\
Nitrate $\left(\mathrm{NO}_{3}^{-}\right)$ & 0.10 & 2.5 & 5.0 & 7.5 & 10.0 \\
Sulfate $\left(\mathrm{SO}_{4}{ }^{-}\right)$ & 1.0 & 25.0 & 50.0 & 75.0 & 100 \\
\hline
\end{tabular}

Table A1-2. Anion concentrations (mg/L) in mixed quality control standards. Modified from Haas (2015).

\begin{tabular}{ccc}
\hline & & Quality control standard \\
Anion & A & B \\
\hline Fluoride $\left(\mathrm{F}^{-}\right)$ & 4.5 & 0.9 \\
Chloride $\left(\mathrm{Cl}^{-}\right)$ & 17.5 & 3.5 \\
Nitrite $\left(\mathrm{NO}_{2}^{-}\right)$ & 3.5 & 0.7 \\
Nitrate $\left(\mathrm{NO}_{3}^{-}\right)$ & 8.75 & 1.75 \\
Sulfate $\left(\mathrm{SO}_{4}^{2-}\right)$ & 87.5 & 17.5 \\
\hline
\end{tabular}




\section{Appendix 2: Environment Canada protocols for atrazine and neonicotinoid analyses}

Water samples were analyzed for atrazine and neonicotinoids using solid phase extraction followed by high performance liquid chromatography-mass spectrometry. In this analytical process, each water sample is spiked with immunosorbents and passed through a solid cartridge. Immunosorbents and attached analytes bind to the cartridge, from which they are then extracted. Dissolved analytes are injected into a high performance liquid chromatograph (HPLC), which is connected to a mass spectrometer (MS). In the HPLC, each sample is pumped at high pressures through a column filled with adsorbent material, in order to separate the analytes. In the MS, analytes are ionized and vapourized, then separated based on their mass-to-charge ratios. Each group of analyte ions creates a current that is converted into a voltage pulse. The identity of analytes in a sample is determined based on retention time in the HPLC and MS, and the amount of each analyte is determined based on the magnitude of the voltage pulse.

Environment Canada conducted solid phase extraction using an OASIS HLB cartridge, and high performance liquid chromatography-mass spectrometry using an Agilent 1200 HPLC system and an AB Sciex API 5000 Triple Quadropole Mass Spectrometer. Detailed protocol descriptions, including modified excerpts from Environment Canada's Laboratory Services Test Reports, BMK-HERB-15-03 and BMK-NEO-15-06, are below (Environment Canada 2015a, b).

\section{Sampling and storage}

Samples of 100 to $300 \mathrm{~mL}$ were collected in amber glass bottles, and stored at $4{ }^{\circ} \mathrm{C}$. Prior to analysis, samples were allowed to reach room temperature overnight, and were well mixed. The $\mathrm{pH}$ of the solution was determined, and adjusted to between 7 and 8 when necessary. 


\section{Analytical process for solid phase extraction}

A $100 \mathrm{~mL}$ aquilot was taken from each water sample bottle for analysis. Aquilots were spiked with a mixed immunosorbent solution (atrazine-d5, acetamiprid-d3, clothianidin-d3, imidacloprid-d4, and thiamethoxam-d3), stirred for a few minutes, and passed through an Oasis HLB cartridge, which had been sequentially pre-conditioned with $10 \mathrm{~mL}$ methanol and $10 \mathrm{~mL}$ water. The analytes and immunosorbents were extracted from the cartridge by washing it with 4 $\mathrm{mL}$ of methanol. A $200 \mu \mathrm{L}$ aquilot was taken from this eluent to be analyzed for atrazine. Because neonicotinoids can be difficult to extract in measurable quantities, the cartridge was then re-washed with $6 \mathrm{~mL}$ of methanol. The resultant eluent was combined with the remaining eluent from the first wash to make a $9.8 \mathrm{~mL}$ solution of neonicotinoids and their associated immunosorbents in methanol.

\section{Sample preparation for high-performance liquid chromatography}

Each $200 \mu \mathrm{L}$ aquilot of eluent for atrazine analysis was diluted $50 \%$ in water and mixed with ammonium acetate so that all samples contained 70\% HPLC grade methanol with $0.05 \%$ formic acid, and 30\% $10 \mathrm{mM}$ ammonium acetate with $0.05 \%$ formic acid. Samples were then filtered through a Millex ${ }^{\circledR}$ HV 4 mm syringe filter with a $0.45 \mu \mathrm{m}$ PVDF membrane, directly into a $2 \mathrm{~mL}$ autosampler vial containing a $500 \mu \mathrm{L}$ flat bottom glass insert.

Each $9.8 \mathrm{~mL}$ of eluent for neonicotinoid analysis was evaporated to dryness and the extract was re-dissolved in $500 \mu \mathrm{L}$ of HPLC grade acetonitrile solution (acetonitrile: water ratio of $20: 80$ ) with $0.1 \%$ formic acid. As with the atrazine sample, the re-dissolved neonicotinoid sample was filtered through a Millex ${ }^{\circledR}$ HV 4 mm syringe filter with a $0.45 \mu \mathrm{m}$ PVDF membrane, directly into a $2 \mathrm{~mL}$ autosampler vial containing a $500 \mu \mathrm{L}$ glass insert. 


\section{Operating conditions for HPLC and MS}

When atrazine was analyzed, the HPLC analytical column was an Atlantis ${ }^{\circledR} \mathrm{dC} 183 \mu \mathrm{m}$, $2.1 \times 50 \mathrm{~mm}$ at $35^{\circ} \mathrm{C}$. Flow rate in the HPLC was $600 \mu \mathrm{L} /$ minute. In the MS, the ion spray (TurboSpray in positive polarity) voltage was $4000 \mathrm{~V}$, the channel electron multiplier in the detector had a voltage of $2000 \mathrm{~V}$, the deflector in the detector had zero voltage, the declustering potential was $86 \mathrm{~V}$, the entrance potential was $10 \mathrm{~V}$, and the temperature was $650^{\circ} \mathrm{C}$. Flow rates for various gases in the MS were as follows: curtain gas $-35 \mathrm{~mL} / \mathrm{s}$, nebulizer gas $-60 \mathrm{~mL} / \mathrm{s}$, heater gas $-65 \mathrm{~mL} / \mathrm{s}$, and collision gas $-8 \mathrm{~mL} / \mathrm{s}$. The MS was in multiple reaction monitoring mode.

When neonicotinoids were analyzed, the HPLC analytical column was an X-Terra ${ }^{\circledR}$ MS C8 $3.5 \mu \mathrm{m}, 2.1 \times 100 \mathrm{~mm}$ at $40^{\circ} \mathrm{C}$. Flow rate in the HPLC was $500 \mu \mathrm{L} /$ minute. In the MS, the ion spray (TurboSpray in positive polarity) voltage was $3000 \mathrm{~V}$, the channel electron multiplier in the detector had a voltage of $2000 \mathrm{~V}$, the deflector in the detector had zero voltage, the entrance potential was $10 \mathrm{~V}$, and the temperature was $750^{\circ} \mathrm{C}$. Flow rates for various gases in the MS were as follows: curtain gas $-50 \mathrm{~mL} / \mathrm{s}$, nebulizer gas $-70 \mathrm{~mL} / \mathrm{s}$, heater gas $-40 \mathrm{~mL} / \mathrm{s}$, and collision gas $-7 \mathrm{~mL} / \mathrm{s}$. The MS was in multiple reaction monitoring mode.

\section{Analytical process for high-performance liquid chromatography and mass spectrometry}

Atrazine and neonicotinoid samples were injected at $20^{\circ} \mathrm{C}$ into the HPLC in $20 \mu \mathrm{L}$ aquilots. In the HPLC, each sample was passed through an adsorbent column to help separate the different components. In the MS, each sample was ionized and vapourized with the ion spray, and then passed through multiple quadrupoles (sets of four electrically charged metal rods). The first two quadrupoles helped to focus the ions; the third quadrupole filtered and sorted the ions 
based on their mass-charge ratios. In the fourth quadrupole, ions were collided with pure, inert nitrogen gas, and broken into fragments. These fragments were predictable, with atrazine and its associated immunosorbent each breaking up in one of two possible ways, and each neonicotinoid and its associated immunosorbent breaking up in only one way (Table A2-1). The fifth quadrupole further sorted the ion products from these reactions based on mass-charge ratios, and then ions were drawn into the detector where they created a current that was converted into a voltage pulse.

The MS reported voltage pulses in a mass spectrum, so analysts could identify atrazine or neonicotinoid ion products based on retention time, and the amount of atrazine, acetamiprid, clothianidin, imidacloprid, or thiamethoxam present in the original sample based on pulse magnitude (peak area). Because atrazine and its associated immunosorbent could follow one of two reaction pathways, analysts used the more frequently-occurring reaction product corrected for the less frequent reaction product (Table A2-1) to calculate atrazine concentration.

\section{Calibration and quality control}

A calibration curve was created every day before samples were injected into the HPLC. Calibration curves for atrazine were built using seven calibration standards ranging from 0.005 to $1.0 \mathrm{ppb}$ atrazine. Calibration curves for neonicotinoids were built using calibration standards ranging from 0.1 to $20 \mathrm{ppb}$ for each neonicotinoid pesticide. In each case, calibration data points were summarized with a regression line of $\mathrm{r}^{2}>0.995$.

To monitor injection cross-contamination, two to three blanks (water:methanol 50:50 for atrazine, or water:acetonitrile 80:20 for neonicotinoids) were injected before and after the calibration standards, and at the beginning and end of each set of samples. 
To monitor contamination from the rest of the laboratory process, a sample blank (100 $\mathrm{mL}$ of water spiked with the immunosorbent for atrazine, or the four immunosorbents for neonicotinoids) was included every 10 samples.

To monitor precision and accuracy, one of every 10 samples was extracted through solid phase extraction in duplicate, and one random extract per set was also injected in duplicate. Furthermore, aliquots of various levels of calibration standards were injected between each set of samples, and percent differences between experimental and expected values were calculated. Lastly, an aquilot of known atrazine or neonicotinoid concentration (1.0 ppb for atrazine, and 0.1 ppb for acetamiprid, clothianidin, imidacloprid, and thiamethoxam) was analyzed along with samples each day to check for day-to-day variation.

\section{Sample dilutions}

When atrazine or thiamethoxam concentrations exceeded the calibration range, water samples were diluted to $10 \%$ to ensure that peaks were on-scale. Acetamiprid, clothianidin, and imidacloprid concentrations never exceeded the calibration range.

\section{Detection limits}

The lower detection limits for atrazine, acetamiprid, clothianidin, imidacloprid, and thiamethoxam were $0.0004,0.0001,0.00025,0.00025$, and $0.00020 \mathrm{ppb}$, respectively. These are the concentrations at which the pesticides could be detected with a signal:noise ratio of at least 3:1 for a $20 \mu \mathrm{L}$ injection. 
Table A2-3. Molecular mass of ions for five pesticides and their associated immunosorbents before and after collision with an inert gas. Modified from Environment Canada Laboratory Test Services Reports BMK-HERB-15-03 and BMK-NEO-15-06.

\begin{tabular}{cccc}
\hline Compound & Precursor ion (Da) & Product ion (Da) & $\begin{array}{c}\text { Relative probability of } \\
\text { reaction pathway (\%) }\end{array}$ \\
\hline Atrazine & 215 & 174 & 75 \\
Atrazine-d5 & 220 & 104 & 25 \\
Acetamiprid & 222.4 & 179 & 75 \\
Acetamiprid-d3 & 225.4 & 101 & 25 \\
Clothianidin & 249.5 & 126.0 & 100 \\
Clothianidin-d3 & 252.5 & 126.0 & 100 \\
Imidacloprid & 255.6 & 169.0 & 100 \\
Imidacloprid-d4 & 259.6 & 172.0 & 100 \\
Thiamethoxam & 291.7 & 209.1 & 100 \\
Thiamethoxam-d3 & 294.7 & 213.1 & 100 \\
\hline
\end{tabular}


Appendix 3: Correlations between predictor variables and potentially confounding variables

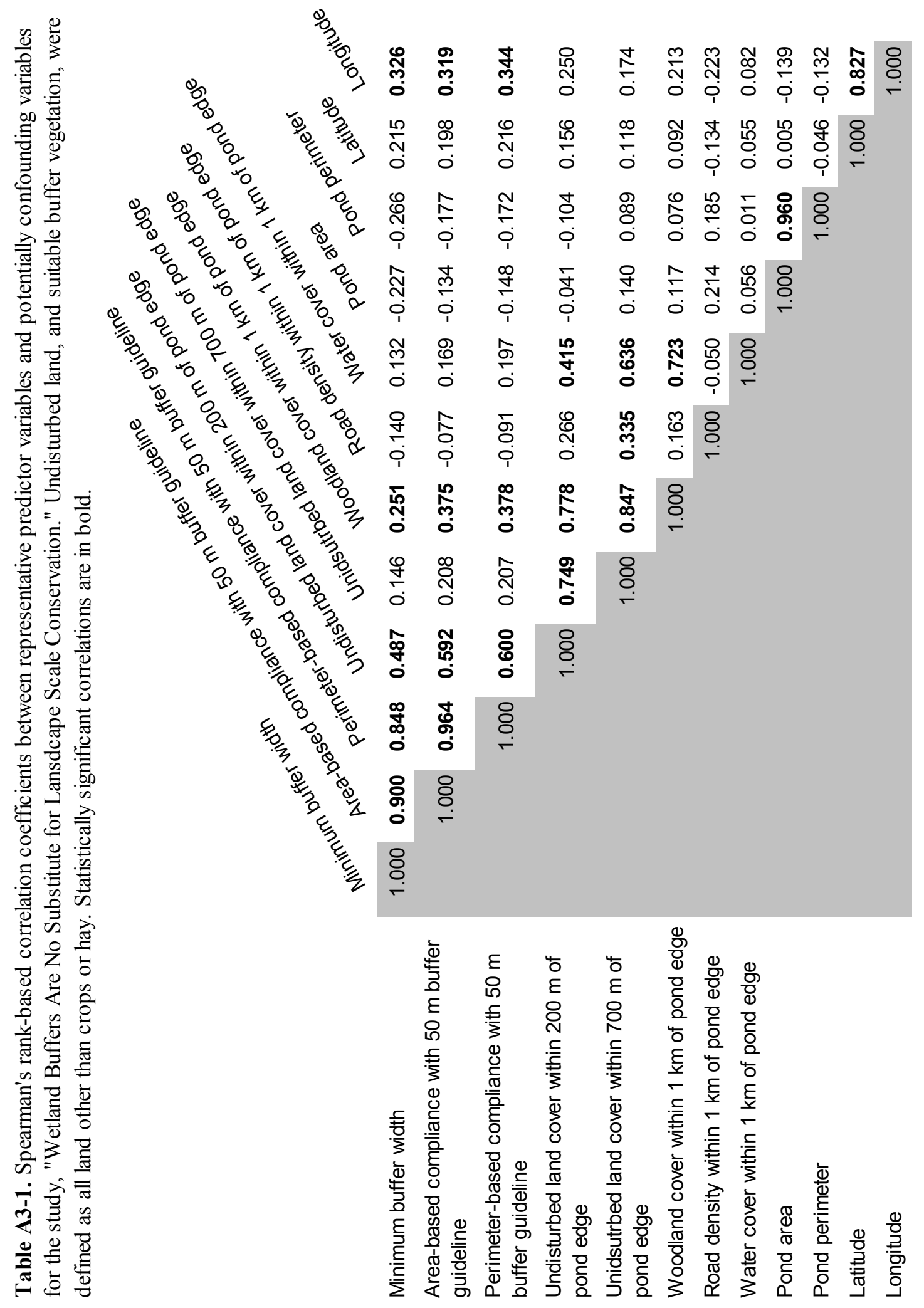


Appendix 4: Model fits for water quality variables regressed on various measures of buffer guideline compliance

\begin{tabular}{|c|c|c|c|c|}
\hline$g=\stackrel{\overrightarrow{0}}{g}$ & 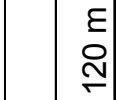 & $\stackrel{\infty}{\grave{i}}$ & $\stackrel{\text { L }}{i}$ & $\stackrel{+}{T}$ \\
\hline 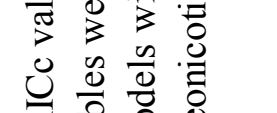 & \begin{tabular}{|l|l|} 
& $\varepsilon$ \\
0 & 0 \\
0
\end{tabular} & $\stackrel{m}{0}$ & $\stackrel{m}{i}$ & ì \\
\hline 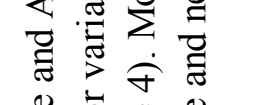 & \begin{tabular}{|c|c}
$\frac{\bar{w}}{\overline{\bar{a}}}$ & $\varepsilon$ \\
$\bar{c}$ & 0 \\
\end{tabular} & $\stackrel{\circ}{\Gamma}$ & $\stackrel{\infty}{\infty}$ & $\stackrel{0}{0}$ \\
\hline 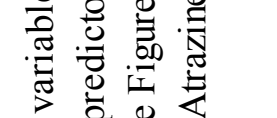 & \begin{tabular}{|l|l|} 
& $\varepsilon$ \\
0 & $\varepsilon$ \\
0 & 0 \\
0 & 0 \\
0 & -
\end{tabular} & $\stackrel{N}{N}$ & $\stackrel{\circ}{\circ}$ & $\stackrel{\circ}{\circ}$ \\
\hline & 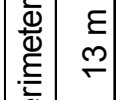 & $\stackrel{N}{N}$ & 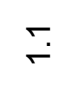 & $\stackrel{\circ}{\Gamma}$ \\
\hline 党. & है & $\stackrel{?}{\longrightarrow}$ & $\stackrel{\circ}{\leftarrow}$ & กั \\
\hline & $\begin{array}{c}E \\
\omega\end{array}$ & $\stackrel{\circ}{\dot{P}}$ & $\stackrel{+}{\mathrm{N}}$ & $\begin{array}{l}\infty \\
0 \\
i\end{array}$ \\
\hline & 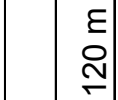 & $\stackrel{\leftrightarrow}{i}$ & $\stackrel{m}{i}$ & $\stackrel{+}{+}$ \\
\hline & $\begin{array}{l}\varepsilon \\
0 \\
b\end{array}$ & $\stackrel{9}{0}$ & íj & $\begin{array}{l}0 \\
\stackrel{0}{0}\end{array}$ \\
\hline & 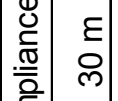 & $\stackrel{r}{r}$ & $\stackrel{\infty}{0}$ & $\stackrel{\circ}{\circ}$ \\
\hline & 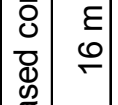 & $\stackrel{\rho}{\Gamma}$ & $\stackrel{m}{r}$ & $\overline{0}$ \\
\hline & 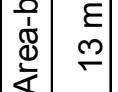 & $\stackrel{\infty}{-}$ & $\stackrel{\leftrightarrow}{\stackrel{0}{r}}$ & $\stackrel{\circ}{\circ}$ \\
\hline & हీ & $\stackrel{\text { ? }}{\longrightarrow}$ & $\stackrel{N}{N}$ & $\begin{array}{l}0 \\
i \\
i\end{array}$ \\
\hline & $\begin{array}{c}E \\
D\end{array}$ & $\stackrel{\infty}{\longrightarrow}$ & $\stackrel{\grave{N}}{\mathrm{~J}}$ & : \\
\hline$\stackrel{\overrightarrow{0}}{0}$ & 离 & $\stackrel{\circ}{r}$ & $\stackrel{\digamma}{\digamma}$ & $\stackrel{m}{r}$ \\
\hline 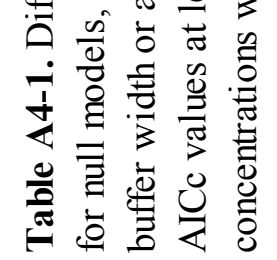 & 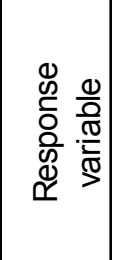 & 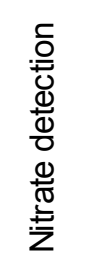 & 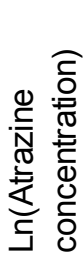 & 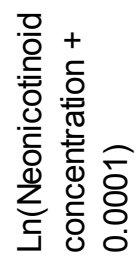 \\
\hline
\end{tabular}




\title{
Do Wetland Buffers Work for Frogs and Toads?
}

\begin{abstract}
Wetlands in agricultural areas can be important havens for pond-breeding anurans (frogs and toads), but many of these species also require terrestrial habitat. Governments often encourage farmers to implement permanently vegetated buffers around wetland perimeters to provide this habitat, but whether this habitat is sufficient has not yet been empirically determined. We examined the effects of wetland buffer size and vegetation type on anuran species richness, as well as on the abundance and occurrence of six anuran species. We also compared the effects of wetland buffers with the effects of landscape composition within 500 to $2000 \mathrm{~m}$ of study ponds. We found that species richness was increased by $30 \mathrm{~m}$ wide buffers vegetated with grass and scattered trees, but this was probably due to cumulative small effects of buffers on species: individual anuran species were usually more strongly affected by landscape composition than by wetland buffers. Our results suggest that terrestrial habitat contained within wetland buffers is not sufficient to protect anurans in agricultural wetlands. To effectively protect anurans, we should employ wetland buffers, but should also conserve woodland cover and limit road density in the broader landscapes surrounding these wetlands.
\end{abstract}

Key words: terrestrial habitat, buffer, landscape composition, local vs. landscape effects, agriculture, wetland, pond, amphibian diversity, Pseudacris crucifer, Pseudacris triseriata, Lithobates sylvaticus, Lithobates pipiens, Anaxyrus americanus, Hyla versicolor, Hyla chrysoscelis, Lithobates septentrionalis, Lithobates clamitans, Lithobates catesbeianus 


\section{INTRODUCTION}

Habitat loss is a well-established cause of anuran (frog and toad) declines, with agricultural land conversion being of particular concern (Cushman 2006; Scoccianti 2009). In Europe and North America, over 50\% of ponds, small lakes, and inland and coastal marshes were converted to intensive agricultural land between 1900 and 1985, essentially halving the breeding habitat available to these amphibians (Millennium Ecosystem Assessment 2005). Conversion of natural terrestrial land cover, such as woodland, to agriculture is also problematic because many juvenile and adult anurans require terrestrial habitat for foraging, overwintering, or dispersal (Semlitsch and Bodie 2003; Lannoo 2005; Cushman 2006).

In agricultural regions with high rates of wetland loss, small wetlands such as farmland ponds can provide crucial breeding habitat for semi-aquatic species (Knutson et al. 2004; Ruggiero et al. 2008); however, anurans can only persist in these wetlands if there is also sufficient terrestrial habitat. For example, multiple studies have shown that anuran richness and occurrence rates of specific species in wetlands increases with the proportion of woodland in the surrounding area (Hecnar and M'Closkey 1998; Mensing et al. 1998; Knutson et al. 1999; Findlay et al. 2001; Houlahan and Findlay 2003; Herrmann et al. 2005; Rubbo and Kiesecker 2005; Brazner et al. 2007).

One way to provide terrestrial habitat for semi-aquatic anurans is to retain or implement permanently vegetated buffer zones along the edge of breeding wetlands. Wetland buffers have been empirically shown to improve water quality in some aquatic systems, and are believed to provide wildlife habitat (Castelle et al. 1994; Wenger 1999). The Ontario Ministry of Agriculture 
and Food, for example, states that $15 \mathrm{~m}$ wide buffers of grass, trees, and shrubs around isolated wetlands provide terrestrial habitat for amphibians (Coukell et al. 2004).

However, many ecologists have expressed the concern that wetland buffers cannot provide enough terrestrial habitat for anurans. Most recommended buffer widths in North America are $30 \mathrm{~m}$ or less, with the maximum government-recommended buffer width for terrestrial habitat being 120-300 m (Coukell et al. 2004; Ontario Farm Environmental Coalition 2004). In contrast, mark-recapture, radiotelemetry, and genetic studies suggest that anurans frequently move and forage within $300 \mathrm{~m}$ of breeding wetlands, and can travel up to several kilometres during dispersal events (Semlitsch and Bodie 2003; Baldwin et al. 2006; Forester et al. 2006; Semlitsch 2008). Many landscape ecology studies have also shown that anurans can be affected by landscape composition variables such as woodland cover, wetland cover, and road density within 500-3000 m of breeding wetlands - much larger scales than governmentrecommended buffer sizes (Hecnar and M'Closkey 1998; Mensing et al. 1998; Knutson et al. 1999; Pope et al. 2000; Findlay et al. 2001; Guerry and Hunter 2002; Houlahan and Findlay 2003; Rubbo and Kiesecker 2005; Herrmann et al. 2005; Brazner et al. 2007; Hartel et al. 2010; Jeliazkov et al. 2014).

Thus, although many studies have shown that landscape composition can affect anuran diversity, the effects of wetland buffers on anuran diversity remain relatively unexplored (Powell and Babbitt 2015). In particular, to the best of our knowledge, no studies to date have empirically assessed the effects of compliance with buffer size guidelines or buffer vegetation type on anuran diversity or abundance in agricultural environments. The usefulness of buffers relative to landscape-scale management strategies is also unknown.

We use a focal patch study to address the following questions: 
(1) Can wetland buffers increase anuran species richness and abundance in agricultural wetlands? If so, how should buffers be vegetated, and how large should they be?

(2) How strong are wetland buffer effects on anuran species richness and abundance in agricultural wetlands, relative to the effects of landscape composition (woodland cover, road density, and water cover)?

\section{METHODS}

\subsection{Study sites}

Study region

All research was conducted in the eastern Ontario, Canada portion of the Mixedwood Plains Ecozone, to the east and south of the Canadian Shield (Figure 1). Approximately 50\% of the study region has been converted to agriculture, $20 \%$ is mixed coniferous and deciduous woodland, $10 \%$ is wetland, $10 \%$ is a combination of woodland and wetland, and $4 \%$ is built up; the remaining $6 \%$ consists of a variety of land cover types such as quarries and abandoned farmland.

\section{Site selection}

We selected study wetlands to maximize variation in buffer guideline compliance and landscape-scale woodland cover (a landscape composition variable), while minimizing correlation between these variables. We focused on woodland cover as a measure of landscape composition at the site selection stage because woodland — like wetland buffers — can be used as 
terrestrial habitat, and multiple previous studies have shown anuran species richness to respond positively to landscape-scale woodland cover (Hecnar and M'Closkey 1998; Mensing et al. 1998; Knutson et al. 1999; Findlay et al. 2001; Houlahan and Findlay 2003; Herrmann et al. 2005; Rubbo and Kiesecker 2005; Brazner et al. 2007). During site selection, buffer guideline compliance was estimated as treed area contiguous with wetland edges because woodland was the easiest type of anuran habitat to distinguish from aerial photographs. However, we later updated these measurements with field-based estimates (Sections 2.3 and 2.4). Likewise, during site selection, landscape-scale woodland cover was measured within a $1 \mathrm{~km}$ radius, but the appropriate landscape scale was later determined using multi-scale analyses (Section 2.5). During site selection, we also aimed to avoid spatial autocorrelation and control for wetland size and type. Of the almost 100,000 wetlands in our study region, we selected a set of 61 potential study wetlands.

After asking private landowners for permission to access the 61 potential study wetlands, we secured a final set of 36 study sites (Figure 1), with contiguous treed buffers ranging from 0 to 16 ha and landscape-scale woodland cover ranging from 1 to $50 \%$ of the landscape within 1 $\mathrm{km}$ of wetlands. Study wetlands were at least $2 \mathrm{~km}$ apart, and those with similar combinations of buffer size and landscape-scale woodland cover were spread as evenly as possible across the study region to avoid confounding buffer or landscape effects with any regional gradients in anuran occurrence and richness. All study wetlands were ponds - primarily open water, with some emergent vegetation around the edge—less than $0.5 \mathrm{ha}$, with perimeters less than $450 \mathrm{~m}$. Study ponds were either natural or naturalized (not used for agriculture for at least 5 years, and not used for quarrying for at least 20 years), were not adjacent to pasture, and were at least 150 $\mathrm{m}$ from major watercourses and $40 \mathrm{~m}$ from the nearest road. Ponds also had at least $25 \%$ 
agricultural cover, up to $10 \%$ built-up cover, up to $2.5 \mathrm{~km}$ roads $/ \mathrm{km}^{2}$, and up to $40 \%$ water cover, within a $1 \mathrm{~km}$ landscape radius.

\section{Data sources}

Most of the wetland, buffer, and landscape information used during site selection was collected from government maps and aerial photographs. Potential study wetlands were located using the Wetland Unit dataset (OMNR 2011), the Ontario Hydro Network Waterbody dataset (OMNR 2010), and aerial photographs from the Digital Raster Acquisition Project Eastern Ontario (OMNR 2009) and Google Maps (Google 2015). Buffer size was estimated using the same aerial photographs as above. Information about surrounding landscapes was gathered from the same government datasets as above, as well as the Wooded Area dataset (OMNR 2013), the Ontario Hydro Network Small Scale Watercourse dataset (OMNR 2012), the Agricultural Resource Inventory (OMAFRA 2010), the Southern Ontario Land Resource Information System (OMNR 2002), and the National Road Network Ontario dataset (OMNR 2014). Information about pond history and current usage was determined by speaking with landowners and through personal observation in the field.

All calculations of wetland size, landscape-scale variables, and buffer size were conducted in ArcMap 10.3 or ArcMap 10.3.1 (ESRI 2014, 2015).

\subsection{Anuran surveys}

We conducted four sets of anuran breeding call surveys between April 14 and July 30, 2015. Within each sampling period, we generally sampled more southerly ponds and then more 
northerly ponds, because we expected that anurans would breed slightly earlier at lower latitudes. Surveys at each pond were spaced approximately 3.5 weeks apart (minimum 2 weeks). On each sampling date, we conducted anuran call surveys at 1-6 ponds, but we varied the combinations of ponds, as well as the time of day that each pond was surveyed, between sampling periods to avoid spurious correlations. All surveys were conducted at least 30 minutes after sunset, and before 01:30 the following morning. We only visited ponds when temperatures were above freezing in the first two sampling periods, above $5^{\circ} \mathrm{C}$ in the third sampling period, and above $16^{\circ} \mathrm{C}$ in the fourth sampling period because calling frequencies may be affected by temperature, and later-breeding species require progressively warmer temperatures (Oseen and Wassersug 2002; Lannoo 2005). We avoided windy or rainy conditions as far as possible, because both wind and rain can affect calling frequency, as well as an observer's ability to hear anurans (Oseen and Wassersug 2002; Dorcas et al. 2009). We never conducted surveys in winds of $>4$ on the Beaufort scale, and although 5 of 144 surveys took place in light to moderate rain, we never sampled a given pond in the rain more than once.

Each anuran breeding call survey lasted for 12 minutes. We waited 2 minutes to allow anurans to adjust to our presence, and spent 10 minutes listening for breeding calls. We identified anuran species based on calls, and counted the number of calling individuals for each species. In 128 of 144 surveys, two observers independently estimated the species numbers. When two observers were present, our abundance estimates were always similar-within 4 individuals for each species - and we came to a consensus before leaving a site. When, on three occasions, we estimated that at least 30 individuals of a given species were present at a site, we recorded the abundance as 30 because we could not confidently count specific individuals beyond this point. 
At the end of the field season we calculated species richness for each pond, and we estimated relative abundance for each species at a given pond as the total number of individuals of that species heard calling throughout the breeding season. We estimated relative abundance in this way to reduce the influence of nights with exceptionally low or exceptionally high calling frequencies.

We finalized our anuran response variables as follows. Species richness data were used without further modification. Relative abundance data were used without further modification for species occurring in more than $75 \%$ of ponds. Relative abundance data were converted into occurrence data ( 0 if never detected, 1 if detected at least once) for species heard calling at 25 to $75 \%$ of ponds. Other anuran species observed were not present at enough ponds to be analyzed individually.

\subsection{Land cover}

To later measure buffer size and vegetation, we examined cover types around each study pond in detail in August 2015. Based on aerial photographs and manual examination in the field, we identified all land cover within $300 \mathrm{~m}$ of study pond edges as woodland (continuous canopy), scrub (grassland with scattered trees or shrubs), lawn, orchard, pasture, hay, annual row crops (corn, soy, grains, or commercial vegetables), or non-vegetated land (roads, quarries, or sand pits). We did not attempt to identify other wetlands within this area because it was impossible to locate all of them in the field, and we accounted for wetland cover elsewhere in our analyses (Section 2.6). 
For landscape composition estimates, we relied on land cover data from remote sensing. We measured woodland cover, road density, and water cover within 500, 1000, 1500, and 2000 $\mathrm{m}$ from the edge of each pond using the same datasets as for site selection (Section 2.1).

\subsection{Wetland buffers}

We measured compliance with wetland buffer size guidelines in two ways. First, we measured buffer width: the minimum width of suitable buffer vegetation contiguous with the study pond (Cecily Flemming, OMECC, pers. comm.). We then considered that, when buffers are inconsistent in width, anurans may benefit from terrestrial habitat in portions of buffers farther from the pond than the minimum buffer width. Therefore, we additionally measured the degree to which buffers complied with a variety of Ontario buffer width guidelines for wildlife habitat: 5, 16, 30, 50, 120, and 300 m (Coukell et al. 2004; Ontario Farm Environmental Coalition 2004). Specifically, we measured area-based compliance: the proportion of the area circumscribed by a recommended buffer width that contained suitable buffer vegetation contiguous with the pond (Figure 2).

When measuring buffer width and area-based compliance, we considered seven possible types of suitable buffer vegetation. First, we considered permanent vegetation (woodland, scrub, lawn, orchard, pasture, or hay) as per Ontario guidelines (Coukell et al. 2004). We also considered specific types of vegetation based on anuran habitat needs. Because some anurans avoid lands that are frequently disturbed by humans or livestock (Gibbs 1998; DeMaynadier and Hunter 1999; Rothermel and Semlitsch 2002; Regosin et al. 2005), we measured buffers of natural (non-anthropogenic) vegetation (woodland or scrub). Because some anuran species prefer 
woodland as terrestrial habitat while others prefer grassland (Lannoo 2005), we measured buffers of woodland and of grassland (scrub, lawn, orchard, pasture, or hay). We considered scrub, lawn, and orchard and pasture to be grassland because although they often contained trees, they never had a closed canopy. Since anurans might prefer natural vegetation as well as grassland, we also measured buffers of "natural grassland" (scrub). We then considered that hay is frequently rotated with annual row crops such as corn and soy in our study region, and thus might not represent truly permanent vegetation. Therefore, we examined two additional types of buffer vegetation: (i) permanent vegetation excluding hay (woodland, scrub, lawn, orchard, or pasture), and (ii) grassland excluding hay (scrub, lawn, orchard, or pasture).

\subsection{Analyses}

To evaluate the effects of wetland buffer size and vegetation type on anurans (Question 1), we conducted bivariate regressions of anuran response variables on buffer width and areabased compliance with one of six buffer width guidelines $(5,16,30,50,120$, or $300 \mathrm{~m})$, and repeated these analyses for each of the seven buffer vegetation types (permanent vegetation including hay, permanent vegetation excluding hay, natural vegetation, woodland, grassland including hay, grassland excluding hay, and natural grassland). We used linear regression analyses to examine buffer effects on anuran species richness, spring peeper abundance, and green frog abundance, and logistic regression to examine buffer effects on wood frog, leopard frog, American toad, and gray treefrog occurrence. We determined the best buffer size and vegetation type for each anuran response variable by selecting the best-fitting (lowest AICc) regression model in which the buffer predictor variable had a positive regression coefficient. We 
did not consider regression models in which buffer predictor variables had negative coefficients, because buffers that negatively affect anurans would be counter-productive for anuran conservation.

We determined the effects of landscape composition on anuran response variables (preliminary work for Question 2) using multi-model inference. The full regression model for each response variable had three predictor variables: woodland cover, road density, and water cover. We used linear multiple regression to determine the effects of landscape composition on anuran richness, spring peeper abundance, and green frog abundance, and logistic multiple regression to determine the effects of landscape composition on wood frog, leopard frog, American toad, and gray treefrog occurrence. We repeated these analyses for each of the four landscape scales considered (500, 1000, 1500, and $2000 \mathrm{~m})$.

We then determined the relative strength of buffer and landscape effects on anuran response variables (Question 2) by comparing the AICc values for the best buffer model and the best landscape model. As above, the best buffer model in this context was considered to be the best-fitting model with a positive regression coefficient. The best landscape model was considered to be the best-fitting model regardless of the number of predictors or direction of effect. We did not require landscape composition variables to specifically have a positive effect because, unlike for buffers, we were not examining the effectiveness of a particular conservation strategy.

All statistical tests were performed in R, Version 3.2.4 (R Core Team 2016). We conducted most analyses using standard R functions, but calculated AICc values and conducted multi-model inference using the package, MuMIn (Barton 2016). 


\section{Data transformations}

To meet the assumptions of parametric tests, spring peeper abundances were logtransformed, and green frog abundances were square root-transformed, for all of the above analyses. Buffer widths were log-transformed for all linear regression analyses, although not for logistic regression analyses, because logistic regression is not a parametric test. We did not regress species richness, spring peeper abundance, or green frog abundance on area-based compliance with $5 \mathrm{~m}$ buffer guidelines when buffer vegetation was permanent vegetation (including or excluding hay) or natural vegetation, because so many of these area-based compliance values were $100 \%$.

\section{RESULTS}

\subsection{Anuran surveys}

Anuran species richness in each pond ranged from 1 to 6 species, with a total of 10 species observed across the study region. We observed two species in over $75 \%$ of study ponds: spring peeper (Pseudacris crucifer; 29 ponds) and green frog (L. clamitans; 33 ponds). We observed four species in 25-75\% of study ponds: wood frog (Lithobates sylvaticus; 12 ponds), leopard frog (L. pipiens; 22 ponds), American toad (Anaxyrus americanus; 11 ponds), and eastern gray treefrog (Hyla versicolor; 23 ponds). We also observed western chorus frogs (P. triseriata) in two ponds, Cope's gray treefrogs (H. chrysoscelis) in one pond, bullfrogs (L. catesbeianus) in three ponds, and mink frogs (L. septentrionalis) in one pond. 


\subsection{Wetland buffers and landscape composition}

Buffers ranged from 0 to $235 \mathrm{~m}$ in width, depending on the wetland and the buffer vegetation type. Area-based compliance with buffer guidelines ranged from $0-100 \%$. Depending on the wetland and the scale of landscape measurement, woodland cover in the landscape ranged from $0-52 \%$, road density from $0-3.3 \mathrm{~km} / \mathrm{km}^{2}$, and water cover from $0-39 \%$. Correlations between buffer variables and landscape composition variables were all low ( $\mid$ Spearman's $\rho \mid<$ 0.4), although some measures of buffer compliance were correlated with each other depending on the vegetation type considered, and landscape-scale woodland and water cover were correlated with each other (Appendix 1).

\subsection{Evaluation of study questions}

\section{Buffer effects on anurans (Question 1)}

All significant positive effects of buffers on anuran response variables were for one of the three types of grassland buffer (Table 1). When buffer vegetation was grassland excluding hay, anuran species richness and green frog abundance increased with area-based buffer guideline compliance, particularly at spatial scales of 30 and $5 \mathrm{~m}$, respectively (Figure 3). Green frog abundance additionally increased, though less strongly, with area-based compliance when buffer vegetation was grassland including hay, or natural grassland (Figure 3). However, when buffer vegetation was woodland, anuran species richness and green frog abundance decreased with buffer width and area-based compliance (Figure 4). When buffer vegetation was permanent vegetation including hay, anuran species richness, wood frog occurrence, and American toad 
occurrence all decreased with area-based compliance (Figure 5). Spring peeper abundance, leopard frog occurrence, and gray treefrog occurrence were not significantly affected by compliance with buffer guidelines, regardless of buffer vegetation type (Appendix 2).

\section{Landscape effects on anurans (Preliminary work for Question 2)}

Four anuran species were significantly affected by landscape composition (Table 2). Spring peeper abundance increased with woodland cover and decreased with water cover at several spatial scales, with the best-fitting model occurring at $1000 \mathrm{~m}$ (Table 2). Leopard frog occurrence decreased with road density and water cover at several spatial scales, with the bestfitting model occurring at $1500 \mathrm{~m}$ (Table 2). American toad occurrence increased with woodland cover and decreased with road density and water cover at a $1000 \mathrm{~m}$ spatial scale (Table 2). Gray tree frog occurrence increased with woodland cover at scales of 500 to $1500 \mathrm{~m}$, with the bestfitting model at $1500 \mathrm{~m}$ (Table 2).

\section{Relative importance of wetland buffers and landscape composition for anurans (Question 2)}

The relative importance of wetland buffers and landscape composition varied depending on the response variable. Species richness and green frog abundance were more strongly affected by wetland buffers, while spring peeper abundance, leopard frog occurrence, and eastern gray treefrog occurrence were more strongly affected by landscape composition (Figure 6). The remaining response variables (wood frog and American toad occurrence) were neither positively affected by compliance with wetland buffer guidelines, nor affected by landscape composition (Figure 6). 


\section{DISCUSSION}

Our results indicate that wetland buffers work if the goal is simply to increase anuran species richness in a given wetland, but that wetland buffers are insufficient to ensure the presence of all species. To summarize our results, we think that maintaining a $30 \mathrm{~m}$ wetland buffer of contiguous grassland scattered with trees, while conserving or increasing woodland and limiting road density within $1500 \mathrm{~m}$ of wetlands, will maximize species richness and abundance in agricultural wetlands.

In our study, $30 \mathrm{~m}$ wetland buffers were positively related to anuran species richness when buffer vegetation was grassland excluding hay. Since this vegetation consists of scrub, lawn, orchard, and pasture, it can also be described as grassland with scattered trees. The increase in species richness was probably a cumulative response to slight increases in the abundance and occurrence of several species for which buffers of grassland and scattered trees provide at least some suitable terrestrial habitat. Green frog abundance increased significantly with several types of grassland buffer compliance (Figure 3), and spring peeper abundance, American toad occurrence, leopard frog occurrence, and eastern gray treefrog occurrence increased (but not significantly) with area-based compliance when buffer vegetation was grassland excluding hay (Appendix 2). Responses of chorus frogs, Cope's gray treefrogs, mink frogs, and American bullfrogs to buffer compliance may also have contributed to buffer effects on species richness, but we were unable to evaluate these individual effects due to low detection rates for these species.

The slight positive effects of grassland buffers on the above species are generally consistent with known habitat use patterns. Green frogs use terrestrial habitat close to ponds, and 
tend to avoid woodland (Birchfield and Deters 2005; Pauley and Lannoo 2005). American toads and leopard frogs typically prefer grassland habitat as adults (Green 2005; Rorabaugh 2005). Adult eastern and Cope's gray treefrogs are typically associated with woodland, but they likely do not require a closed canopy; therefore, gray treefrogs probably used the trees and shrubs scattered throughout the grassland buffers (Cline 2005a,b). The slightly positive relationship between spring peeper abundance and buffer compliance may have been spurious, as adults of the species are known to prefer woodland habitat (Butterfield et al. 2005).

Although we found that wetland buffers can increase species richness, our results also indicate that conserving landscape-scale terrestrial habitat and limiting road density have stronger effects on individual species than implementing wetland buffers. Of the five species with statistically significant responses to either buffers or landscape composition, three (spring peepers, leopard frogs, American toads, and eastern gray treefrogs) were more strongly affected by landscape composition at scales of 1000-1500 $\mathrm{m}$ than by compliance with wetland buffer guidelines. Spring peeper abundance, American toad occurrence, and eastern gray treefrog occurrence increased with woodland cover in the landscape; since woodland is the main nonbreeding habitat for adult spring peepers and eastern gray treefrogs (Butterfield et al. 2005; Cline 2005), and provides acceptable non-breeding habitat for American toads (Green 2005), this finding indicates that landscape-scale conservation of terrestrial habitat is important. We did not observe any landscape-scale woodland effects on leopard frogs, but this is expected because leopard frogs are primarily a grassland species; other studies have shown leopard frog abundance to increase with landscape-scale grassland cover (Pope et al. 2000). However, we found leopard frog occurrence and American toad occurrence to decrease with road density, which highlights 
the problematic effects of roads on anuran mortality (Fahrig et al. 1995), particularly since road density around study sites was fairly low (less than $2.5 \mathrm{~km} / \mathrm{km}^{2}$ ).

Interestingly, we also found that spring peeper abundance, leopard frog occurrence, and American toad occurrence decreased with water cover in the surrounding landscape. This finding contrasts with previous studies, which have shown anuran species occurrence to increase with landscape-scale wetland cover, presumably because larger amounts of aquatic habitat in the landscape foster larger anuran metapopulations (Knutson et al. 1999; Pope et al. 2000; Jeliazkov et al. 2014). We speculate that farmland ponds are less suitable breeding habitat than are more natural or secluded wetlands, so when multiple natural wetlands are available in the surrounding landscape, anurans may select these wetlands instead of farmland ponds for breeding. It is also possible that leopard frogs decreased with wetland cover in our study because wetland cover was positively correlated with woodland cover (Appendix 1), and leopard frogs prefer grassland to woodland habitat (Rorabaugh 2005). However, we find this explanation unlikely because we did not detect a significant negative effect of landscape-scale woodland cover on leopard frog occurrence.

We did not find significant positive effects of buffer compliance, or significant effects of landscape composition, on wood frog occurrence. This may have been because our sample size was insufficient to detect weak effects. This explanation seems probable, as wood frog occurrence in our study increased non-significantly with woodland buffer width, and other studies have found wood frog occurrence and abundance to increase with landscape-scale woodland cover (Guerry and Hunter 2002; Houlahan and Findlay 2003; Herrmann et al. 2005; Eigenbrod et al. 2008). Another possibility is that wood frogs may be affected by landscape composition at scales larger than $2000 \mathrm{~m}$. In this scenario, landscape composition effects would 
go undetected because the correct landscape scale was not examined. However, if this scenario was correct we would expect landscape effects at $2000 \mathrm{~m}$ to be nearly significant, due to correlations between land cover amounts across spatial scales. We did not observe such effects, so we find this explanation unlikely.

Based on our results, we speculate that the landscape composition and wetland buffers might act as progressive environmental filters, such that species will only occur in landscapes of suitable composition, and within these landscapes will only occur in ponds with suitable buffers. Species such as leopard frogs and gray treefrogs that disperse widely as juveniles, are primarily terrestrial as adults, and migrate between hibernation and breeding sites, will experience stronger landscape filter effects and will respond strongly to landscape composition (Cline 2005; Rorabaugh 2005). Wetland buffers can only help populations of these species to persist if the landscape is already suitable. Species that are primarily aquatic, such as green frogs, will experience weaker landscape composition effects, and stronger buffer effects (Pauley and Lannoo 2005).

In conclusion, both wetland buffers and landscape-scale conservation should be used to promote anuran diversity in agricultural environments. To increase anuran species richness, wetland buffers should be at least $30 \mathrm{~m}$ wide, and as much of the buffer as possible should be vegetated with grass (not hay) and scattered trees. To maximize anuran species richness and abundance, agricultural landscapes should also include as much woodland cover, and as few roads, as possible. 


\section{FIGURES AND TABLES}

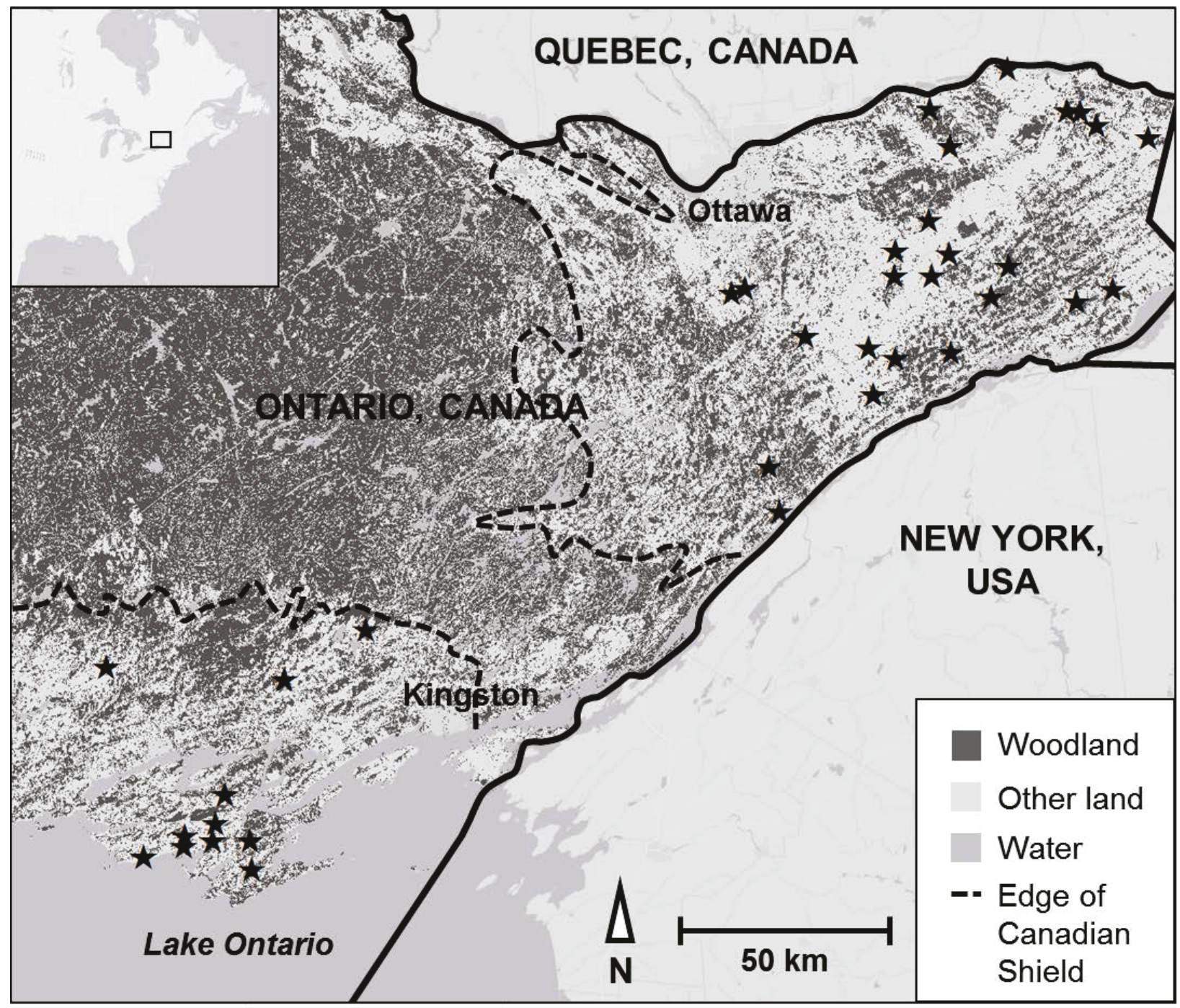

Figure 1. Locations of all 36 study ponds (black stars) in agricultural landscapes of eastern Ontario, Canada. 

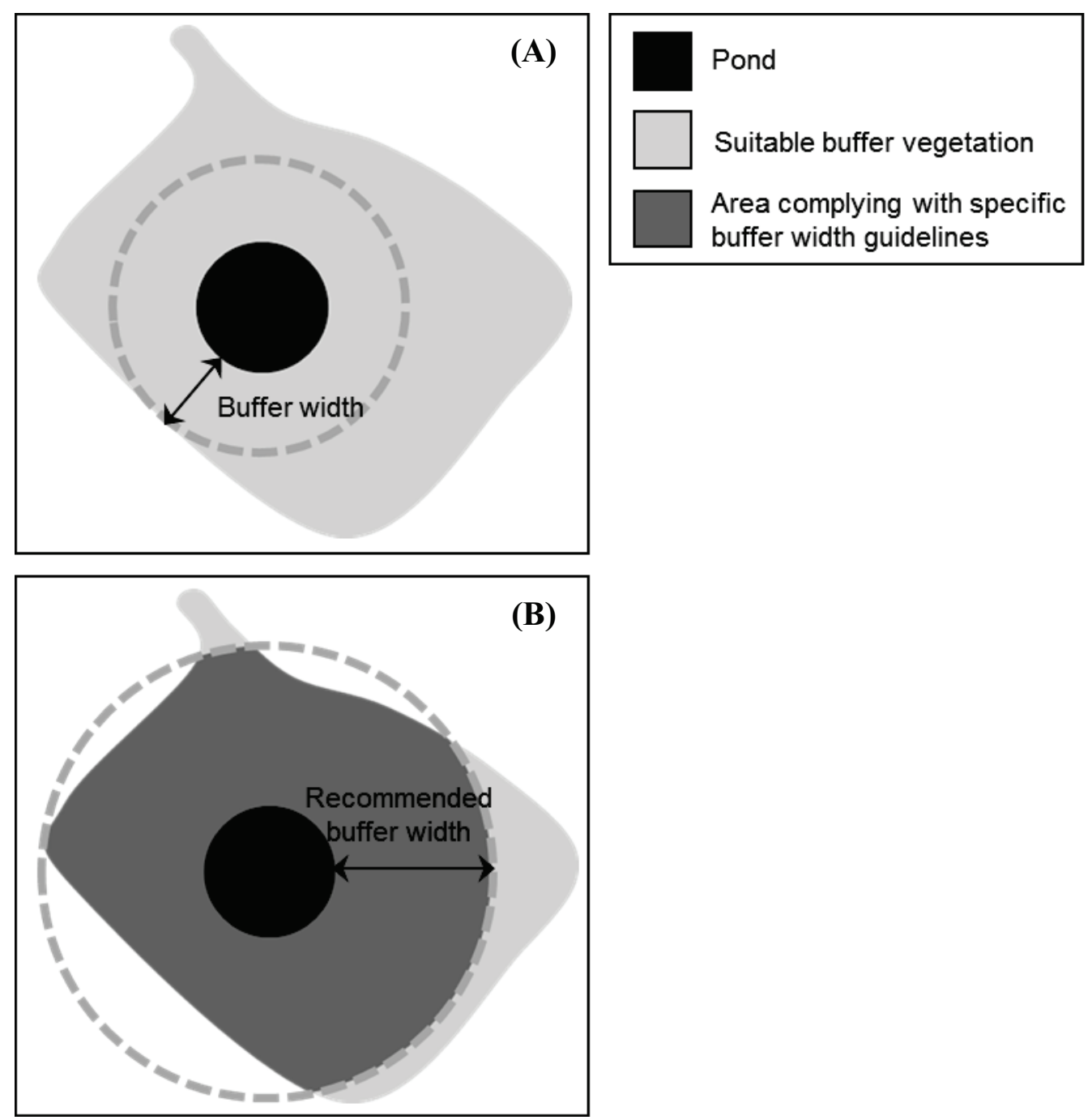

Figure 2. Diagram showing the two ways that compliance with buffer guidelines was measured. (A) Buffer width was measured as the minimum width of buffer vegetation contiguous with the pond. (B) Area-based compliance was measured as the proportion of area circumscribed by a recommended buffer width that contained buffer vegetation contiguous with the pond. Compliance with buffer guidelines (A and B) was measured for seven different buffer vegetation types (Section 2.4). 


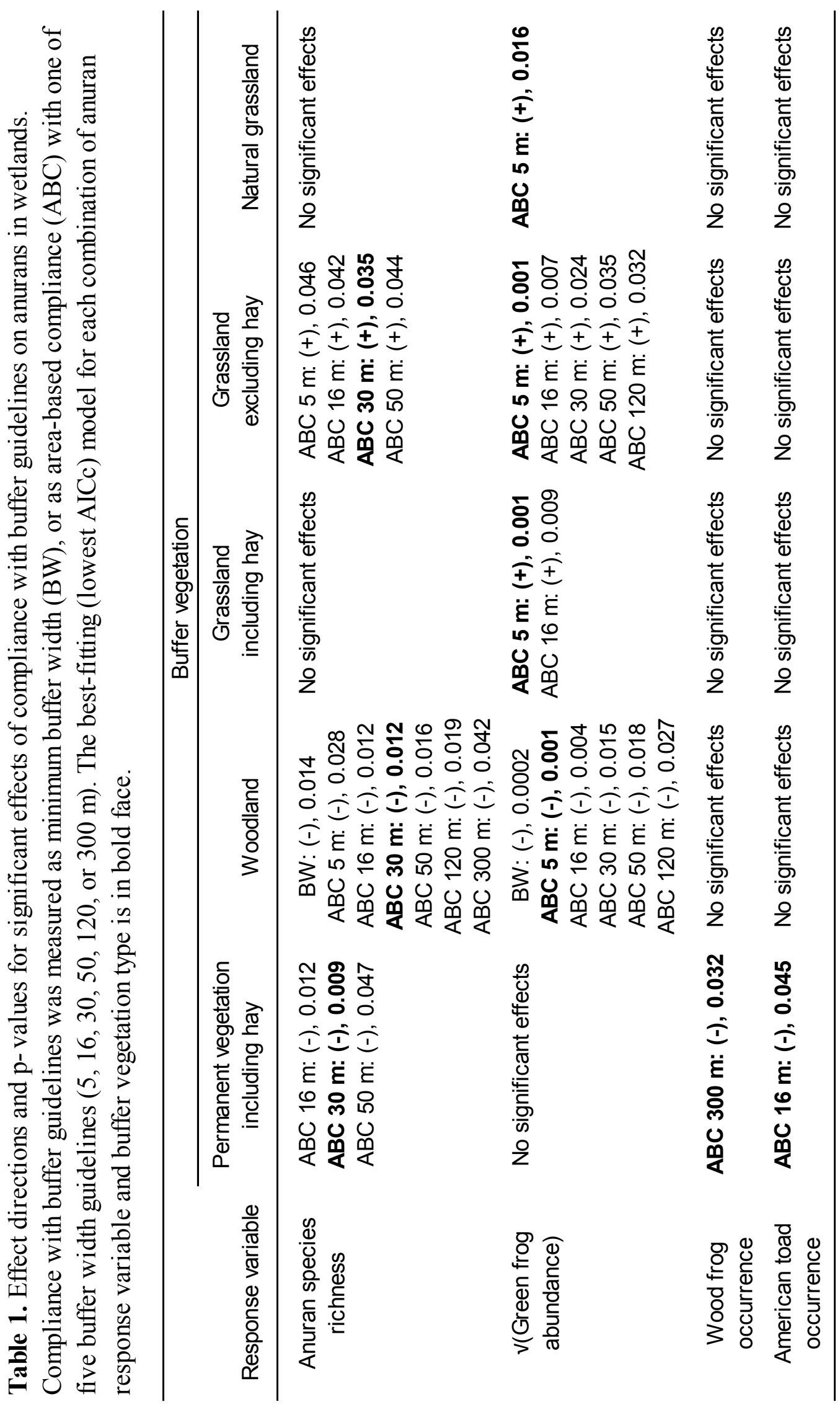



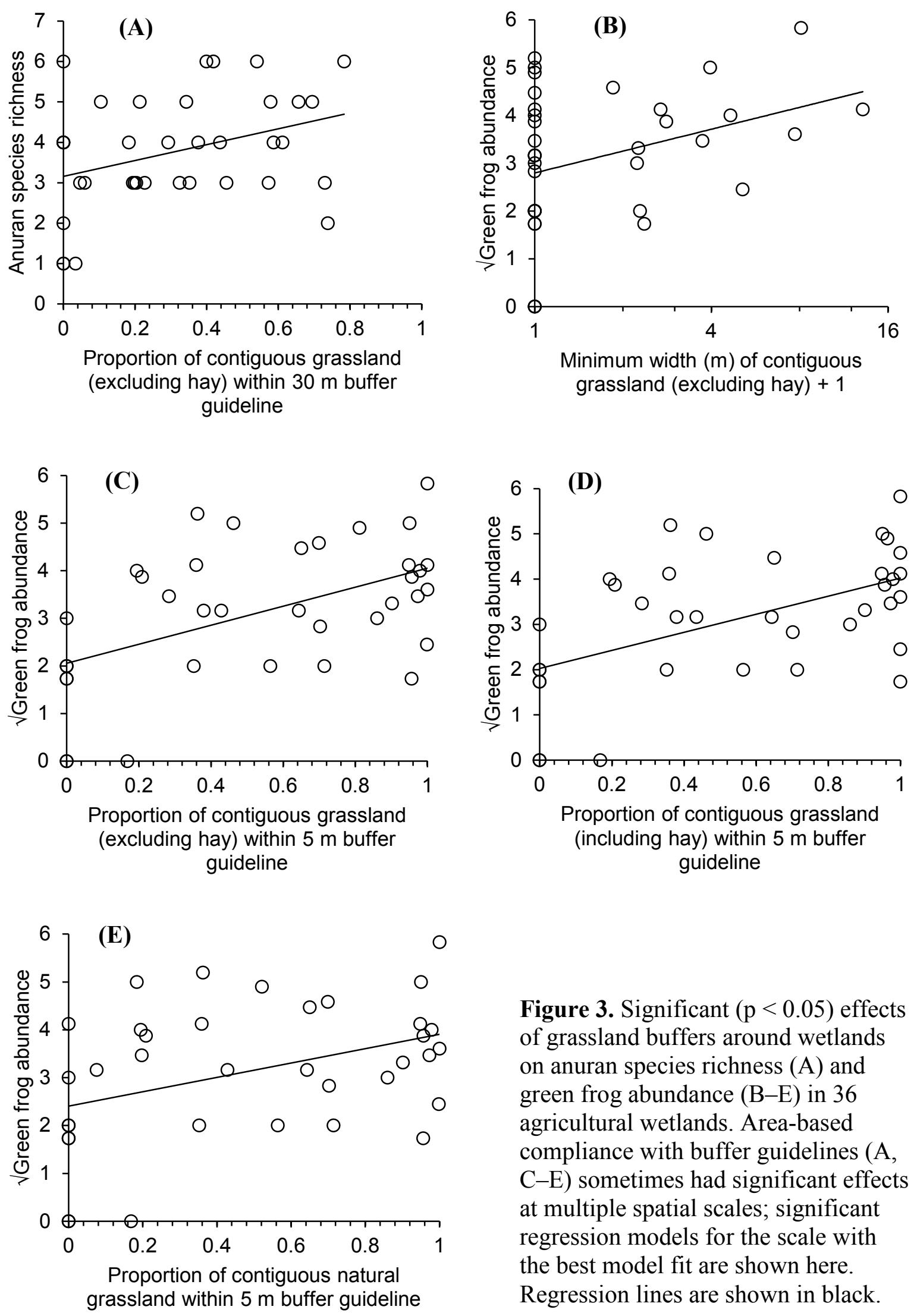

Figure 3. Significant $(p<0.05)$ effects of grassland buffers around wetlands on anuran species richness (A) and green frog abundance (B-E) in 36 agricultural wetlands. Area-based compliance with buffer guidelines (A, C-E) sometimes had significant effects at multiple spatial scales; significant regression models for the scale with the best model fit are shown here. Regression lines are shown in black. 

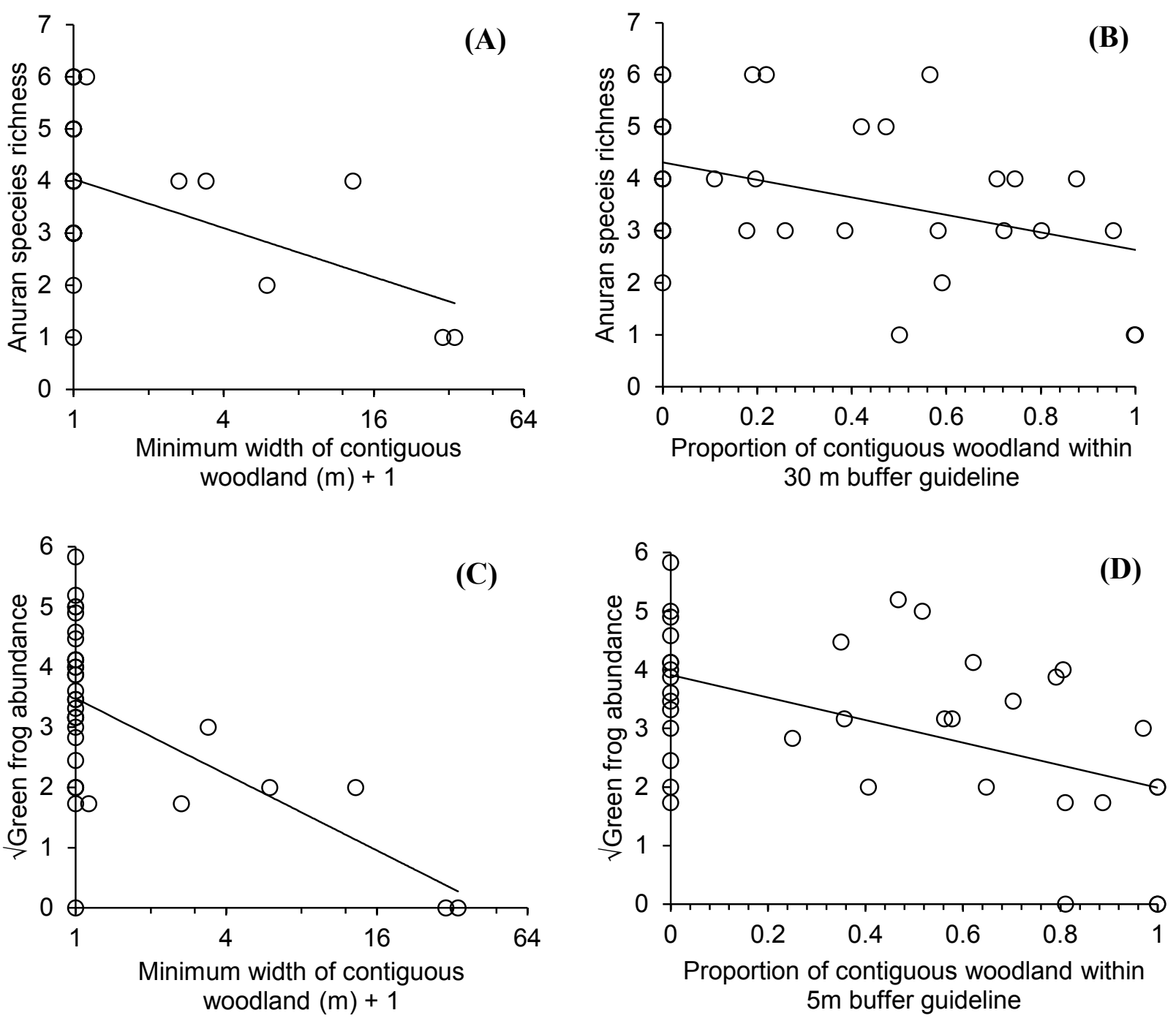

Figure 4. Significant $(p<0.05)$ effects of woodland buffers on anuran species richness $(A-B)$ and green frog abundance $(\mathrm{C}-\mathrm{D})$ in 36 agricultural wetlands. Area-based compliance with buffer guidelines (B, D) sometimes had significant effects at multiple spatial scales; significant regression models for the scale with the best model fit are shown here. Regression lines are shown in black. 

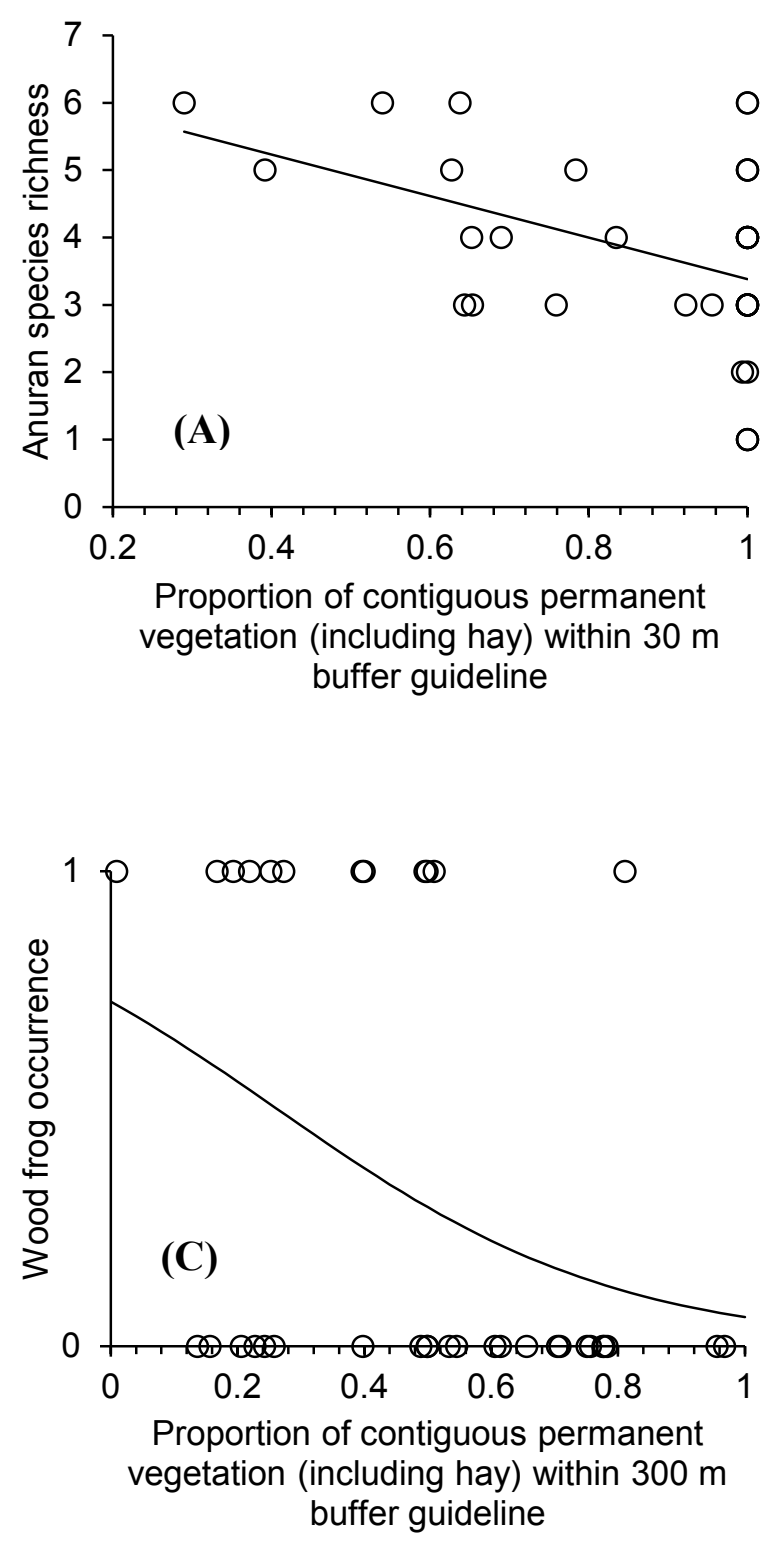

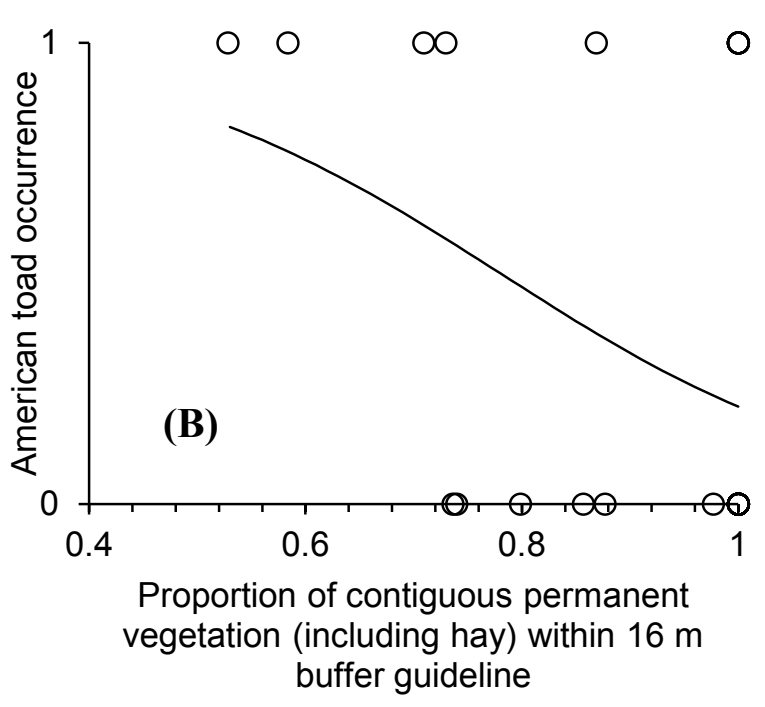

Figure 5. Significant $(\mathrm{p}<0.05)$ effects of "permanent vegetation" buffers (including hay) on anuran species richness (A), American toad occurrence (B), and wood frog occurrence $(C)$ in 36 agricultural wetlands. Area-based compliance with buffer guidelines (A-C) sometimes had significant effects at multiple spatial scales; significant regression models for the scale with the best model fit are shown here. Logistic regression curves are shown in black. 


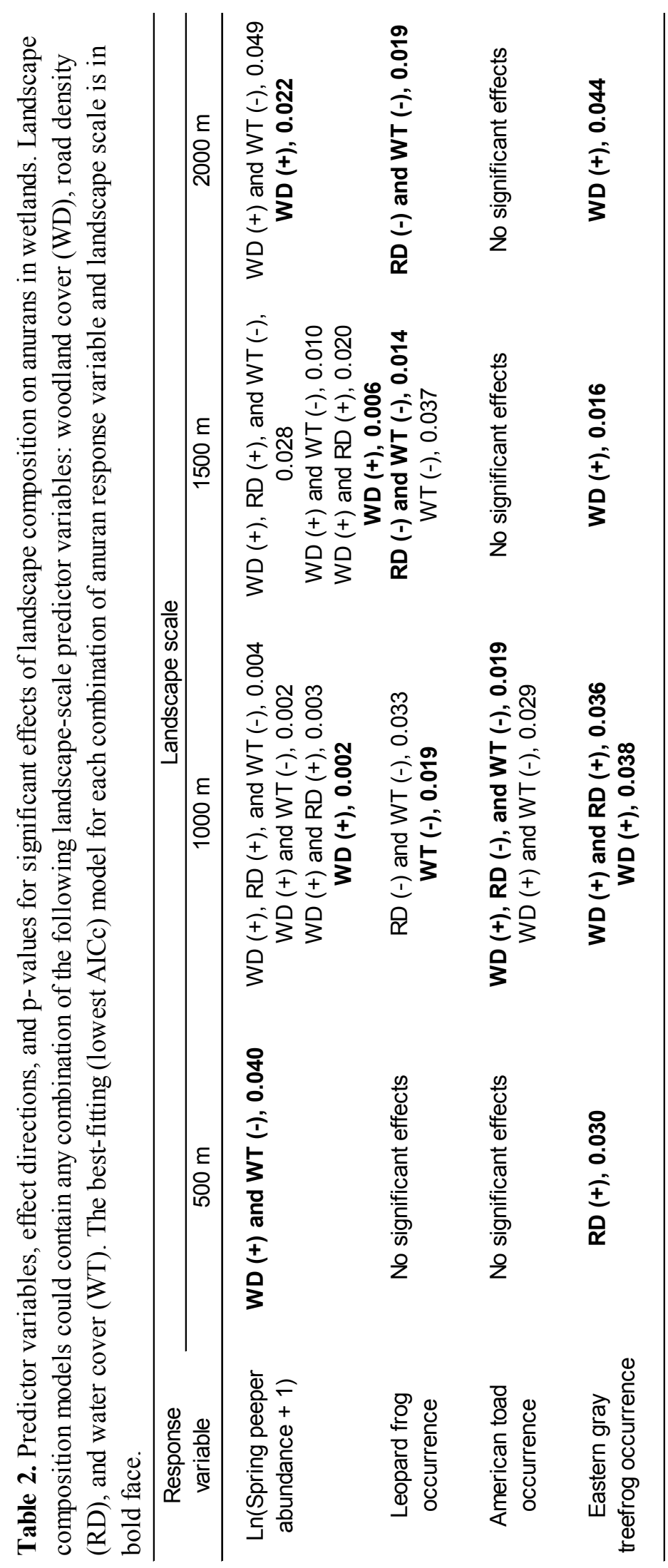




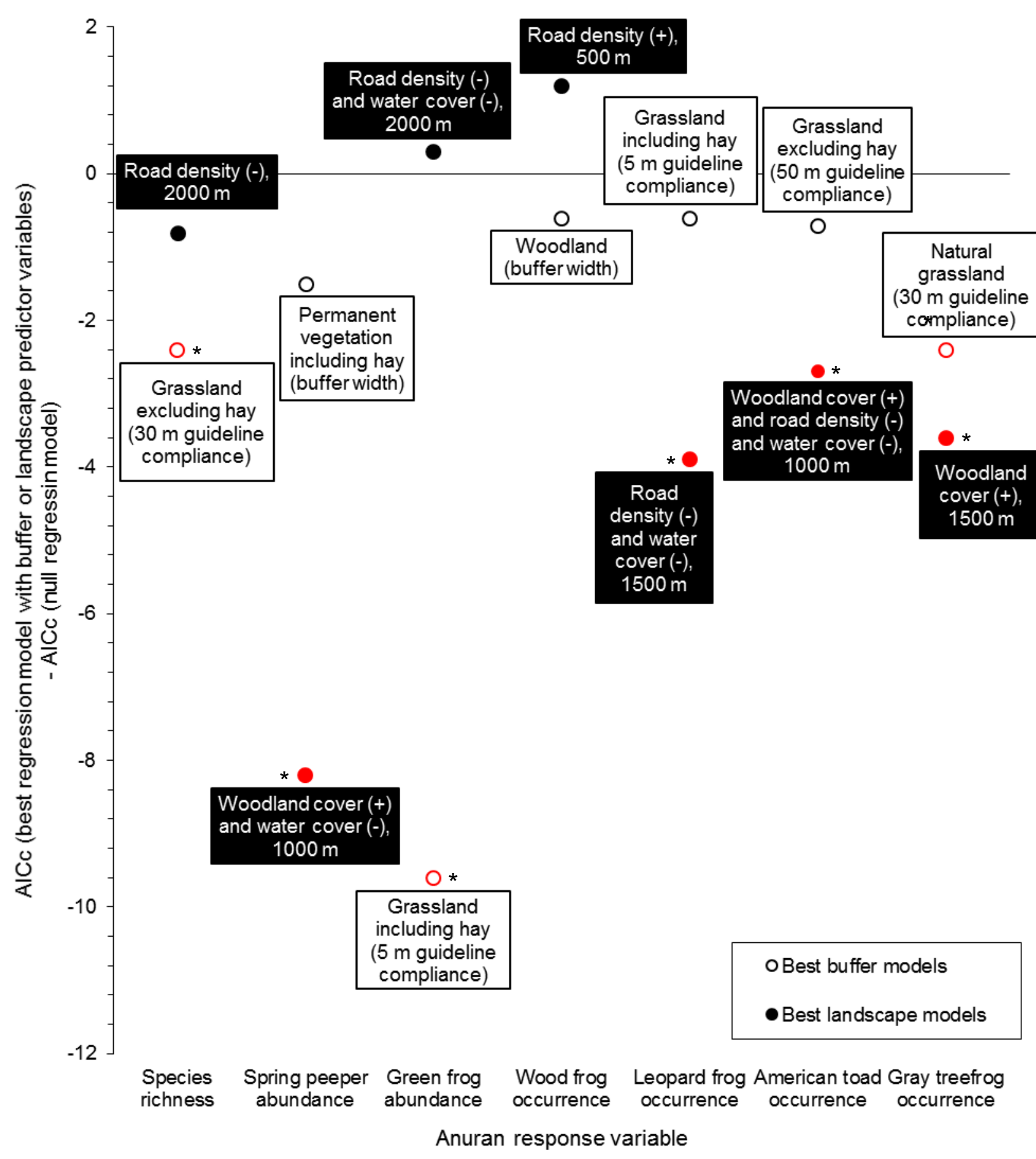

Figure 6. Differences between AICc values of the best-fitting regression models and AICc values for null models, when anuran response variables in study ponds were regressed on either buffer or landscape composition variables. White boxes show the vegetation type used to calculate buffer width or area-based buffer guideline compliance for each best-fitting buffer model. Black boxes show the landscape composition variables and scale of landscape measurement for each best-fitting landscape composition model. Regression models with AICc values at least 2 points lower (better fit) than the null model are indicated in red; statistically significant models $(\mathrm{p}<0.05)$ are additionally indicated with asterisks. 


\section{REFERENCES}

Baldwin RF, Calhoun AJ, and deMaynadier PG. 2006. Conservation planning for amphibian species with complex habitat requirements: A case study using movements and habitat selection of the wood frog Rana sylvatica. Journal of Herpetology 40: 442-53.

Barton K. 2016. MuMIn: Multi-Model Inference. Written for R package version 1.15.6.

Birchfield GL and Deters JE. 2005. Movement paths of displaced northern green frogs (Rana clamitans melanota). Southeastern Naturalist 4: 63-76.

Brazner JC, Danz NP, Trebitz AS, et al. 2007. Responsiveness of Great Lakes wetland indicators to human disturbances at multiple spatial scales: a multi-assemblage assessment. Journal of Great Lakes Research 33: 42-66.

Butterfield BP, Lannoo MJ, and Nanjappa P. 2005. Pseudacris crucifer (Wied-Neuwid, 1838): Spring peeper. In:Michael J. Lannoo (Ed). Amphibian Declines: The Conservation Status of United States Species. Berkley and Los Angeles, CA: University of California Press.

Cline GR. 2005a. Hyla chrysoscelis Cope, 1880: Cope's gray treefrog. In:Michael J. Lannoo (Ed). Amphibian Declines: The Conservation Status of United States Species. Berkley and Los Angeles, CA: University of California Press.

Cline GR. 2005b. Hyla versicolor LeConte, 1825: Eastern gray treefrog. In:Michael J. Lannoo (Ed). Amphibian Declines: The Conservation Status of United States Species. Berkley and Los Angeles, CA: University of California Press.

Coukell G, Williamson E, Shulist R, et al. 2004. Best Management Practices: Buffer Strips (Alison Lane, Ed). Toronto, Canada: OMAFRA.

Cushman SA. 2006. Effects of habitat loss and fragmentation on amphibians: a review and prospectus. Biological Conservation 128: 231-40.

DeMaynadier PG and Hunter ML Jr. 1999. Forest canopy closure and juvenile emigration by pool-breeding amphibians in Maine. The Journal of Wildlife Management: 441-50.

Dorcas ME, Price SJ, Walls SC, and Barichivich WJ. 2009. Auditory monitoring of anuran populations. In:C. Kenneth Dodd, Jr (Ed). Amphibian Ecology and Conservation: A Handbook of Techniques. New York, NY: Oxford University Press.

Eigenbrod F, Hecnar SJ, and Fahrig L. 2008. The relative effects of road traffic and forest cover on anuran populations. Biological Conservation 141: 35-46.

ESRI. 2014. ArcMap 10.3. Environmental Systems Research Institute: Redlands, CA. 
ESRI. 2015. ArcMap 10.3.1. Environmental Systems Research Institute: Redlands, CA.

Fahrig L, Pedlar JH, Pope SE, et al. 1995. Effect of road traffic on amphibian density. Biological Conservation 73: 177-82.

Findlay CS, Lenton J, and Zheng L. 2001. Land-use correlates of anuran community richness and composition in southeastern Ontario wetlands. Ecoscience 8: 336-43.

Forester DC, Snodgrass JW, Marsalek K, and Lanham Z. 2006. Post-breeding dispersal and summer home range of female American toads (Bufo americanus). Northeastern Naturalist 13: 59-72.

Gibbs JP. 1998. Amphibian movements in response to forest edges, roads, and streambeds in southern New England. The Journal of Wildlife Management: 584-9.

Google. 2015. Google Maps. www.google.ca/maps. Viewed Apr 2015.

Green DM. 2005. Bufo americanus Holbrook, 1836: American toad. In:Michael J. Lannoo (Ed). Amphibian Declines: The Conservation Status of United States Species. Berkley and Los Angeles, CA: University of California Press.

Guerry AD and Hunter ML. 2002. Amphibian distributions in a landscape of forests and agriculture: An examination of landscape composition and configuration. Conservation Biology 16: 745-54.

Hartel T, Schweiger O, Öllerer K, et al. 2010. Amphibian distribution in a traditionally managed rural landscape of Eastern Europe: Probing the effect of landscape composition. Biological Conservation 143: 1118-24.

Hecnar SJ and M'Closkey RT. 1998. Species richness patterns of amphibians in southwestern Ontario ponds. Journal of Biogeography 25: 763-72.

Herrmann H, Babbitt K, Baber M, and Congalton R. 2005. Effects of landscape characteristics on amphibian distribution in a forest-dominated landscape. Biological Conservation 123: $139-49$.

Houlahan JE and Findlay CS. 2003. The effects of adjacent land use on wetland amphibian species richness and community composition. Canadian Journal of Fisheries and Aquatic Sciences 60: 1078-94.

Jeliazkov A, Chiron F, Garnier J, et al. 2014. Level-dependence of the relationships between amphibian biodiversity and environment in pond systems within an intensive agricultural landscape. Hydrobiologia 723: 7-23.

Knutson MG, Richardson WB, Reineke DM, et al. 2004. Agricultural ponds support amphibian populations. Ecological Applications 14: 669-684. 
Knutson MG, Sauer JR, Olsen DA, et al. 1999. Effects of landscape composition and wetland fragmentation on frog and toad abundance and species richness in Iowa and Wisconsin, USA. Conservation Biology 13: 1437-46.

Lannoo MJ. 2005. Amphibian Declines: The Conservation Status of United States Species (Michael J. Lannoo, Ed). Berkley and Los Angeles, CA: University of California Press.

Mensing D, Galatowitsch S, and Tester J. 1998. Anthropogenic effects on the biodiversity of riparian wetlands of a northern temperate landscape. Journal of Environmental Management 53: 349-77.

Millennium Ecosystem Assessment. 2005. Ecosystems and human well-being: wetlands and water synthesis.

Niagara Planning and Development Services Department. 2015. Natural environment. In:Niagara Regional Official Plan. Niagara, Canada: Regional Municipality of Niagara.

OMAFRA. 2010. Agricultural Resource Inventory (ARI). geo1.scholarsportal.info.proxy.library.carleton.ca. Viewed Nov 2014.

OMNR. 2002. Southern Ontario Land Resource Information System (SOLRIS). geo1.scholarsportal.info.proxy.library.carleton.ca. Viewed Oct 2014.

OMNR. 2009. Digital Raster Acquisition Project Eastern Ontario (DRAPE). geo1.scholarsportal.info.proxy.library.carleton.ca. Viewed Mar 2015.

OMNR. 2010. Ontario Hydro Network (OHN) - Waterbody. geo1.scholarsportal.info.proxy.library.carleton.ca. Viewed Oct 2014.

OMNR. 2011. Wetland Unit. geo1.scholarsportal.info.proxy.library.carleton.ca. Viewed Oct 2014.

OMNR. 2012. Ontario Hydro Network (OHN) - Small Scale Watercourse. geo1.scholarsportal.info.proxy.library.carleton.ca. Viewed Oct 2014.

OMNR. 2013. Wooded Area. www.javacoeapp.lrc.gov.on.ca/geonetwork/srv/en/main.home. Viewed Jul 2016.

OMNR. 2014. National Road Network Ontario (ON). www.geobase.ca. Viewed Oct 2014.

Ontario Farm Environmental Coalition. 2004. Canada-Ontario Environmental Farm Plan Workbook (Smith, H J and Myslik, Jim and Stone, Bob and MacMillan, Cindy Bradley and Armitage, David and Fitzgibbon, John and Graham, Andrew, Ed). 
Oseen KL and Wassersug RJ. 2002. Environmental factors influencing calling in sympatric anurans. Oecologia 133: 616-25.

Pauley TK and Lannoo MJ. 2005. Rana clamitans Latreille, 1801: Green frog. In:Michael J. Lannoo (Ed). Amphibian Declines: The Conservation Status of United States Species. Berkley and Los Angeles, CA: University of California Press.

Pope SE, Fahrig L, and Merriam HG. 2000. Landscape complementation and metapopulation effects on leopard frog populations. Ecology 81: 2498-508.

Powell JSV and Babbitt KJ. 2015. An experimental test of buffer utility as a technique for managing pool-breeding amphibians. PloS one 10: e0133642.

R Core Team. 2016. R: A Language and Environment for Statistical Computing. Vienna, Austria.

Regosin JV, Windmiller BS, Homan RN, and Reed JM. 2005. Variation in terrestrial habitat use by four pool-breeding amphibian species. Journal of Wildlife Management 69: 1481-93.

Rorabaugh JC. 2005. Rana pipiens Schreber, 1782: Northern leopard frog. In:Michael J. Lannoo (Ed). Amphibian Declines: The Conservation Status of United States Species. Berkley and Los Angeles, CA: University of California Press.

Rothermel BB and Semlitsch RD. 2002. An experimental investigation of landscape resistance of forest versus old-field habitats to emigrating juvenile amphibians. Conservation Biology 16: $1324-32$.

Rubbo MJ and Kiesecker JM. 2005. Amphibian breeding distribution in an urbanized landscape. Conservation Biology 19: 504-11.

Ruggiero A, Céréghino R, Figuerola J, et al. 2008. Farm ponds make a contribution to the biodiversity of aquatic insects in a French agricultural landscape. Comptes Rendus Biologies 331: 298-308.

Scoccianti C. 2009. Biodiversity Conservation and Habitat Management. In:Francesca Gherardi, Claudia Corti, Manuela Guatieri (Ed). Oxford, United Kingdom: EOLSS Publishers Co. Ltd.

Semlitsch RD. 2008. Differentiating migration and dispersal processes for pond-breeding amphibians. The Journal of Wildlife Management 72: 260-7.

Semlitsch RD and Bodie JR. 2003. Biological criteria for buffer zones around wetlands and riparian habitats for amphibians and reptiles. Conservation Biology 17: 1219-28. 


\section{Appendix 1: Correlations between predictor variables and potentially confounding}

variables

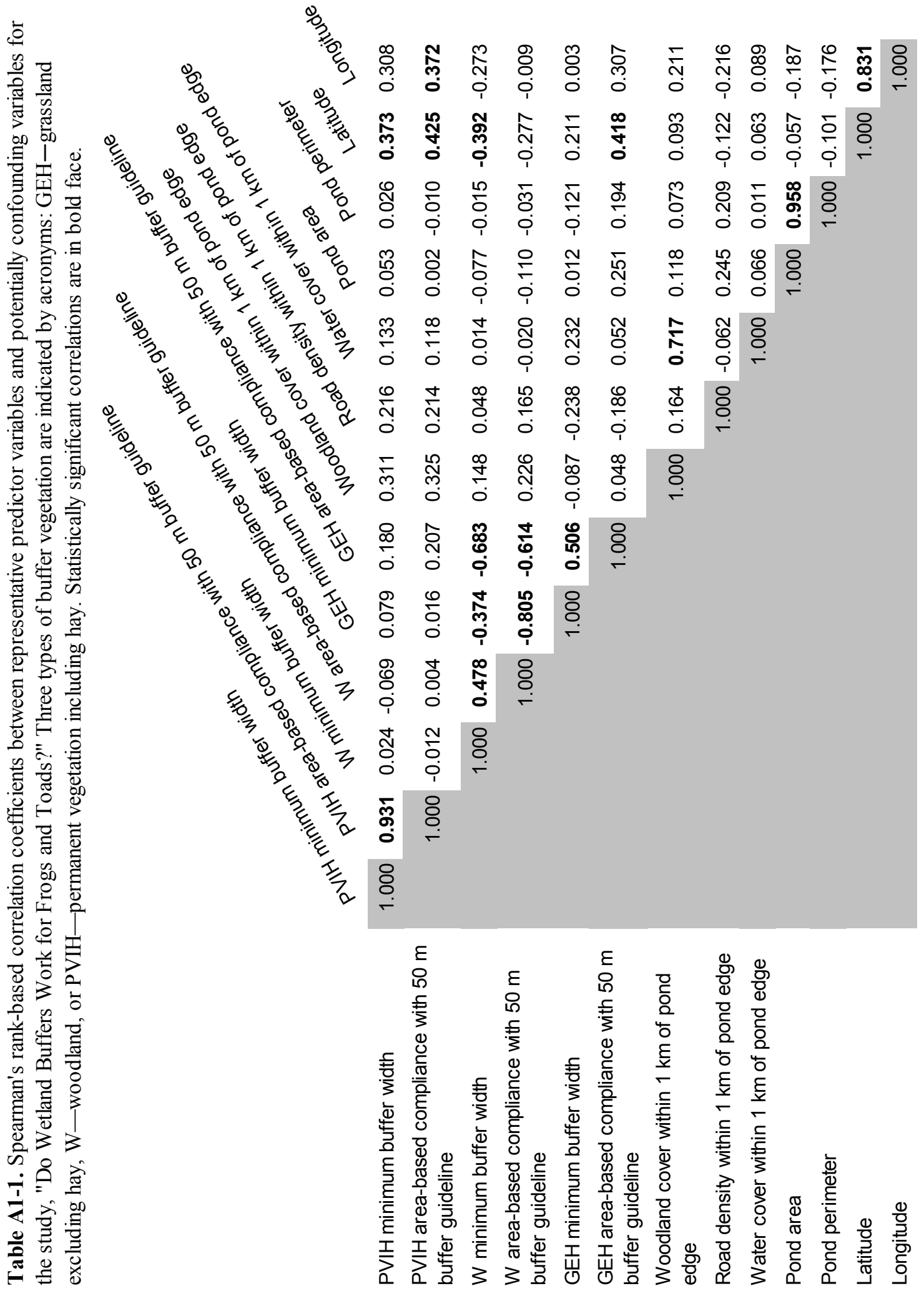




\section{Appendix 2: Relationships between anuran response variables and buffer predictor variables}
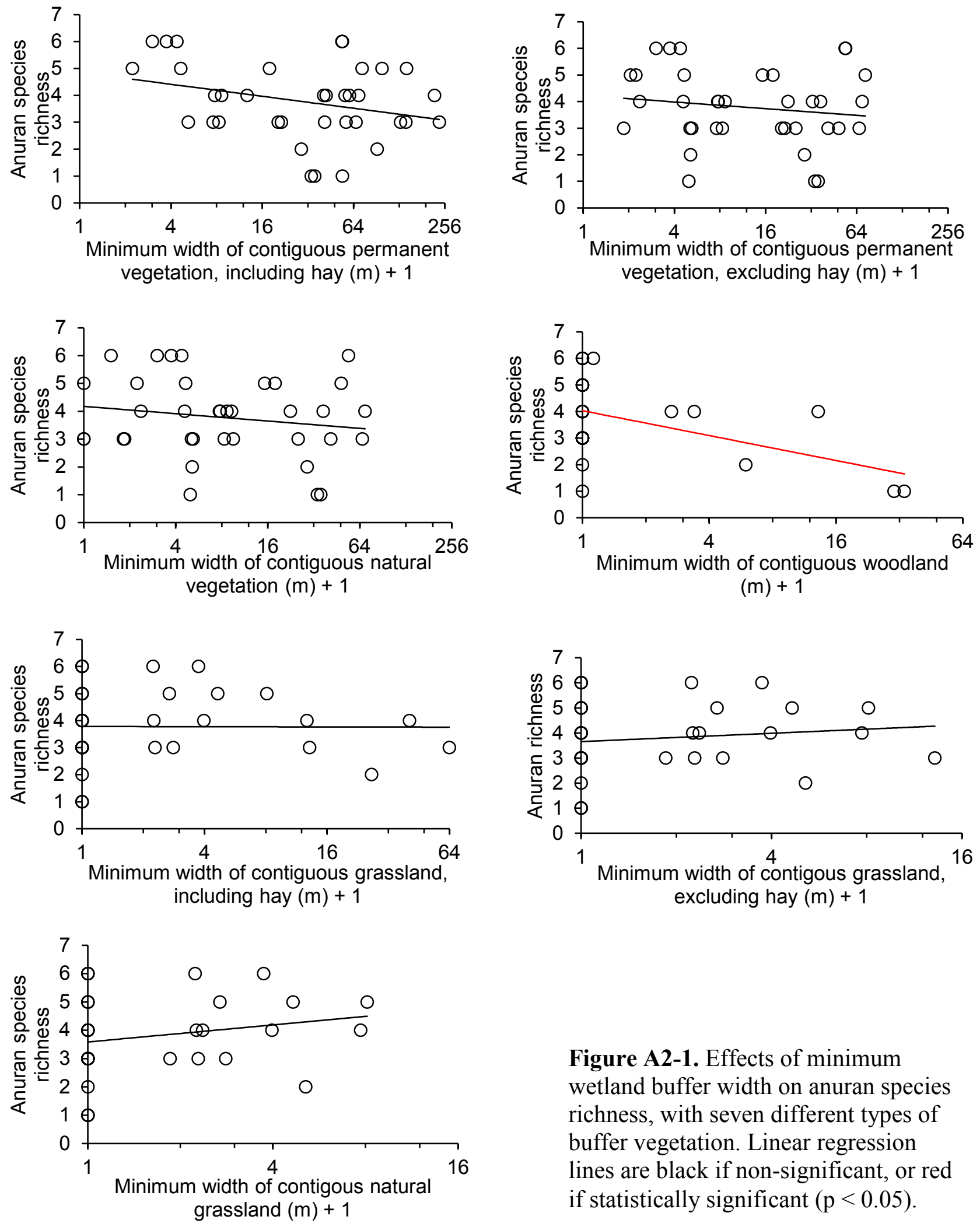

Figure A2-1. Effects of minimum wetland buffer width on anuran species richness, with seven different types of buffer vegetation. Linear regression lines are black if non-significant, or red if statistically significant $(\mathrm{p}<0.05)$. 

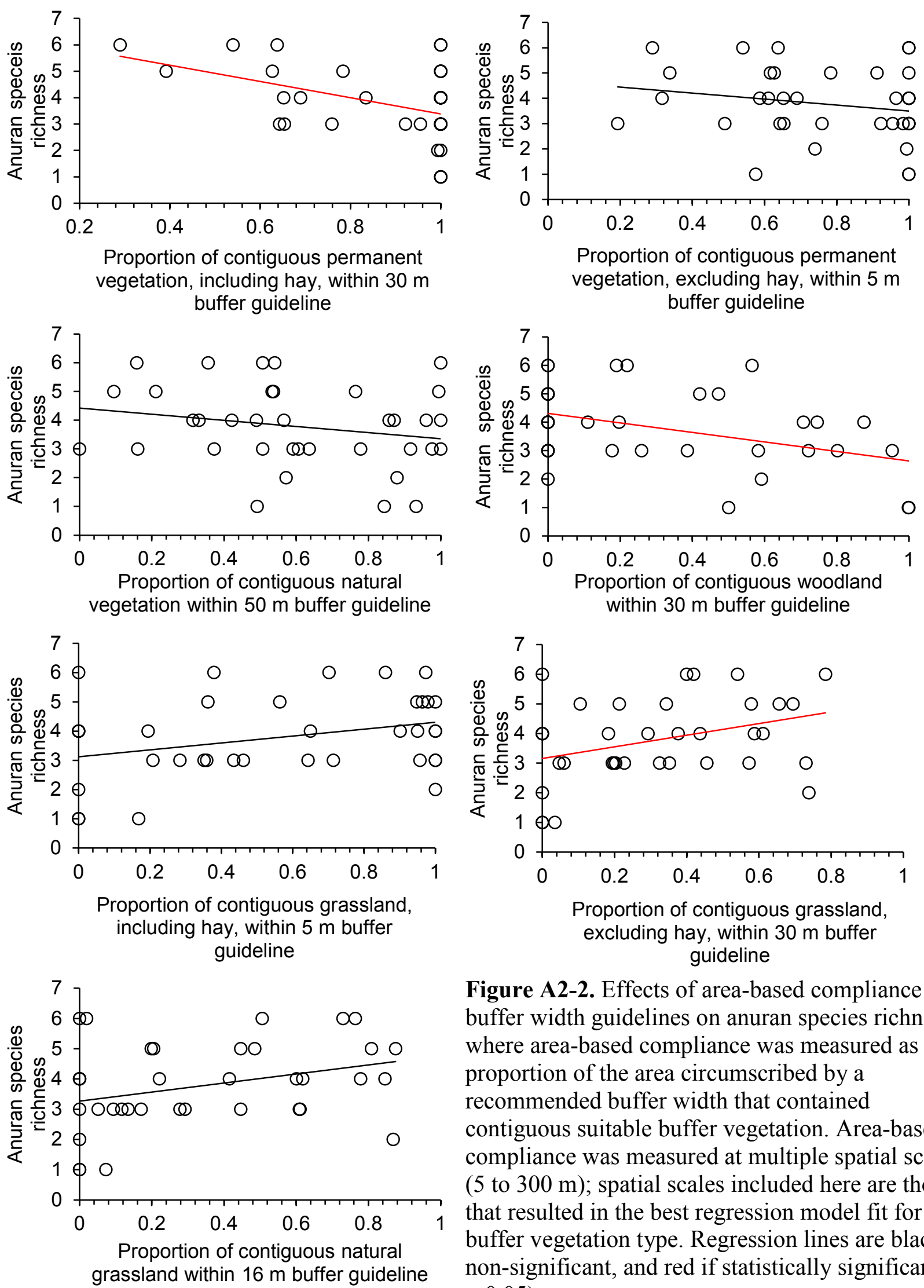

Figure A2-2. Effects of area-based compliance with buffer width guidelines on anuran species richness, where area-based compliance was measured as the proportion of the area circumscribed by a recommended buffer width that contained contiguous suitable buffer vegetation. Area-based compliance was measured at multiple spatial scales (5 to $300 \mathrm{~m}$ ); spatial scales included here are those that resulted in the best regression model fit for buffer vegetation type. Regression lines are black if non-significant, and red if statistically significant ( $p$ $<0.05)$. 

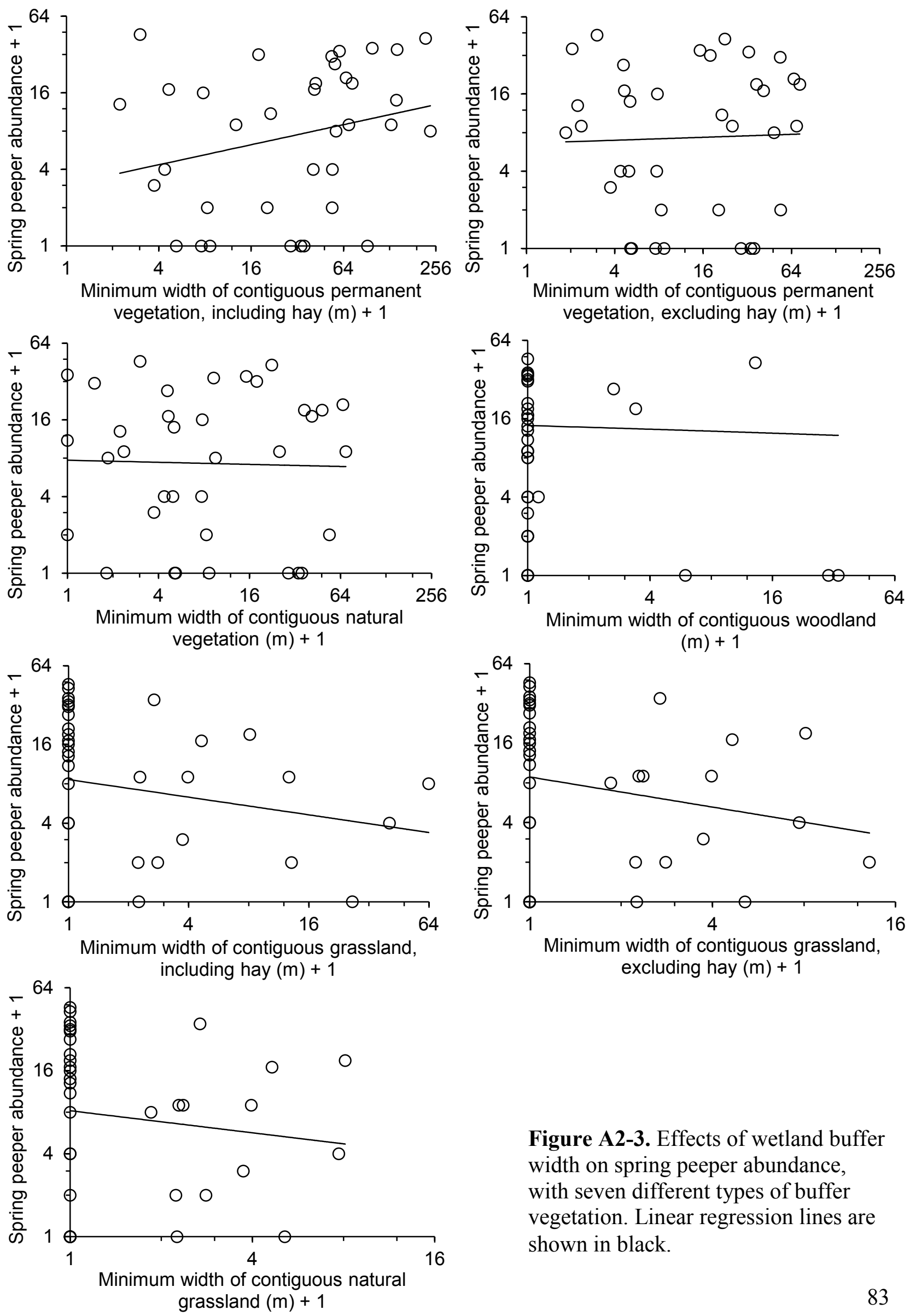

Figure A2-3. Effects of wetland buffer width on spring peeper abundance, with seven different types of buffer vegetation. Linear regression lines are shown in black. 


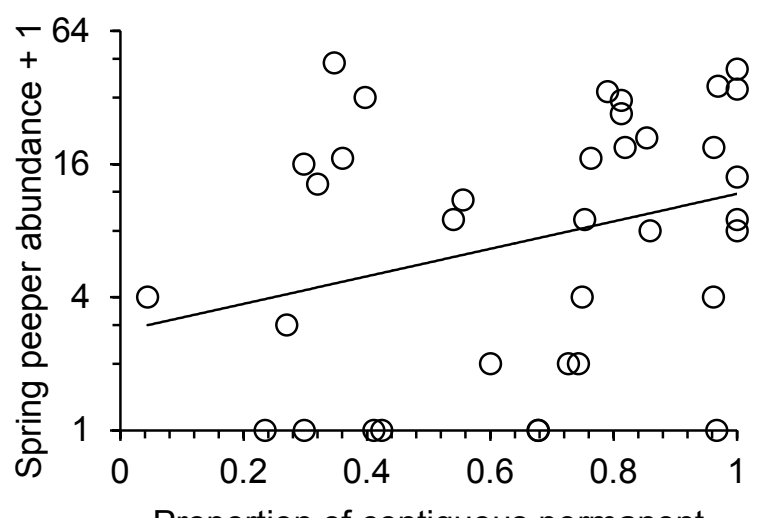

Proportion of contiguous permanent vegetation, including hay, within $120 \mathrm{~m}$

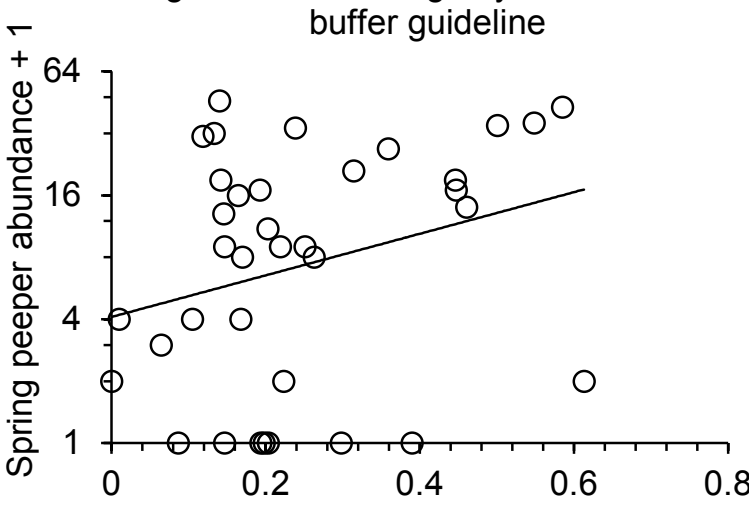

Proportion of contiguous natural vegetation within $300 \mathrm{~m}$ buffer guideline

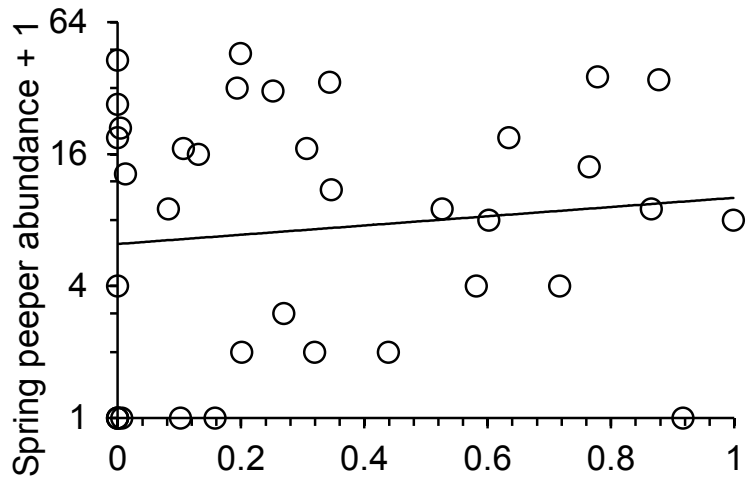

Proportion of contiguous grassland, including hay, within $120 \mathrm{~m}$ buffer

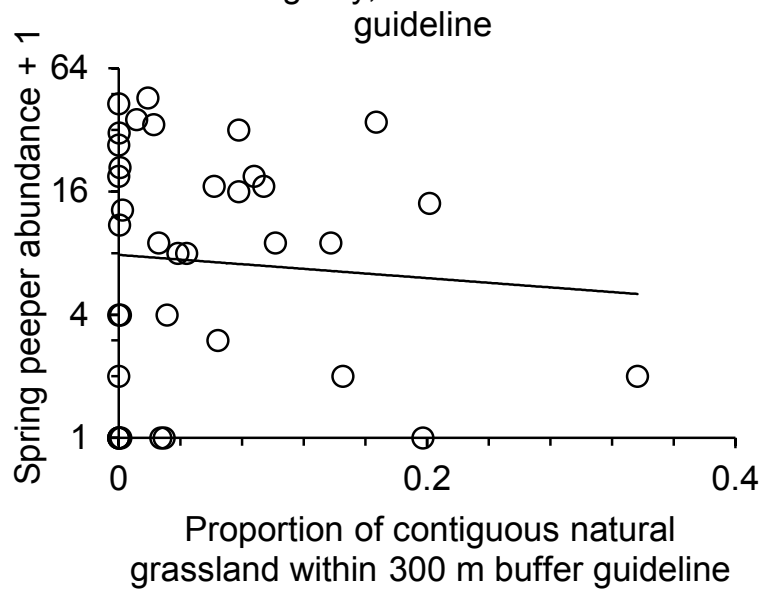

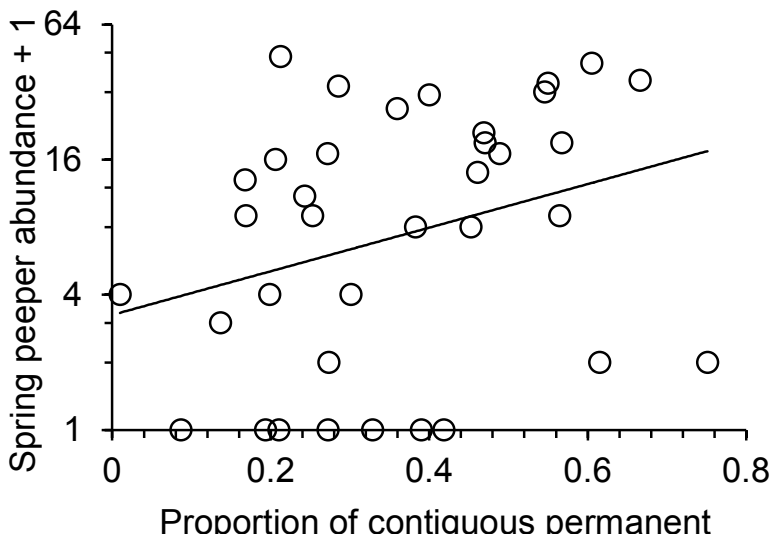

Proportion of contiguous permanent vegetation, excluding hay, within 300
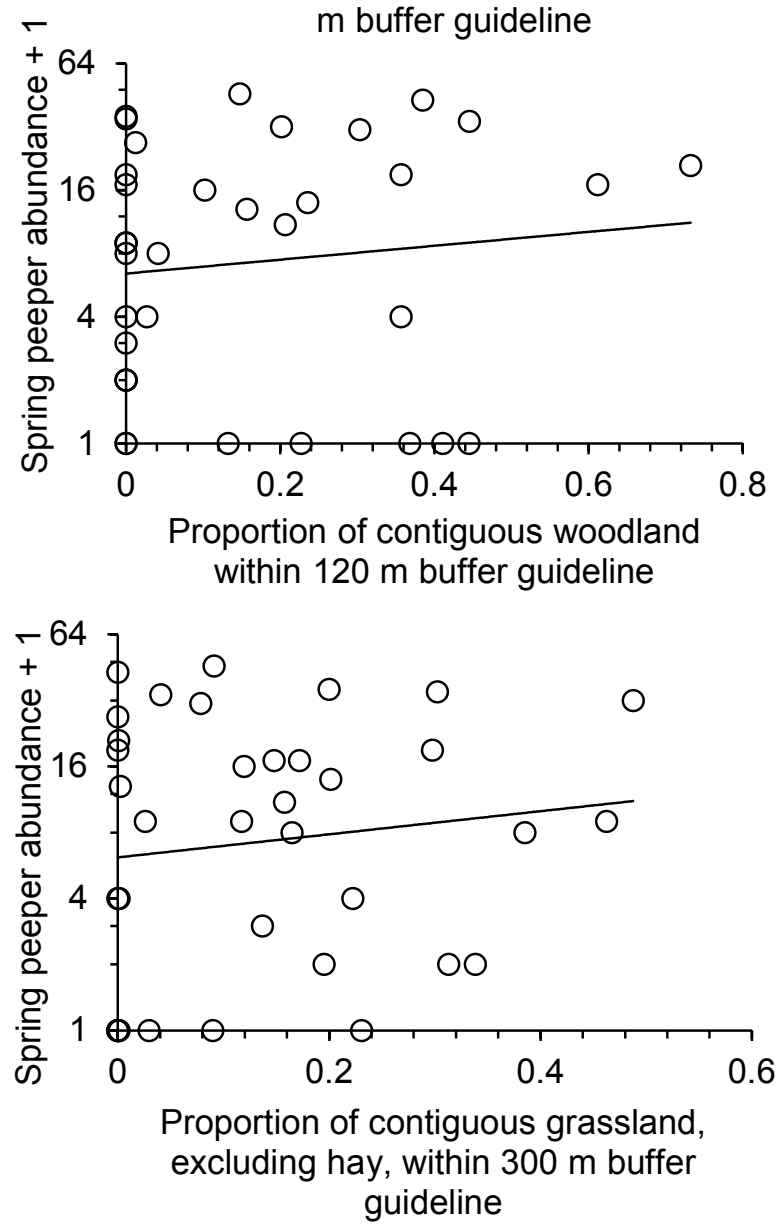

Figure A2-4. Effects of area-based compliance with buffer width guidelines on spring peeper abundance, where area-based compliance was measured as the proportion of the area circumscribed by a recommended buffer width that contained contiguous suitable buffer vegetation. Area-based compliance was measured at multiple spatial scales (5 to $300 \mathrm{~m}$ ); spatial scales included here are those that resulted in the best regression model fit for buffer vegetation type. Regression lines are shown in black. 

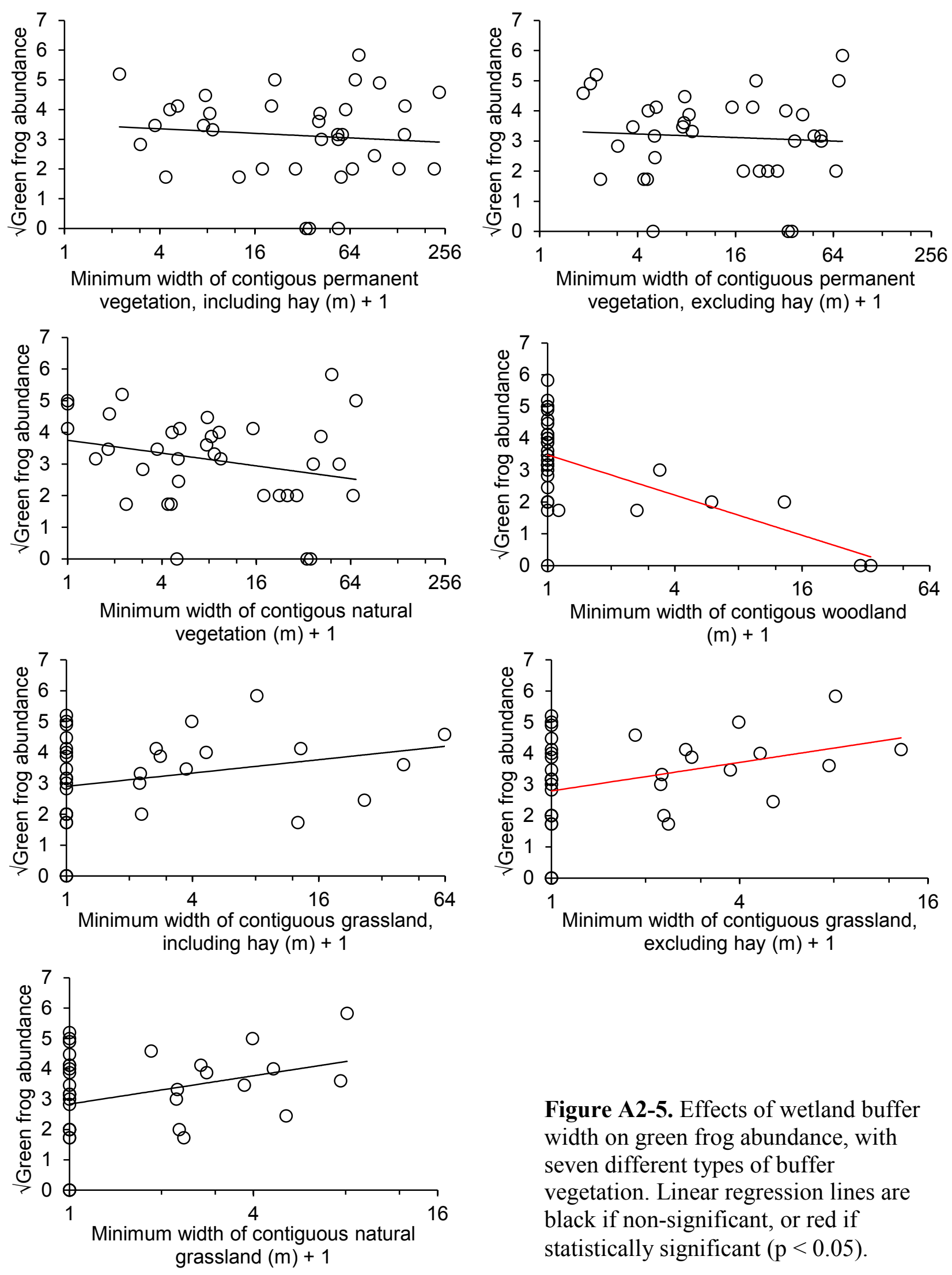

Figure A2-5. Effects of wetland buffer width on green frog abundance, with seven different types of buffer vegetation. Linear regression lines are black if non-significant, or red if statistically significant $(\mathrm{p}<0.05)$. 


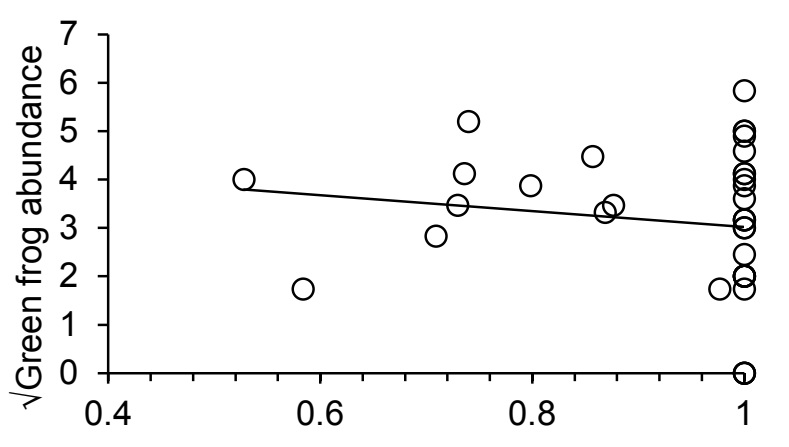

Proportion of contiguous permanent vegetation, including hay, within $16 \mathrm{~m}$ buffer guideline
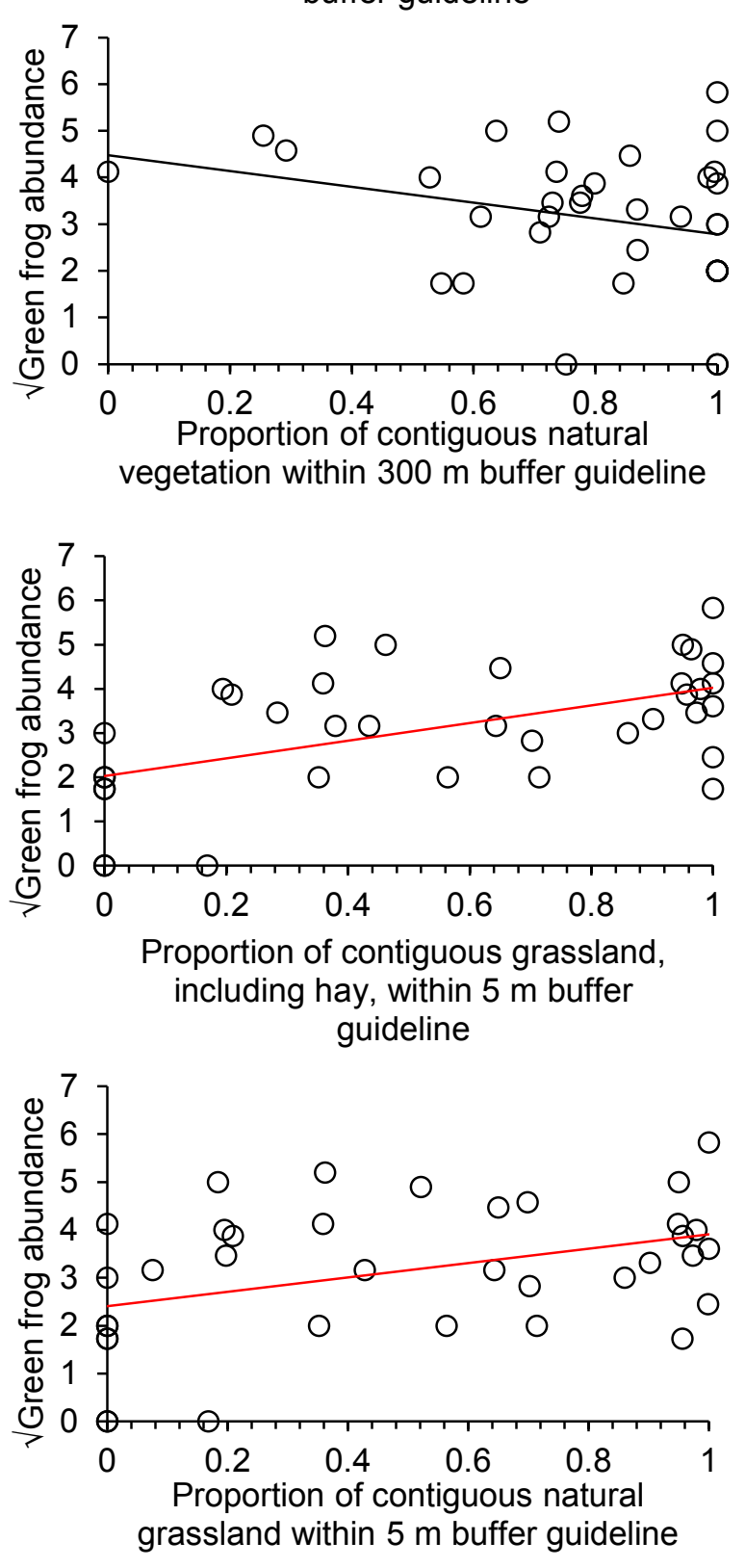

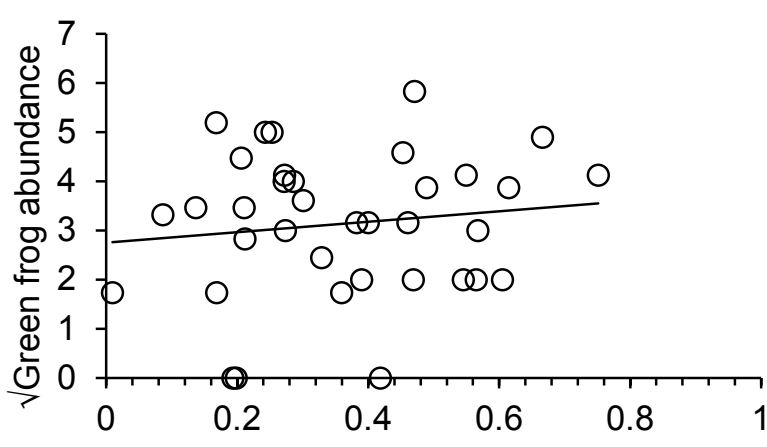

Proportion of contiguous permanent vegetation, excluding hay, within $5 \mathrm{~m}$ buffer guideline
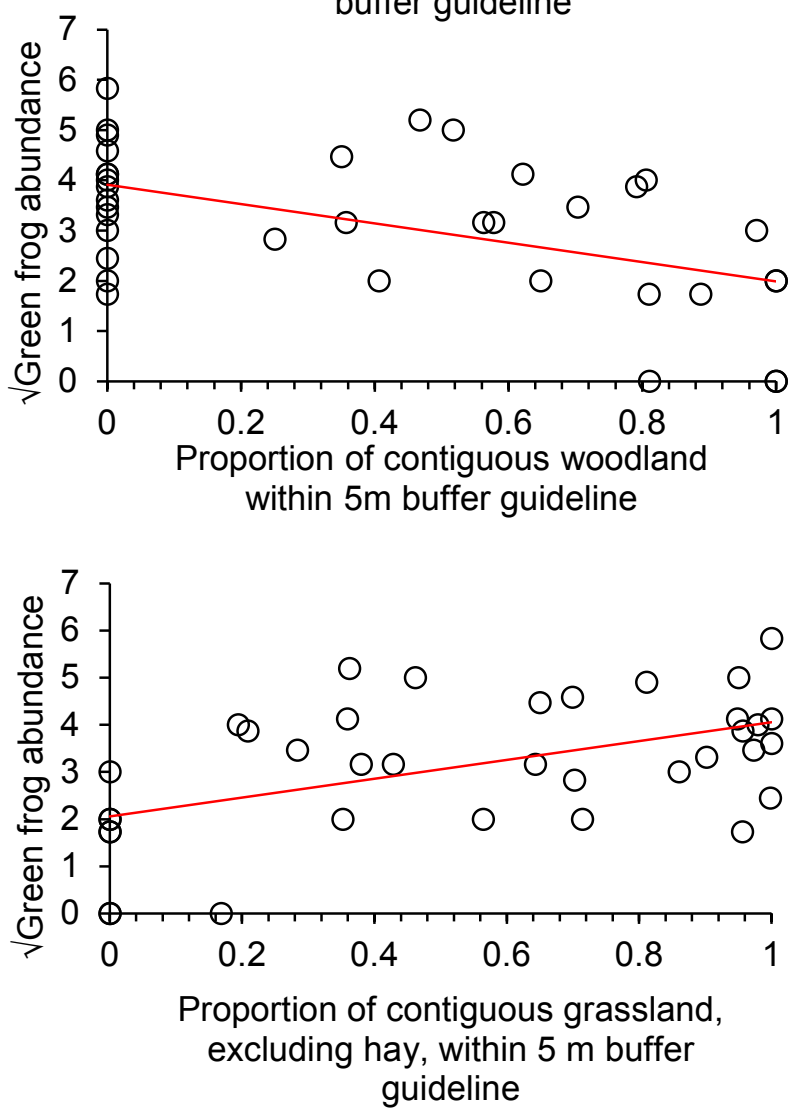

Figure A2-6. Effects of area-based compliance with buffer width guidelines on green frog abundance, where area-based compliance was measured as the proportion of the area circumscribed by a recommended buffer width that contained contiguous suitable buffer vegetation. Area-based compliance was measured at multiple spatial scales (5 to $300 \mathrm{~m}$ ); spatial scales included here are those that resulted in the best regression model fit for each buffer vegetation type. Regression lines are black if non-significant, and red if statistically significant $(\mathrm{p}<0.05)$. 

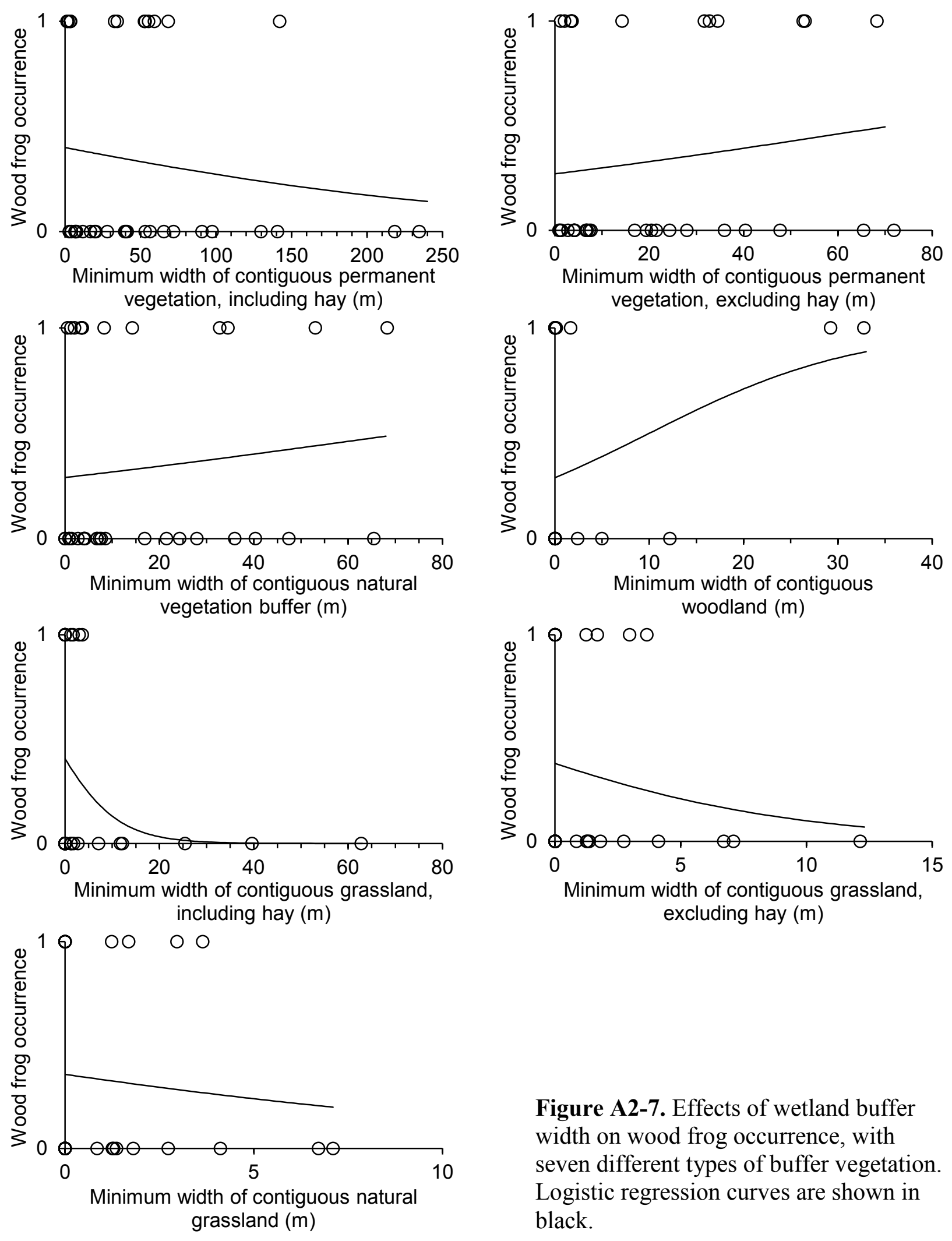

Figure A2-7. Effects of wetland buffer width on wood frog occurrence, with seven different types of buffer vegetation. Logistic regression curves are shown in black. 


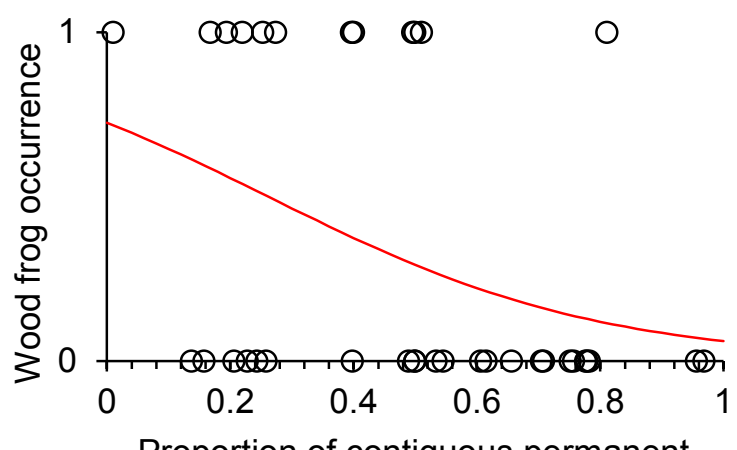

Proportion of contiguous permanent vegetation, including hay, within $300 \mathrm{~m}$ buffer guideline
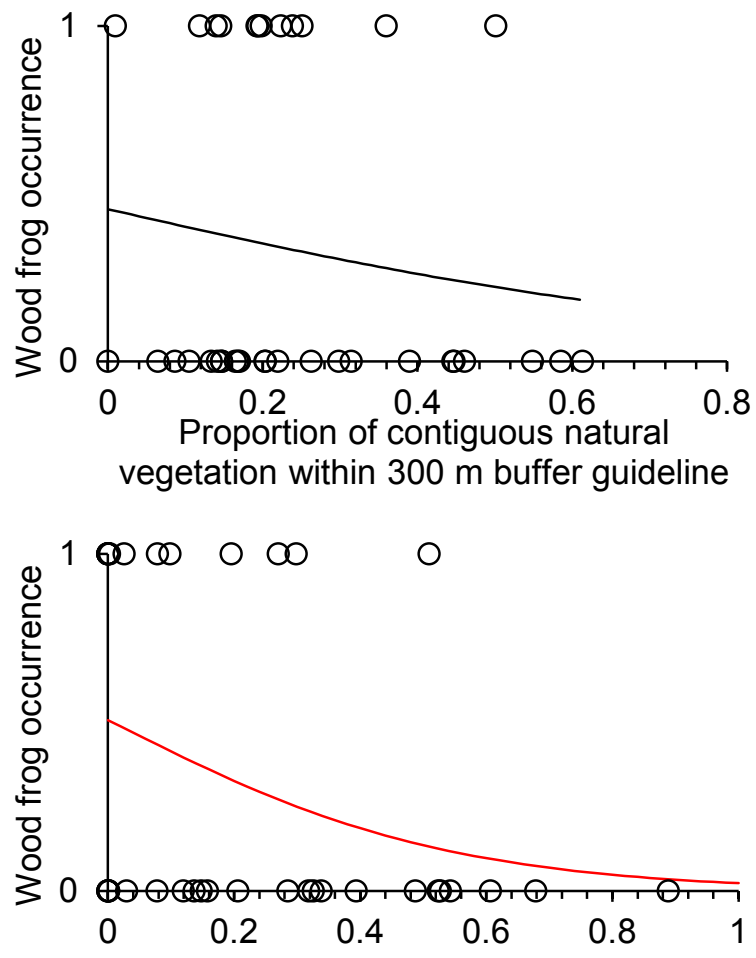

Proportion of contiguous grassland, including hay, within $300 \mathrm{~m}$ buffer guideline

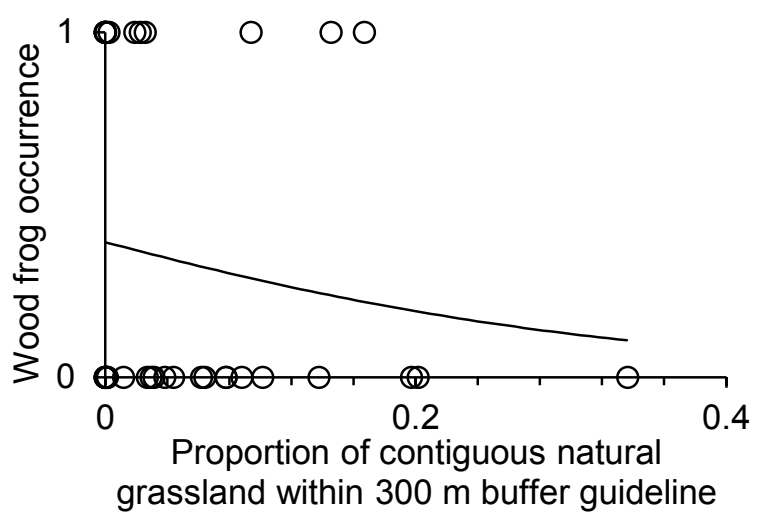

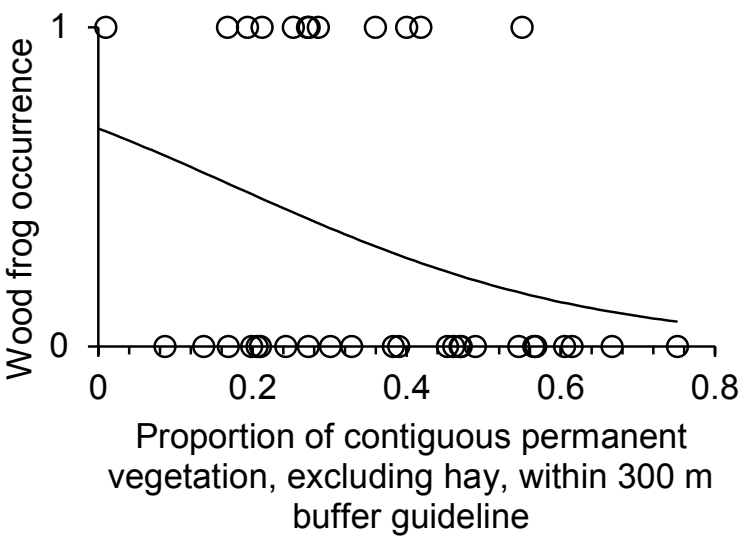
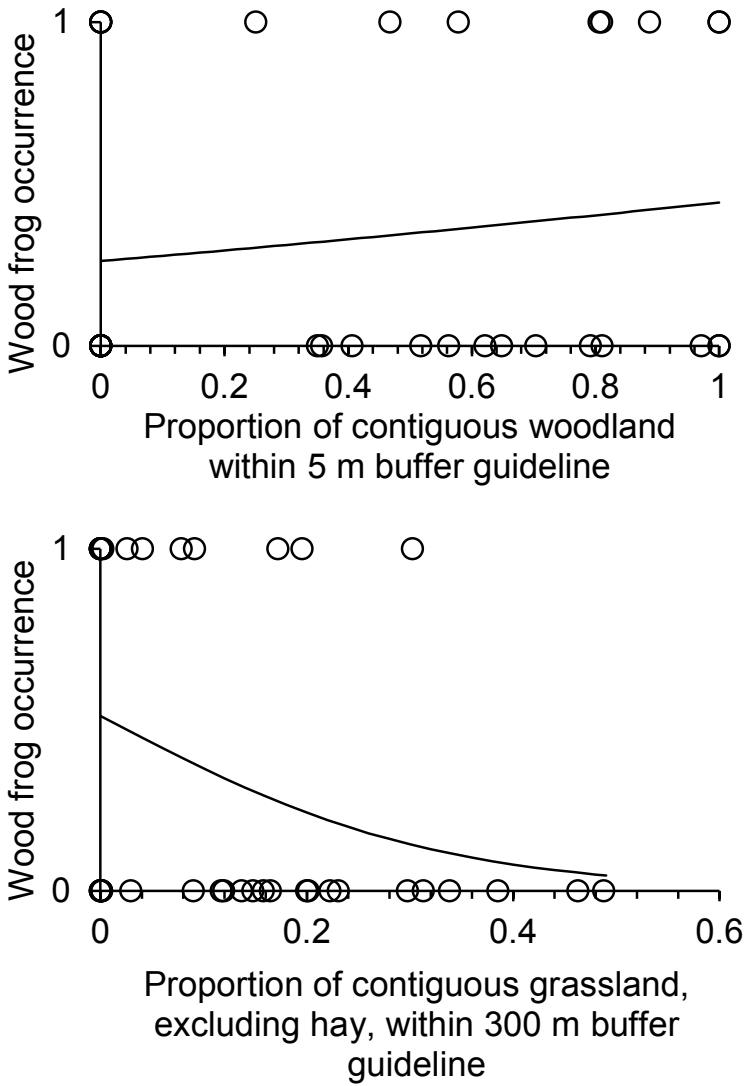

Figure A2-8. Effects of area-based compliance with buffer width guidelines on wood frog occurrence, where area-based compliance was measured as the proportion of the area circumscribed by a recommended buffer width that contained contiguous suitable buffer vegetation. Area-based compliance was measured at multiple spatial scales (5 to $300 \mathrm{~m}$ ); spatial scales included here are those that resulted in the best regression model fit for buffer vegetation type. Logistic regression curves are black if non-significant, and red if statistically significant $(\mathrm{p}<0.05)$. 

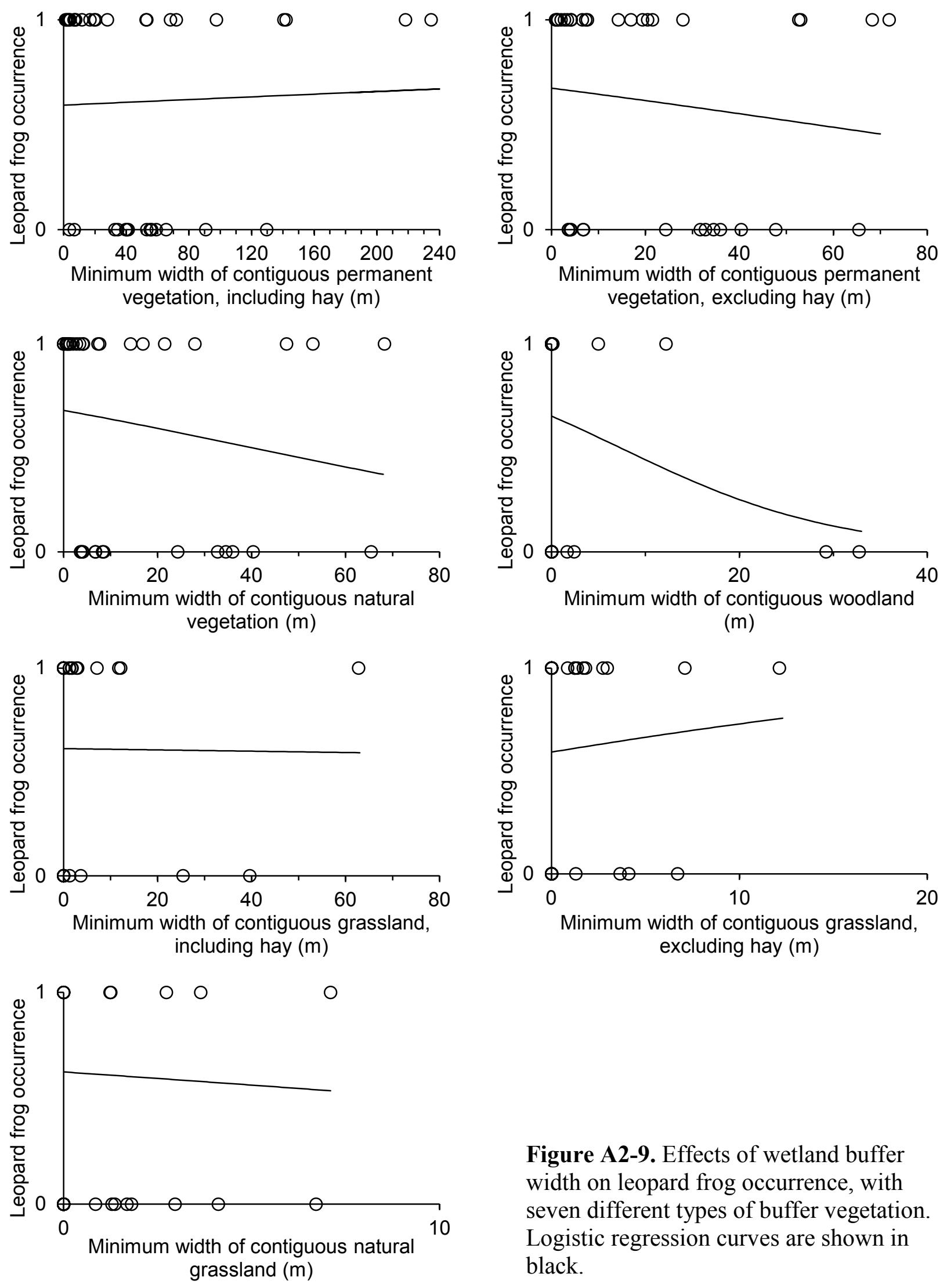

Figure A2-9. Effects of wetland buffer width on leopard frog occurrence, with seven different types of buffer vegetation. Logistic regression curves are shown in black. 

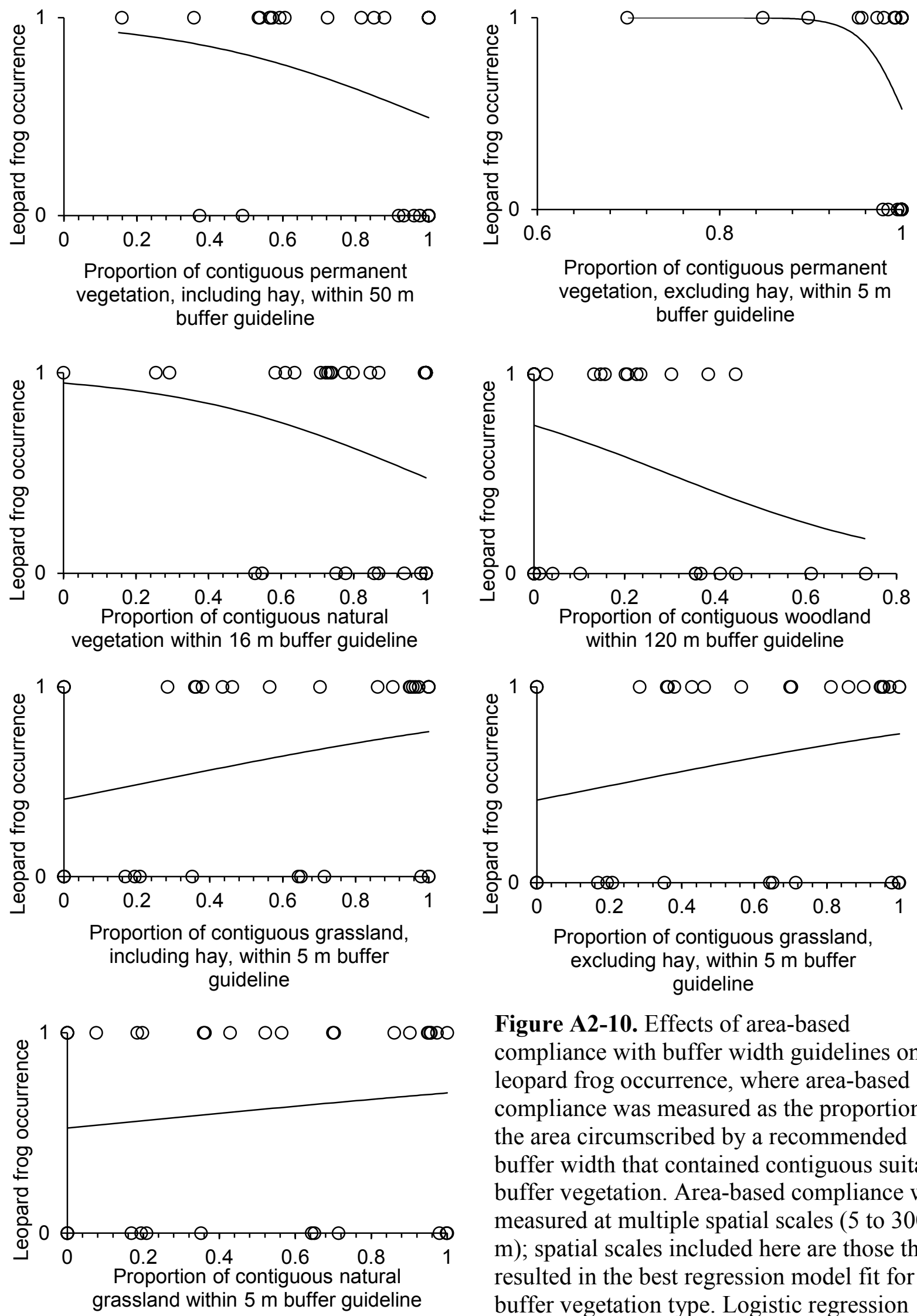

Figure A2-10. Effects of area-based compliance with buffer width guidelines on leopard frog occurrence, where area-based compliance was measured as the proportion of the area circumscribed by a recommended buffer width that contained contiguous suitable buffer vegetation. Area-based compliance was measured at multiple spatial scales (5 to 300 $\mathrm{m}$ ); spatial scales included here are those that resulted in the best regression model fit for buffer vegetation type. Logistic regression curves are shown in black. 

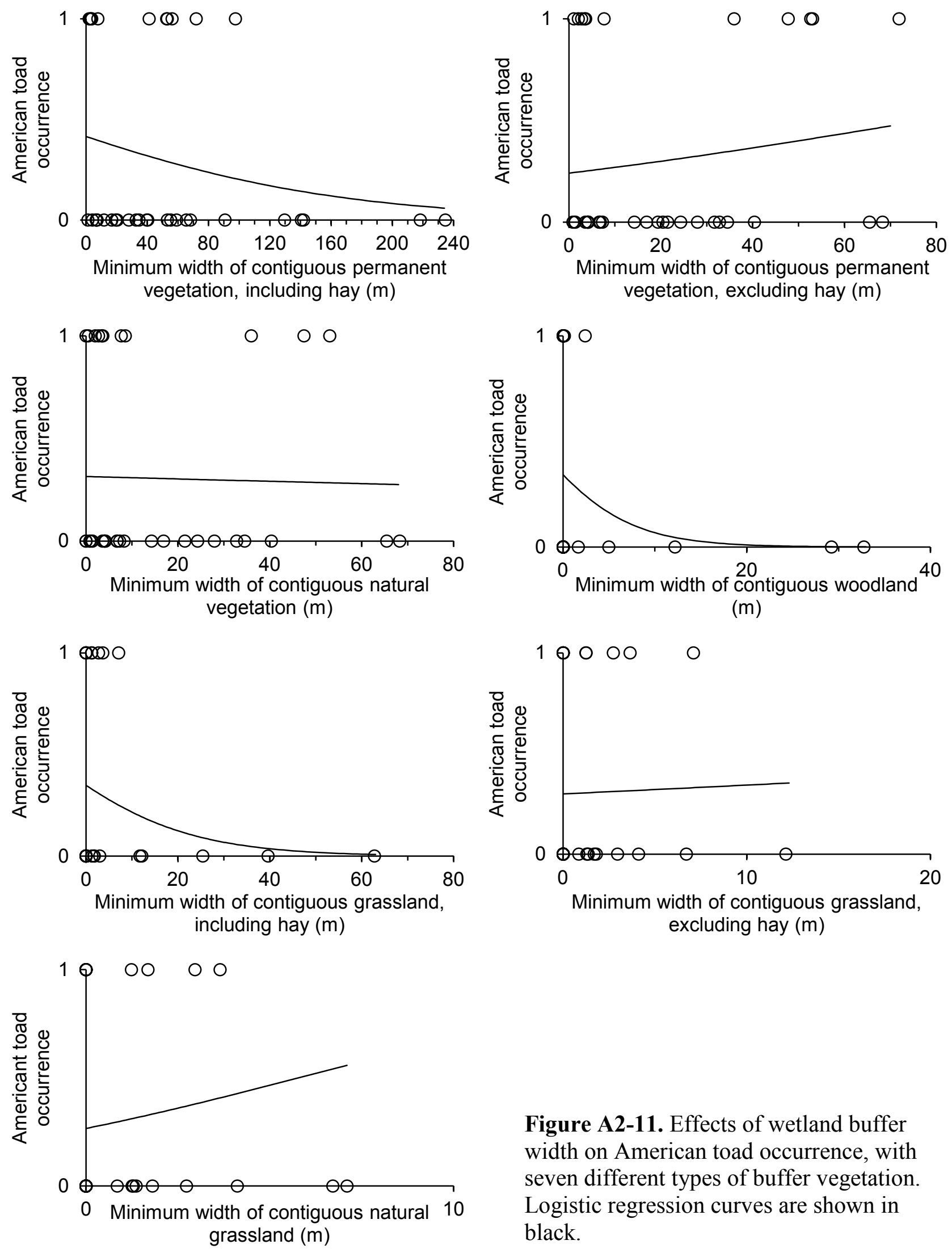

Figure A2-11. Effects of wetland buffer width on American toad occurrence, with seven different types of buffer vegetation. Logistic regression curves are shown in black. 

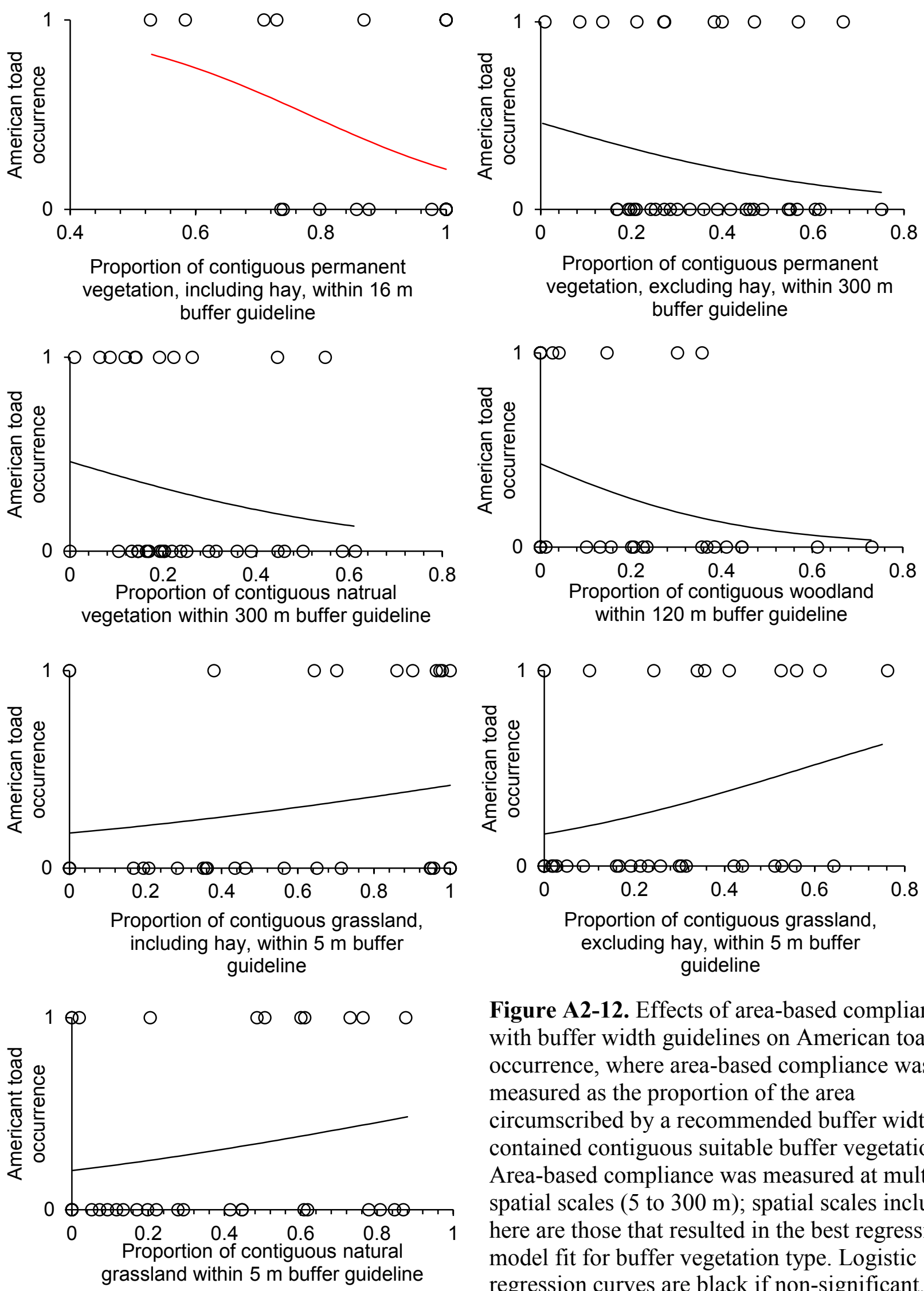

Figure A2-12. Effects of area-based compliance with buffer width guidelines on American toad occurrence, where area-based compliance was measured as the proportion of the area circumscribed by a recommended buffer width that contained contiguous suitable buffer vegetation. Area-based compliance was measured at multiple spatial scales (5 to $300 \mathrm{~m}$ ); spatial scales included here are those that resulted in the best regression model fit for buffer vegetation type. Logistic regression curves are black if non-significant, and red if statistically significant $(p<0.05)$. 

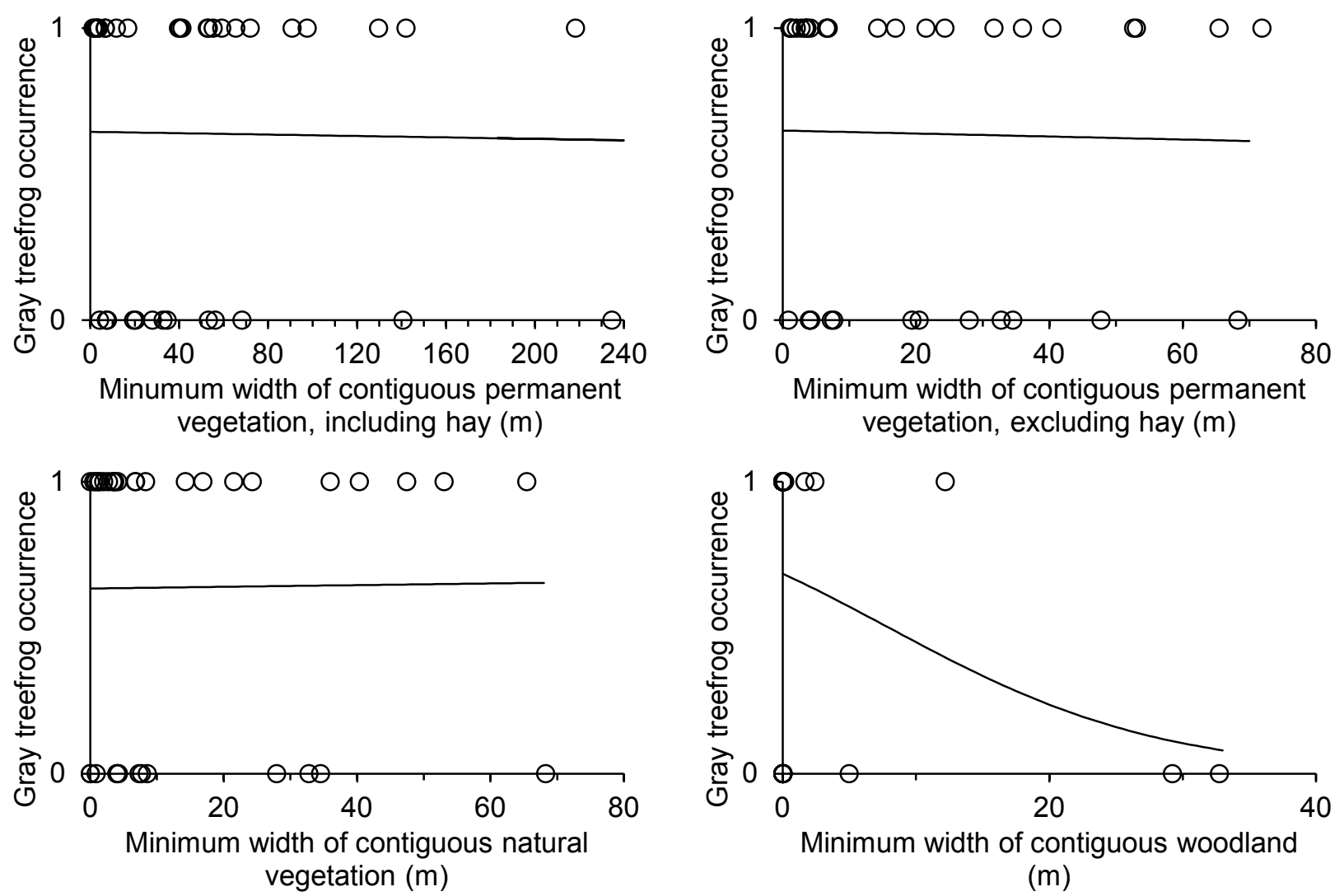

(m)
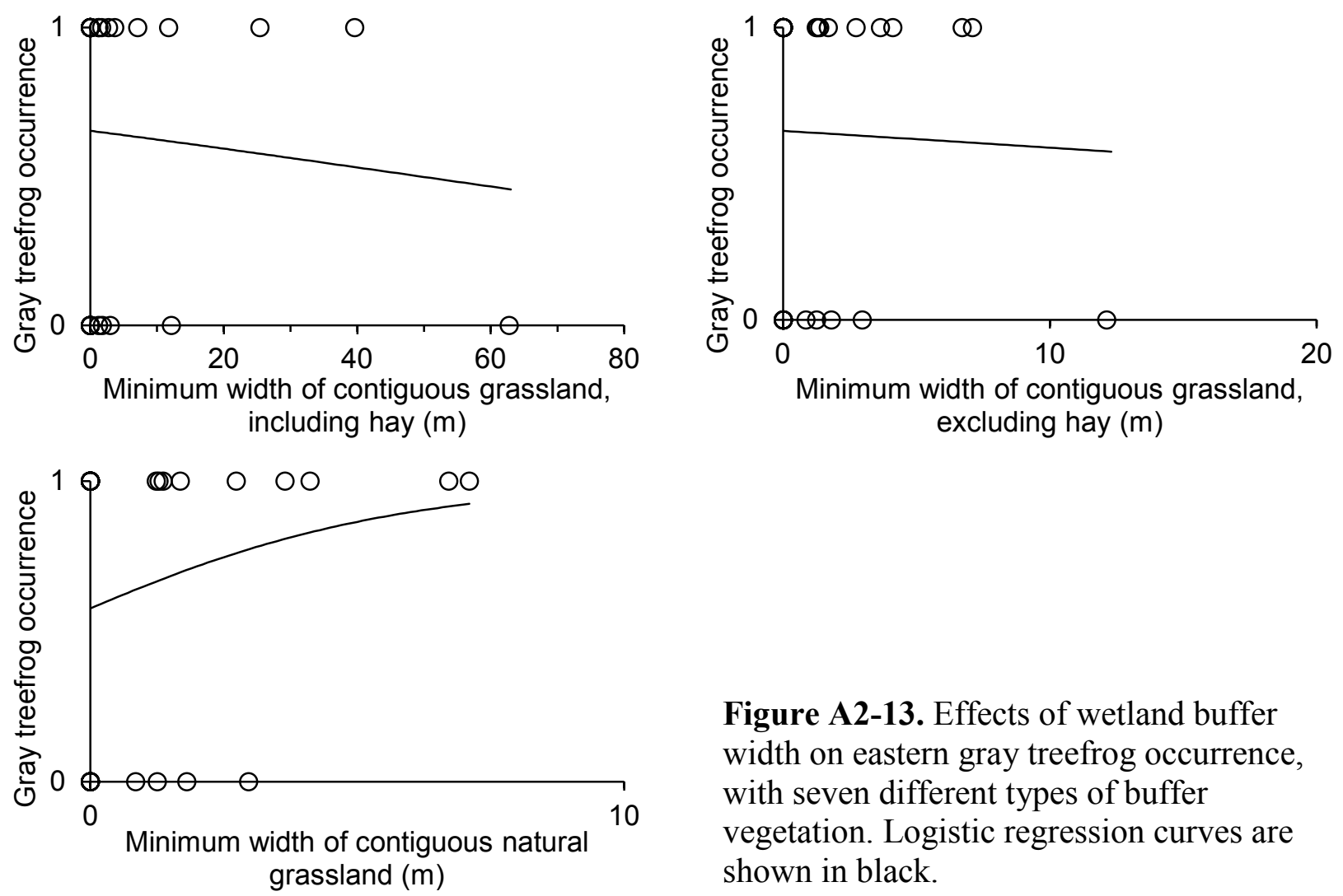

Figure A2-13. Effects of wetland buffer width on eastern gray treefrog occurrence, with seven different types of buffer vegetation. Logistic regression curves are shown in black. 

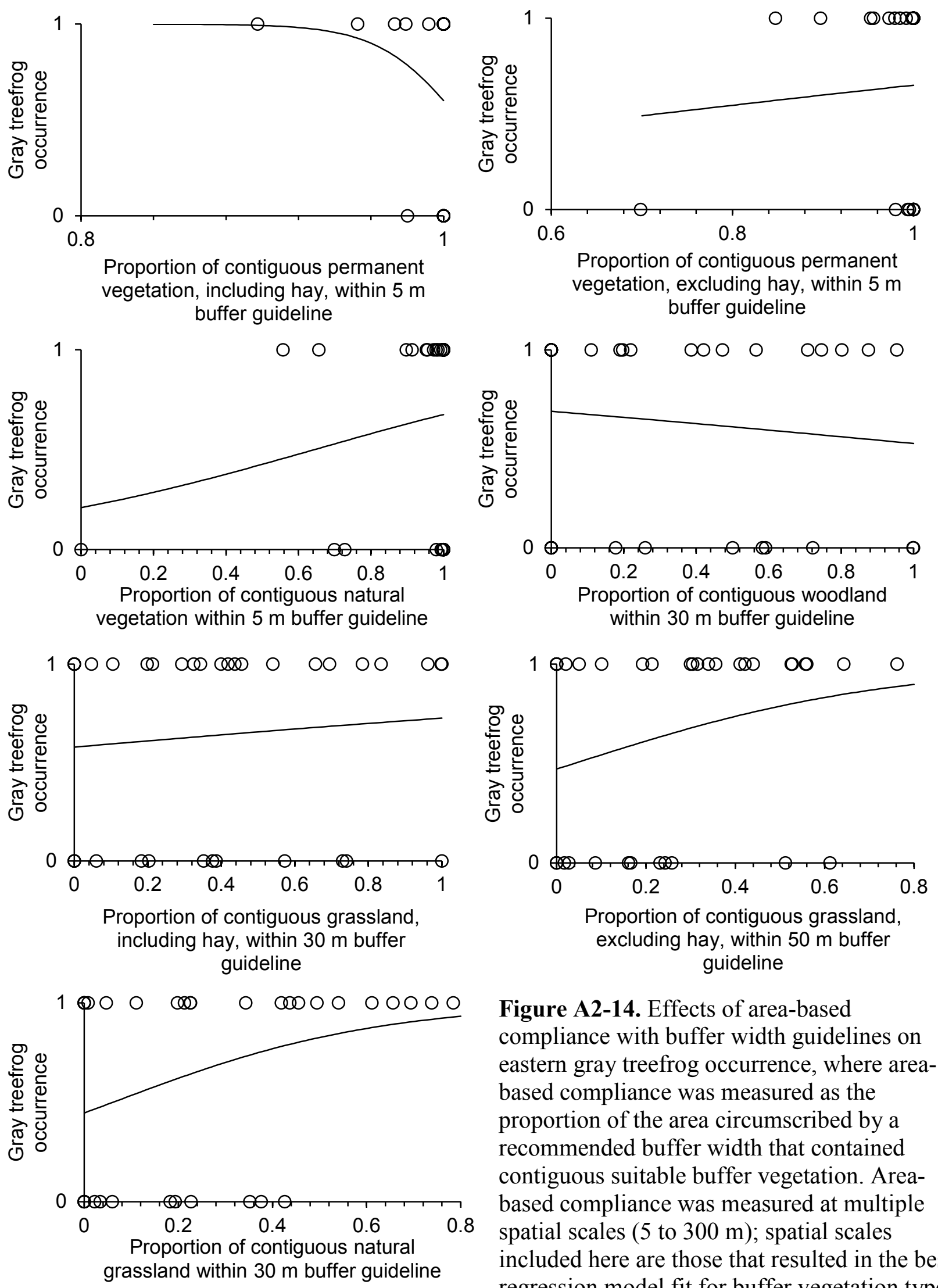

Figure A2-14. Effects of area-based compliance with buffer width guidelines on eastern gray treefrog occurrence, where areabased compliance was measured as the proportion of the area circumscribed by a recommended buffer width that contained contiguous suitable buffer vegetation. Areabased compliance was measured at multiple spatial scales (5 to $300 \mathrm{~m}$ ); spatial scales included here are those that resulted in the best regression model fit for buffer vegetation type. Logistic regression curves are shown in black. 